


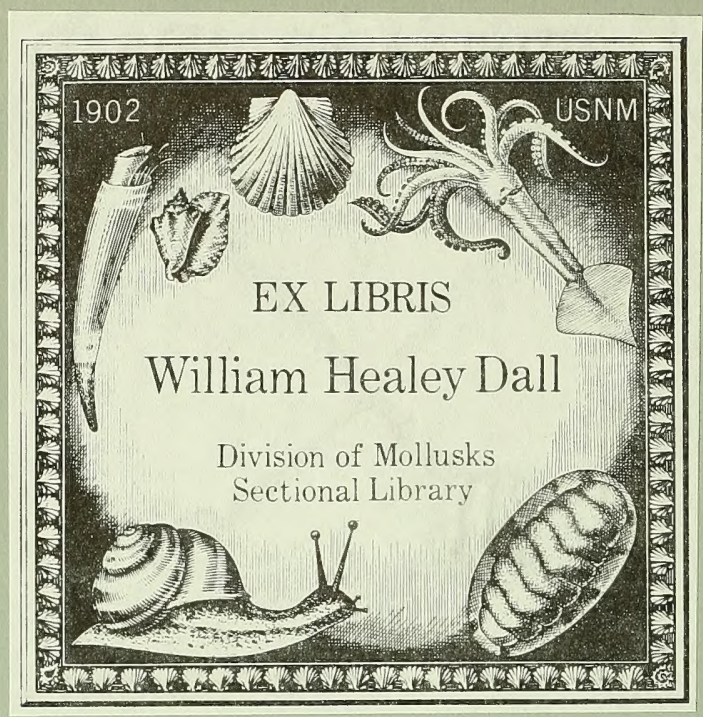




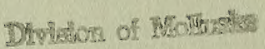

Socting जा … 


\title{
BEITRÄGE ZUR ANATOMIE UND SYSTEMATIK DER STYLOMATOPHOREN AUS DEM GEBIETE DER MONARCHIE UND DER ANGRENZENDEN BALKANLÄNDER
}

VON

\author{
DR. A. J. WAGNER
}

K. u. K. OBERSTABSARZT d. R. IN DIEMLACH BEI BRUCK a. d. MUR, STEIERMARK

Mit 24 Tafeln

BESONDERS ABGEDRUCKT AUS DEM 91. BANDE DER DENKSCHRIFTEN DER MATHEMATISCH-NATURWISSENSCHAFTLICHEN KLASSE DER KAISERLICHEN AKADEMIE DER WISSENSCHAFTEN

\section{WIEN 1915}

AUS DER KAISERLICH-KÖNIGLICHEN HOF- UND STAATSDRUCKEREI

\section{IN KOMMISSION BEI ALFRED HÖLDER}

I. U. K. HOF- UND UNIVERSITÄTSBUCHHÄNDLER

BUCHHÄNDLER DER KAISERLICHEN AKADEMIE DER WISSENSCHAFTEN 



\title{
BEITRÄGE ZUR ANATOMIE UND SYSTEMATIK DER STYLOMATOPHOREN AUS DEM GEBIETE DER MONARCHIE UND DER ANGRENZENDEN BALKANLÄNDER
}

VON

\author{
D. A. J. WAGNER
}

K. u. K. OBERSTABSARZT d. R. IN DIEMLACH BEI BRUCK a. d. MUR, STEIERMARK

\author{
Mit 24 Tafeln
}

BESONDERS ABGEDRUCKT AUS DEM 91. BANDE DER DENKSCHRIFTEN DER MATHEMATISCH-NATURWISSENSCHAFTLICHEN KLASSE DER KAISERLICHEN AKADEMIE DER WISSENSCHAFTEN

\section{WIEN 1915}

AUS DER KAISERLICH-KÖNIGLICHEN HOF- UND STAATSDRUCKEREI

\section{IN KOMMISSION BEI ALFRED HÖLDER}

K. U. K. HOF- UND UNIVERSITÄTSBUCHHÄNDLER BUCHHANDLER DER KAISERLICHEN AKADEMIE DER WISSENSCHAFTEN 


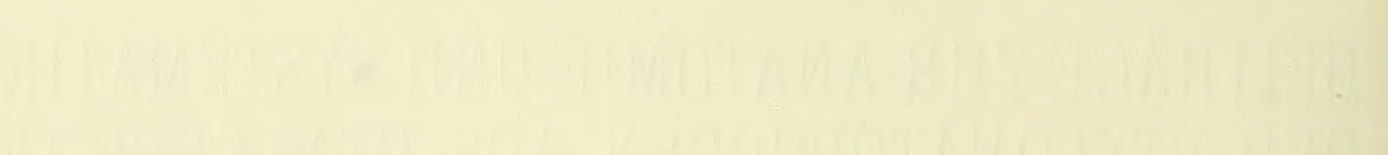

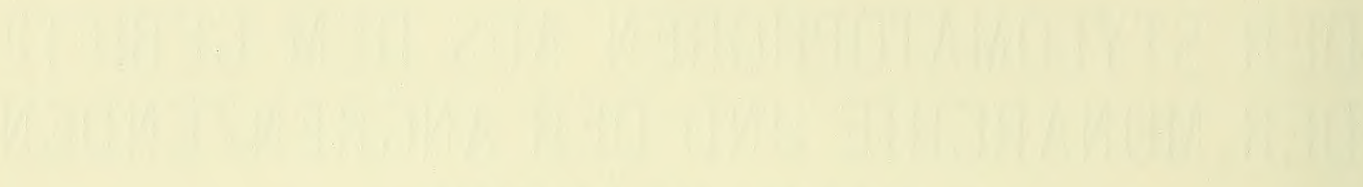

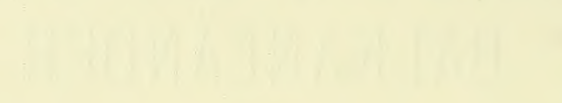




\title{
BEITRÄGE ZUR ANATOMIE UND SYSTEMATIK DER STYLOMATOPHOREN AUS DEM GEBIETE DER MONARCHIE UND DER ANGRENZENDEN BALKAN- LÄNDER
}

\author{
VON \\ D. A. J. WAGNER \\ K. u. K. OBERSTABSARZT d. R. IN DIEMLACH BEI BRUCK a. d. MUR, STEIERMARK
}

Mit 24 Tafeln

VORGELEGT IN DER SITZUNG AM 22. MAI 1914

\section{Einleitung.}

DerVorwurf des amerikanischen Zoologen Pilsbry, in Europa befände sich das Studium der Heliceen in einem halbchaotischen Zustande, da nur wenige Formen anatomisch untersucht wären und dementsprechend die Kenntnis dieser Gruppen eine unvollkommene, nur das Gehäuse umfassende sei, mußte besonders auch Österreich-Ungarn mit seiner besonders reich entwickelten Molluskenfauna treffen.

Die Malakozoologen Deutschlands, Frankreichs und Englands haben uns schon seit längerer Zeit mit den anatomischen Verhältnissen der wichtigsten Formelemente ihrerer heinnischen Molluskenfauna bekannt gemacht. Die Publikationen von Ad. Schmidt, Ihering, Wiegmann, Lehmann, Shepman, Bourguignat und besonders jene von P. Hesse erweiterten auch die Kenntnisse der Molluskenfauna von Österreich-Ungarn, da ja zahlreiche Formelemente unserer Fauna auch in Deutschland und Frankreich auftreten, anderseits auch ostalpine und karpatische Formen untersucht und beschrieben wurden. Wie jedoch P. Hesse richtig bemerkt, fördert die isolierte Untersuchung einzelner Formen aus verschiedenen Gruppen die Kenntnis unserer Wissenschaft nur wenig, indem nur der Vergleich ganzer Formenreihen und Gruppen eine entsprechende Übersicht über die Verhältnisse bestimmter Organe ermöglicht und so die Beziehungen derselben zueinander erkennen läßt.

Ein zu so umfassenden Untersuchungen geeignetes Studienmaterial kann jedoch nur mühsam zusammengetragen werden; eine ausreichende Beobachtung der Weichteile erfordert möglichst frische Exemplare, indem jede Konservierung diéselben mehr oder minder verändert; dies betrifft zunächst die oft so charakteristische Färbung und durch Schrumpfung erleiden sowohl die äußere Form als die Lagerung der inneren Organe störende Verzerrungen. So muß sich in den meisten Fällen die anatomische Untersuchung auf jene Organe beschränken, welche erfahrungsgemäß für die einzelnen Gruppen charakteristisch sind und durch Konservieiung die geringsten Veränderungen erleiden. Solche konstante Merkmale finden wir zunächst in den Verhältnissen der Sexualorgane, des Pharynx mit Kiefer und Radula, während andere Organe und Organsysteme, wie die Lage der Nieren und die Beschaffenheit des Harnleiters, das Gefäß und 
Nervensystem nur von wenigen Formen annähernd vollkommen bekannt sind und aus diesem Grunde zum Vergleiche wenig herangezogen werden. Ein direkter Vergleich der zarten und oft sehr komplizierten Sexualorgane ist nur selten möglich, derselbe wird aber wesentlich durch die Abbildungen erleichtert, welche mit Reichert's Zeichenapparat angefertigt wurden und die Verhältnisse der präparierten Organe genau wiedergeben; freilich können auch diese Abbildungen nur das enthalten, was präpariert und gesehen wurde, erfahrungsgemäß werden aber zarte und oft rudimentär entwickelte Organteile bei der Präparation leicht übersehen, besonders wenn die Dimensionen der Tiere nur wenige Millimeter betragen. Meine Präparationstechnik wird also viele Mängel aufweisen, da man, wie Ad. Schmidt richtig bemerkt, oft erst während einer Arbeit richtig in diese hineinwächst und mit zunehmender Erfahrung mehr sieht und besser deutet. Die Lagerung einzelner Organe kann oft nur während der Sektion richtig beurteilt werden und ein solches Versäumnis ist nicht leicht gut zu machen, wenn nur ein Exemplar vorhanden war.

Trotz dieser Schwierigkeiten ist es mir im Verlaufe der letzten fünf Jahre gelungen, eine große Zahl der im Gebiete vorkommenden Formen der Stylomatophoren soweit anatomisch zu untersuchen, daß die gewonnenen Resultate die vorhandenen Lücken wesentlich ergänzen.

In der vorliegenden Abhandlung werden die Beziehungen der Raublungenschnecken zu verwandten Gruppen pflanzenfressender Stylomatophoren erörtert und im Anschlusse die Systematik der Familien der Testacelliden, Zonitiden, Vitriniden sowie der Subfamilie der Fruticicolinen mit besonderer Berücksichtigung der im Gebiete der Monarchie und den angrenzenden Balkanländer beobachteten Formen durchgeführt.

Die Beziehungen dieser Gruppen zueinander werden sowohl von der Übereinstimmung der inneren Organe als jener der Gehäuse abgeleitet, denn eine Vernachlässigung der Gehäuse muß ebenso zu unvollkommenen Resultaten führen, wie dies die ausschließliche Berücksichtigung derselben verursacht hat. Bekanntlich können bei genauer Beobachtung und entsprechender Erfahrung aus dem Skelet der Wirbeltiere, ja aus Teilen desselben weitreichende und sichere Schlüsse auf die Organisation der betreffenden Tierform gezogen werden; dies trifft auch bei den Schalen der Mollusken zu, welche ihrer Funktion nach mehrfache Analogien mit dem Skelete der Tiere erkennen lassen. So stellt das Gehäuse eine schützende Hülle wichtiger Organe (Zwitterdrüse, Leber oder des ganzen Eingeweidesackes) dar und bietet andrerseits dem Muskelsystem einen festen Stützpunkt, indem das Retraktorensystem an der Schalenspindel inseriert und in feste Verbindung mit dem Gehäuse tritt.

Die umfangreiche und so mühsam aufgebaute Literatur, welche lediglich die Schalen der Mollusken behandelt, ist durchaus nicht unrichtig oder gar überflüssig, sondern nur ergänzungsbedürftig; systematishe Kategorien, welche lediglich mit Rücksicht auf die Merkmale der Gehäuse aufgestellt wurden, kommen den natürlichen Verhältnissen sogar vielfach näher als solche, welche sich vorzüglich auf Kiefer und Radula stützen. Es wird ferner auch von Anatomen darauf hingewiesen, daß die Merkmale der inneren Organe wohl in besonderem Grade geeignet sind, die Beziehungen der Formen zueinander klarzulegen, so daß verwandte Formen zu natürlichen Gruppen und solche zu systematischen Kategorien höherer Ordnung zusammengefaßt werden können; die Unterscheidung der einzelnen Formen und Arten werde jedoch durch diese Merkmale nicht gefördert. Nach meinen Beobachtungen glaube ich jedoch annehmen zu dürfen, daß diese Unzulänglichkeit der anatomischen Untersuchung nur auf die noch unvollkommenen Untersuchungsmethoden sowie den Mangel einer gleichmäßigen und entsprechend detailierten Terminologie zurückzuführen ist; momentan sind jedoch die Merkmale der Gehäuse für die Unterscheidung der Formen und Arten in den meisten Fällen allein entscheidend.

Bezüglich der anatomischen Verhältnisse anderer Gruppen der Stylomatophoren des Gebietes verweise ich auf nachstehende Publikationen: Die Familie des Clausiliidae von Dr. A. J. Wagner, in Roßmäßler's Iconographie, II, v. 21, 1913 bis 1914. Über schalentragende Landmollusken aus Albanien und Nachbargebieten von Dr. R. Sturany und Dr. A. J. Wagner. Denkschriften der Wiener Akademie, Bd. 91, 1914.

Diemlach bei Bruck a. d. Mur, Mai 1914. 


\section{Beziehungen der Raublungenschnecken zu pflanzenfressenden Stylomatophoren.}

Die bisher unter der Bezeichnung Agnatha zusammengefaßten Raublungenschnecken werden heute wohl auf Grund äußerer Merkmale und besonders solcher der Schale auf mehrere Familien verteilt; mit Rücksicht auf die allen diesen Gruppen eigentümlichen Verhältnisse von Pharynx, Kiefer und Radula werden dieselben jedoch noch immer in nähere Beziehungen zueinander und in scharfen Gegensatz zu den pflanzenfressenden Lungenschnecken gebracht.

Alle Raublungenschnecken besitzen einen kräftig entwickelten, im Verhältnis zu den übrigen Organen oft auffallend großen Pharynx; ein Kiefer fehlt nicht, sondern stellt zumeist nur eine weiche und dünne Membran dar. Die Radula ist im Verhältnis zum Tiere oft auffallend groß; die eigentümlich geformten Zahnplatten derselben sind in zahlreichen Querreihen, aber oft nur in verhältnismäßig wenigen Längsreihen angeordnet, so daß die Radula vielfach lang und schmal, also bandförmig erscheint (Streptaxidae). Die Längsreihen bilden ferner zwei gleichbreite Seitenfelder, innerhalb welcher die Querreihen sich in mehr oder minder spitzem Winkel in der Mittellinie treffen. Bei einigen Gruppen (Ennea H. und A. Ad., Streptaxis Gray, Gibbulina Beck, Glandina Schum.) ist ein symmetrischer Mittelzahn vorhanden, welcher immer kleiner als die Seitenzähne ist, mitunter sogar rudimentär erscheint, bei anderen Gruppen (Testacella Cuv., Daudebardia Hartm.) fehlt der Mittelzahn vollkommen. Dieser anscheinend geringfügige Unterschied gewinnt in Verbindung mit anderen ebenfalls abweichenden Merkmalen des Tieres und der Schale eine besondere Bedeutung und zeigt zunächst, daß auch das Gebiß der Raublungenschnecken nicht gleichartig ist. Für alle Gruppen der Raublungenschnecken sind aber die Seiten- und Randzähne charakteristisch, welche stets einen langen, stachel- oder sensenförmigen Dentikel besitzen, gegen die Mitte und die Ränder zu kleiner werden, sonst aber gleichartig erscheinen; zumeist ist am Dentikel nur eine Hauptspitze entwickelt, während eine Nebenspitze nur bei einigen Formen angedeutet erscheint.

Die von mir anatomisch untersuchten Raublungenschnecken (Formen der Gruppen Ennea Ad., Gibbullina Beck, Streptaxis Gray, Testacella Cuv., Daudebardia Hartm., Glandina Schum.) besitzen oft sehr lebhaft gefärbte Weichteile; dieser Farbstoff bleibt mitunter auch bei den in Alkohol eingelegten Tieren erhalten und löst sich in Wasser und Alkohol. Bei den von mir anatomisch untersuchten Raublungenschnecken fanden sich im allgemeinen wohl einfach, doch nicht übereinstimmend organisierte Sexualorgane; vielfach erscheinen dieselben ihren Dimensionen nach im Verhältnisse zu den Verdauungsorganen auffallend klein. Die bei den Gruppen der pflanzenfressenden Stylomatophoren vielfach vorhandenen Appendiculae des weiblichen Genitaltraktes (Gland. muscosae, Pfeilsack) fehlen hier immer, auch besitzt der Blasenstiel kein Divertikel; nur am Penis wird bei einigen Gruppen ein Appendix beobachtet.

Damit erscheinen die allen Gruppen der Raublungenschnecken gemeinsamen Merkmale erschöpft.

Am Kiefer der Stylomatophoren können wir im allgemeinen alle Übergänge von einer festen hornartigen bis zur dünnen, häutigen Beschaffenheit desselben beobachten. Die besondere Form desselben zeigt schon bei verschiedenen Individuen einer Art bemerkbare Schwankungen; noch deutlicher ist dies bei verschiedenen Arten einer Gruppe der Fall, doch wird bei verwandten Formen zumeist ein bestimmter Typus festgehalten.

An der Radula der Stylomatophoren sehen wir zunächst zwei Haupttypen der Zahnplatten, indem dieselben nur eine Hauptspitze oder daneben noch eine oder mehrere Nebenspitzen besitzen; diese Spitzen sind außerdem etweder abgerundet oder spitzig; kurz und breit oder stachel- bis sensenförmig verlängert, symmetrisch oder asymmetrisch geformt; mituntnr wird neben der Entwickelung von Nebenspitzen auch eine Spaltung der Hauptspitzen beobachtet. Besonders charakteristisch ist die zumeist vorhandene sym- 
metrische Mittelplatte im Gegensatze zu den mehr oder minder asymmetrischen Seiten und Randplatten, indem dieselbe außerdem entweder gleichgroß3 oder wesentlich kleiner als jene erscheint. So ergibt sich aus der Kombination dieser Merkmale, sowie der wechselnden Zahl der in Längs- und Querreihen angeordneten Zahnplatten die große Mannigfaltigkeit der Radulaformen bei den Stylomatophoren. Auch mit Rücksicht auf die Radula finden wir bei nahe verwandten Formen im allgemeinen sehr ähnliche, ja vielfach vollkommen übereinstimmende Verhältnisse, um so auffallender erscheint daher die Beobachtung, daß mitunter einzelne Arten einer auch anatomisch scharf begrenzten Gruppe bezüglich des Kiefers und der Radula vollkommen abweichende Verhältnisse aufweisen. So finden wir bei Vidovicia (Campylaea olim) coerulans C. Pfr., welche mit Rücksicht auf die Sexualorgane und das Gehäuse vollkommen mit den Campyläinen übereinstimmt, einen dünnen, glatten Kiefer und höchst eigentümliche Verhältnisse der Radula; in ähnlicher Weise weicht auch Allognathus grateloupi Graels von den Helicinen ab.

Kiefer und Radula erleiden durch Anpassung an bestimmte Ernährungsverhältnisse anscheinend rascher als andere Organe gewisse Veränderungen, erscheinen schließlich einseitig und haufig exzessiv entwickelt.

Im allgemeinen beobachtet man bei pflanzenfressenden Stylomatophoren kleine, zahlreiche, kurze und mehrspitzige Zahnplatten sowie einen festen hornartigen Kiefer; bei den Raublungenschnecken ist die Zahl der Zahnplatten in einer Querreihe weniger zahlreich, oft gering, dieselben sind aber verhältnismäßig groß, lang ausgezogen und besitzen nur eine gut entwickelte Hauptspitze; der Kiefer ist dünn, weich und oft nur hautartig. Neben diesen Extremen finden wir aber auch Radulaformen, welche nebeneinander sowohl lange einspitzige als kurze mehrspitzige Zähne besitzen, also Übergänge oder Kombinationen zwischen den Verhältnissen bei Pflanzen und Fleischfressern (Raubschnecken) darstellen.

Diese verschiedenen Verhältnisse werden durch nachstehende Figuren der beigegebenen Tafeln erläutert.

Taf. 1, Fig. 2. Testacella hungarica Soos (Raublungeschnecke); langgestreckter, sensenförmiger Dentikel mit schwach entwickelter Nebenspitze.

Taf. 1, Fig. 7. Testacella gestroi Issel (Raublungenschnecke); die mittleren Zähne einer Querreihe; ein symmetrischer Mittelzahn fehlt.

Taf. 2, Fig. 12. Glandina algyra L. (Raublungenschnecke); a Mittelstïck einer Querreihe mit rudimentärem, symmetrischem Mittelzahn, b Seitenplatte mit einspitzigem Dentikel, $c$ Randplatte.

Taf. 2, Fig. 16 bis 17. Daudebardia (Cibinia) transsilvanica Bielz (Raublungenschnecke); Fig. 16: Mittelstück einer Querreihe der Radula; stachelförmige, einspitzige Dentikel, ein symetrischer Mittelzahn fehlt; Fig. 17: Seitenzahn mit cinspitzigem, stachelförmigem Dentikel.

Taf. 3, Fig. 20. Dandebardia (Libania) sanleyi Bgt. (Raublungenschnecke); Mittelstück einer Querreihe der Radula mit einspitzigen, stachelförmigen Dentikeln; ein Mittelzahn fehlt.

Taf. 3, Fig. 23. Gibbulina newtoni Ad. (Raublungenschnecke); Mittelstück einer Querreihe der Radula mit rudimentärem einspitzigen Mittelzahn und stacheltörmigen Seitenzähnen

Taf. 3, Fig. 25. Gibbulina mauritiana Mor1. (Raublungenschnecke); Mittelstück einer Querreihe der Radula mit symmetrischem Mittelzahn, stachelförmigen Seitenzähnen.

Taf. 4, Fig. 28. Zonites (Aegopis) verticillus Fér. (Pflanzenfresser); Querreihe der Radula; die einzelnen Zähne sind im allgemeinen kurz, klein und mehrspitzig; die, symmetrische Mittelplatte so groß wie die Seitenplatten, der Dentikel mit zwei deutlichen Seitenspitzen; die Seitenplatten zweispitzig; die Randplatten einspitzig und stachelförmig wie bei den Raublungenschnecken.

Taf, 4, Fig. 39. Hyalinia cellaria austriaca A. J. Wagner (Raublungenschnecke und PflanzenJresser); Querreihe der Radula; der symmetrische dreispitzige Mittelzahn ist wesentlich kleiner als die Seitenzähne; nur die drei inneren Seitenzähne sind zwei- bis dreispitzig, aber schon verhältnismäßig groß 
und lang; die äußeren Seitenzähne, ebenso die Randzähne zunehmend größer mit einspitzigem, stachelförmigem Dentikel.

Taf, 5, Fig. 46. Zonites (Aegopis) spelaens A. J. Wagner (anscheinend eine Raublungenschnecke); Querreihe der Radula mit durchwegs einspitzigen stachelförmigen Dentikeln; nur der symmetrische Mittelzahn und die inneren Seitenzähne erinnern durch ihre breite Basis und die Andeutung von Seitenspitzen an die Radula verwandter Aegopis-Arten.

Taf. 5, Fig. 45. Rumina decollata L. (Pflanzenfresser); Querreihe der Radula mit zahlreichen kleinen und kurzen sowie mehrspitzigen Zähnen; der symmetrische Mittelzahn ist hier rudimentär und erinnert an die Verhältnisse bei den Gruppen Oleacina, Glandina Schum., Ennea Ad., Streptaxis Schum., Gibbulina Beck.

Taf. 13, Fig. 95. Phenacolimax pellucidns Müller (Pflanzenfresser); Querreihe der Radula mit kleinen kurzen, durchwegs mehrspitzigen Zähnen; der symmetrische, dreispitzige Mittelzahn ist so groß wie die Seitenzähne; die Randzähne sind wohl mehrspitzig, erinnern aber durch ihre Form bereits an die Stachelform der Raublungenschnecken.

Taf. 13, Fig. 107. Vitrina diaphana Drap. (Pflanzenfresser); Querreihe der Radula; die mittleren Zähne mehrspitzig, die Randzähne einspitzig und stachelförmig wie bei den Raublungenschnecken.

Taf. 16, Fig. 146 g. Fruticicola erjaveci Brus. (Typus des Gebisses einer pflanzenfressenden Lungenschnecke); Querreihe der Radula mit zahlreichen sehr kleinen, kurzen und durchwegs mehrspitzigen Zähnen; der symmetrische Mittelzahn ist so groß wie die Seitenzähne.

Neben dieser durch Anpassung an bestimmte Ernährungsverhältnisse bewirkten verschiedenartigen Entwicklung der Mundwerkzeuge fanden wohl auch Veränderungen anderer Organe, doch vielfach in geringerem Grade statt und die Beobachtung zeigt, daß Formen mit auffallend ähnlichen Mundorganen oft sehr abweichende Verhältnisse der übrigen Organe aufweisen.

Die Raublungenschnecken haben sich eben aus verschiedenen Stammformen der Stylomatophoren entwickelt, ihre Übereinstimmung erstreckt sich zumeist nur auf den vorderen Teil des Verdauungstraktes und besonders das sogenannte Gebiß, während andere Organe wesentliche Unterschiede erkennen lassen und deutlich auf eine verschiedene Abstamınung hinweisen. Der Nachweis näherer verwandtschafticher Beziehungen zwischen einzelnen Gruppen der Raublungenschnecken und solchen der pflanzenfressenden Stylomatophoren wird besonders durch den genauen Vergleich der Gehäuse sowie der Verhältnisse der Sexualorgane unterstützt.

Die Gehäuse der Raublungenschnecken erscheinen bei den einzelnen Gruppen derselben oft sehr verschieden, zeigen dafür eine auffallende Übereinstimmung mit Formen pflanzenfressender Stylomatophoren, mit welchen sie früher auch glatt vereinigt wurden (Dandebardia $=$ Helix, Glandina $=$ Bulinus $=$ Achatina, Gibbulina $=$ Pupa).

In der Familie der Testacelliden werden heute die Gruppen Testacella Cuv. und Dandebardia Hartm. zusammengefnßt. Die Formen des Genus Testacella Cuv. besitzen durchwegs rudimentäre, im Verhältnis zum Tiere auffallend kleine Gehäuse; dieselben stellen tütenförmig eingerollte, ovale Schildchen, oder einer phrygischen Mütze ähnliche Schälchen dar, welche kaum einen Umgang erkennen lassen und am Rücken des Tieres ror der Schwanzspitze liegen. Ähnlich rudimentäre Schalen besitzen auch die Formen des Genus Dandebardia Hartm.; bei einigen Arten dieser Gruppe werden jedoch die Gehäuse im Verhältnisse zum Tiere größer, besitzen zwei bis drei Umgänge und erscheinen so besonders in halbausgewachsenem Zustande auffallend hyalinenartig, leiten also zunächst mit Rücksicht auf die Form des Gehäuses zu den Gruppen Hyalinia Ag. und Aegopina Kob. hinüber.

Die Übereinstimmung der Gruppen Testacella Cuv. und Dandebardia Hartm., welche die Vereinigung derselben in einer Familie rechtfertigen soll, besteht also zunächst nur in der Ähnlichkeit der rudimentären Gehäuse, besonders aber in der eigentümlichen und charakteristischen Entwicklung des Kiefers und der 
Radula; sehr abweichend erscheinen aber andere, sowohl äußere als innere Merkmale der Tiere. Äußerlich fält bei den Formen des Genus Testacella Cuv. zunächst die nur sehr undeutlich dreiteilige Fußsohle auf, welche ich überhaupt nur bei lebenden Tieren durch die dunkler gefärbten Sohlenränder angedeutet gefunden habe, während hier bei Dandebardia Hartm. deutliche Furchen vorhanden sind; die Fußsohle wird ferner bei Testacella nur durch einen einfachen schmalen Saum begrenzt und eine Schwanzdrüse fehlt an dem abgerundeten hinteren Ende vollkommen; am Rücken sind nur zwei Furchen vorhanden und die Genitalöffnung liegt ganz vorne neben dem rechten Augenträger.

Mit Rücksicht auf die inneren Organe finden wir die Fußdrüse hier in ganzer Länge frei am Boden der Leibeshöhle (Bauchhöhle), der Schlundkopf liegt nicht in der Mediane, sondern ist nach links verschoben und die zahlreichen Retraktoren desselben inserieren sämtlich an der linken Seitenwand und der linken Hälfte der Fußfläche. Vollkommen abweichend erscheinen auch die Lagerungsverhältnisse der Organe der Mantelhöhle; der Herzbeutel liegt auf der rechten Seite der Niere und kehrt die Kammer nach vorne, die Vorkammer nach hinten (Opisthopneumonie nach Plate). An den Sexualorganen finden wir bei Testacella einen langen Blasenstiel, bei einigen Formen auch einen deutlichen Appendix des Penis mit zweiarmigem Musc. retractor. Von Pollonera und Plate wird bei einigen Arten dieser Gruppe (T.haliotidea Drap., T. dubia Pollon., T. bareinonensis Pollon.) noch ein eigentümliches Flagellum nebst einem faserförmigen Anhange beschrieben, welches ich nicht beobachtet habe.

Wesentlich abweichende Verhältnisse sind diesbezüglich bei allen Formen des Genus Dandebardia Hartm. vorhanden; die Fußsohle ist hier stets deutlich dreiteilig, die Seitenfelder durch Furchen begrenzt, außerdem erscheint dieselbe doppelt berandet, ebenso ist an der verlängerten Schwanzspitze eine deutliche Schwanzdrüse vorhanden; am Rücken verlaufen vier Furchen und die Geschlechtsöffnung liegt an der rechten Halsseite, also ziemlich entfernt vom rechten Augenträger. Die Fußdrüse liegt hier innerhalb der Fußmuskulatur in die obersten Muskelschichten des Fußes eingebettet; der verhältnismäßig kleinere Schlundkopf besitzt paarige Retraktoren, welche an den Seiten entspringen; bei einigen Arten (Daudebardia s. str. = Rufina Clen.) verschmelzen dieselben hinter dem Schlundkopf, dringen als unpaarer Muskel in den Eingeweidesack und inserieren an der Schalenspinde1; bei den Arten der Gruppen Libania Bgt. und Carpathica Wagner bleiben jedoch diese Muskel paarig und inserieren an der linken Seitenwand. Die Sexualorgane stets ohne Appendix und Appendicula, die rundliche Samenblase kurz bis sehr kurz gestielt.

Wir sehen aus diesem Befund, daß die Übereinstimmung der beiden Gruppen Testacella Cuv, und Dandebardia Hartm. nur eine beschränkte, zum Teile äußerliche und durch die ähnliche Lebensweise hervorgerufen ist; der wurmförmige Habitus, die rudimentäre Schale, das Raubschneckengebiß sind eine Folge der Anpassung an die unterirdische Lebensweise als Raubschnecken.

Eine größere Übereinstimmung und nähere Verwandtschaft lassen jedoch die Formen der Gruppe Dandebardia Hartm. mit einigen Gruppen der Zonitiden, so besonders Aegopina Kob. und Hyalinia Ag. erkennen. Wie schon oben bemerkt, zeigen Daudebardienschalen mittlerer Entwicklung eine auffallende Ähnlichkeit mit den Gehäusen einiger junger Zonitiden, so besonders der Aegopina nitens Mich. Eine dreiteilige Fußsohle und eine deutliche Schwanzdrüse an der verlängerten Schwanzspitze ist sowohl bei Daudebardia als den Zonitiden vorhanden, bei letzteren ein glatter oft nur dünner Kiefer und eine Radula, welche die Merkmale der Raublungenschnecken in etwas modifizierter Weise erkennen läßt und einen Übergang zu den Verhältnissen der nur pflanzenfressenden Lungenschnecken darstelit. Die Verhältnisse der Sexualorgane erscheinen bei Daudebardia und den Zonitiden sehr ähnlich, oft vollkommen übereinstimmend. Aus diesen Betrachtungen glaube ich, den Schluß ziehen zu dürfen, daß die Gruppen Testacella Cuv. und Daudebardia Hartm. nur insoweit Analogien erkennen lassen, als dieselben durch ihre gleiche Lebensweise als Raubtiere hervorgerufen wurden, während andere Merkmale auf eine verschiedene Abstammung hinweisen; dem entgegengesetzt finden wir eine auffallende Übereinstimmung zwischen Dandebardia und einzelnen Gruppen der Zonitiden (Aegopina Kob., Hyalinia Ag.), wodurch die Ansicht begrürdet erscheint die Daudebardien als extrem entwickelte Gruppe der Zonitiden aufzufassen. 
Aus der Familie der Oleacinidae interessiert uns zunächst Glandina algyra L. als einzige europäische Art; bei dieser Gruppe finden wir einen besonderen Typus der Radula, welcher außerdem noch bei der Mehrzahl der tropischen Raublungenschnecken beobachtet wird (Ennea Ad., Streptaxis Gray, Gibbulina Beck.). Neben den charakteristischen stachelförmigen Seiten und Randzähnen ist hier ein symmetrischer Mittelzahn vorhanden, welcher immer kleiner als die Seitenzähne, häufig sogar rudimentär erscheint. Diese Anordnung erinnert an die Verhältnisse bei den Stenogyriden und Cochlicopiden, welche jedoch als Pflanzenfresser zahlreiche kleine, kurze und mehrspitzige Zähne besitzen (vgl. Taf. 2, Fig. 12; Taf. 3, Fig. 23 und 25; Taf. 5, Fig. 45). Eigentümliche Verhältnisse weisen ferner die Sexualorgane bei Gl. algyra L. auf; wir finden hier eine langgestielte Samenblase und einen auffallend großen Appendix am Penis, also ein Befund, wie er ähnlich bei den Cochlicopiden beobachtet wird; es erscheint nun bemerkenswert, daß auch das Gehäuse von Gl. algyra L. geradezu auffallend mit solchen der Cochlicopiden übereinstimmt und auch äußere Merkmale der Tiere, wie die ungeteilte nicht berandete Fußsohle sowie der Mangel einer Schwanzdrüse, beiden Gruppen eigentümlich sind. Die geschilderten Verhältnisse lassen nähere verwandtschaftliche Beziehungen zwischen Glandina algyra L. und vermutlich allen Oleaciniden einerseits und den Cochlicopiden erkennen, als solche andererseits zwischen Oleaciniden und Testacelliden bestehen. In einem natürlichen System gehören die Oleaciniden also in die Nachbarschaft der Cochlicopiden.

Über die weiteren Gruppen der Raublungenschnecken liegen mir noch zu wenige anatomische Untersuchungen vor, um ein abschließendes Urteil fällen zu können. Die bisher untersuchten Formen der Gruppen Emea Ad. (E. tonkiniana Bav. et Dautz., E. dealbata Webb. et B.), Streptaxis messageri Bav. et Dautz., Gibbulina newtoni Ad., Gibbulina manritiana Morl. sind vivipar; die Verhältnisse der Sexualorgane gleichen jedoch auffallend jenen von Rumina decollata L., Prosopeas excellens Bav. et Dautz., also den Stenogyriden; die Radula zeigt die früher beschriebene Anordnung und erinnert durch den kleinen symmetrischen Mittelzahn ebenfalls an die Stenogyriden und die nahe verwandten Cochlicopiden. Die Gehäuse gleichen vielfach solchen der Pupiden, zeigen aber auch eigenartige und für einzelne Gruppen charakteristische Verhältnisse, indem das Gewinde asymmetrisch und unregelmäßig erscheint (Streptaxis Gray). Auch diese Gruppen lassen also nähere Beziehungen zu den Stenogyriden, Cochlicopiden und Pupiden erkennen (vgl. Taf. 3, Fig. 22 und 24; Taf. 5, Fig. 44). 


\title{
Die Testacelliden und Zonitiden aus dem Gebiete Österreichs und Ungarns sowie aus den angrenzenden Balkanländern.
} STYLOMATOPHORA.

\section{Familia TESTACELLIDAE.}

\author{
Genus Testacella Cuvier 1800.
}

(Helicolimax Férussac 1801).

Aus dieser Gruppe sind mir nur die Weichteile von zwei Arten (T. hnngarica Soos und T. gestroi Issel) durch persönliche Untersuchung bekannt geworden, dieselben unterscheiden sich mit Rücksicht auf die äußere Form als auch die Verhältnisse der Sexualorgane so auffallend, daß sie als Vertreter von zwei verschiedenen Gruppen aufgefaßt werden müssen. Die in der Literatur vorhandenen Angaben über weitere Arten der Gruppe lassen sich trotz der beigegebenen, anscheinend genauen Abbildungen nur unsicher mit den von mir gewonnenen Resultaten vergleichen, da anscheinend einzelne Organe und Organteile verschieden aufgefaßt und gedeutet werden. Ich beschränke aus diesem Grunde die Besprechung des Genus Testacella Cuv. auf eine genaue Beschreibung der mir bekannt gewordenen Arten.

\section{Testacella hungarica Soos.}

$$
\text { Taf. 1, Fig. } 1 \text { bis } 4 .
$$

Testacella hungarica Soos in: Annales Mfusei nationalis hungarici, 1908.

Tier nacktschneckenartig, im kriechenden Zustande langgestreckt und schlankwurmförmig, kontrahiert walzenspindelförmig mit flacher Sohle; trübrotorange mit zahlreichen feinen braunen Punkten. Die Fußsohle ungeteilt, nur an den Rändern dunkler gefärbt, durch einen schmalen Saum begrenzt; die kurze, abgerundete Schwanzspitze ohne Schwanzdrüse. Der Mantel sehr klein, vor der Schwanzspitze gelegen und von der im Verhä!tnisse sehr kleinen, rudimentären Schale bedeckt; unter derselben der Atemporus und die Zwitterdrüse. Am Rücken zwei Furchen, welche vom Mantelrande divergierend zu den Augenträgern verlaufen. Die Genitalöffnung ganz vorne, neben dem rechten Augenträger. Der auffallend kräftige und große Pharynx erstreckt sich fast durch die ganze Länge der kontrahierten Leibeshöhle, liegt aber nicht in der Mediane, sondern etwas nach links verschoben; die zahlreichen Schlundkopfretraktoren entspringen in zwei Längsreihen neben der dorsalen Mittellinie, inserieren aber sämtlich an der linken Seitenwand und der linken Hälfte der Fußfäche. Die verhältnismäßig sehr große Radula ist dreimal länger wie breit, die einzelnen Zahnplatten in zwei gleichbreite Seitenfelder von Querreihen angeordnet, welche sich in der Mittellinie in spitzem Winkel treffen; ein symmetrischer Mittelzahn fehlt. Die Zahl der Platten in einer Halbreihe beträgt durchschnittlich 15 bis 25 . Im übrigen erscheinen die Zähne der ganzen Radula gleichartig angelegt, die vorhandenen Unterschiede beziehen sich auf die Größe derselben sowie die Entwicklung des Dentikels; die größten und am besten entwickelten Zähne befinden sich in der Mitte der Seitenfelder, hier erscheint der Dentikel sensenförmig mit einem bogenförmigen Ausschnitt am konkaven Rand, wodurch ein Widerhacken gebildet wird; dieser Widerhaken kann als undeutlich entwickelte Nebenspitze bezeichnet werden. Die Zähne entlang der Mittellinie sind am kleinsten und besitzen einen kürzeren, breiteren, die äußeren Randzähne einen schmäleren, stachelförmigen Dentikel. 
Die Fußdrüse befindet sich in ganzer Länge frei in der Bauchhöhle am Boden der Leibeshöhle. Die Organe der Mantelhöhle zeigen auch hier die von Plate nachgewiesene Opisthopneumonie, indem der Herzbeutel auf der rechten Seite der Niere liegt und die Kammer nach vorne, die Vorkammer nach hinten kehrt. An den Sexualorganen finden wir: eine rundliche Zwitterdrüse, welche aus kugeligen Acinis zusammengesetzt erscheint; einen fadenförmigen, im mittleren Teil kettengliedartig gewundenen Zwittergang ohne deutlichen Divertikel; eine verhältnismäßig sehr große Eiweißdrüse; ein wenig gewundenes Prostata-Uteruskonvolut; einen ziemlich kurzen Uterushals, aber eine lange Vagina, in welche die rundliche Samenblase mit einem mitteliangen, oben dünnen, an der Basis etwas verdickten Blasenstiel mündet. Der lange, schlankspindelförmige Penis ist im vorderen Teile dünn, im mittleren etwas angeschwollen, vor dem hinteren Ende leicht abgeschnürt; ein kräftiger und langer Musc. retractor ist endständig inseriert; das fadenförmige, lange Vas deferens mündet neben der Insertion des Musc. retractor. Der Muskel des rechten Augenträgers verläuft zwischen Penis und Vagina.

Gehäuse hornfarben, wenig durchscheinend, matt, mit kräftigen, ungleichmäßigen Zuwachsstreifen; ungenabelt, annähernd haliotisartig, aus einem rasch zunehmenden Umgange bestehend, wovon $3 / 4$ auf die Embryonalschale entfallen; das weitere Wachstum erfolgt, indem vorzüglich der Oberrand an Fläche zunimmt, während der Spindelrand auffallend zurückbleibt und sich tütenförmig unter den Oberrand einzurollen beginnt. Das Gehäuse erscheint schließlich schildförmig mit weit offener Mündung, an welcher man nur einen Ober- oder Außenrand und einen Spindel- oder Innenrand unterscheiden kann. Der Oberrand ist an der Insertion deutlich eingezogen, der Spindelrand wie bei Haliotis leistenförmig vorspringend, etwas schwielenförmig verdickt und am Übergang in den Oberrand abgestutzt, wodurch ein seichter Ausschnitt oder Kanal gebildet wird.

$$
D=7 \cdot 5, \quad d=4 \cdot 3 m m .
$$

Fundorte: Gärten des Küstenlandes zwischen Görz und Fiume; besonders häufig in der Umgebung von Triest (Barcola).

Mit Rücksicht auf das Gehäuse steht diese Art der Testacella haliotidea Drap. (vom Fundorte St. Martin, Hérault) sehr nahe und unterscheidet sich von derselben durch das langsamer zunehmende Gewinde, dementsprechend ein schmäleres Gehäuse, einen schmäleren, mehr gebogenen Spindelrand und den an der Insertion stärker" eingezogenen Oberrand. Die kleinere Embryonalschale erscheint ferner hier spitzer vorspringend und vom Oberrande deutlicher abgesetzt, die Oberseite mehr gewölbt.

Die Verhältnisse der Sexualorgane werden jedoch bei T. haliotidea Drap. wesentlich abweichend von jenen bei der vorstehenden Art beschrieben. Die Abbildung in Moquin-Tandon, Hist. nat., Taf. 5 , Fig. 16, läßt freilich bei T. haliotidea Drap. auf den ersten Blick im allgemeinen identische Verhälinisse der Sexualorgane erkennen wie bei T. hmngarica Soos; auch dort läuft der Penis in ein strangförmiges, an seinem Ende dünneres Gebilde aus, welches jedoch als Flagellum gedeutet wird, während ich bei T. hungarica Soos an demselben Orte einen deutlichen Musc. retractor penis gefunden habe. Pollonera beschreibt in "Bollettino dei Musei di zoologica ed Anatomia comparata " Turin 1888, Testacella haliotidea nach Exemplaren von Cavoretto bei Turin; die beigegebene Abbildung läßt ein kurzes Divertikel am hinteren Drittel des Penis, ferner einen kurzen Musc. retractor am Übergange des Penis in ein kurzes Vas deferens und gleichzeitig ein zylindrisches, ziemlich langes Flagellum mit einem faserförmigen Anhang erkennen. Das Vorhandensein eines so großen Flagellums bei einer Testacellidae erscheint mir nicht nur sehr auffallend, sondern mit Rücksicht auf die Übereinstimmung der übrigen Organe auch unverständlich; vielleicht handelt es sich doch bei beiden Arten (T. haliotidea Drap. und T. hmugarica Soos) um identische Organe, welche verschieden gedeutet werden.

Testacella mangei Fér. besitzt nach Pollonera einen schlanken, spindelförmigen Penis mit endständigem Musc. retractor, ohne Appendix, sowie eine kugelige Samenblase mit auffallend langem, sehr dünnen Blasenstiel, welcher an der Einmündung in die Vagina angeschwollen erscheint (nach Exemplaren von Lissabon). Dieser Befund entspricht bis auf den wesentlich längeren Blasenstiel demjenigen bei 
T. Immgarica Soos und läßt eine nähere Verwandtschaft mit dieser Art, jedenfalls dieselbe Gruppe erkennen. Das Gehäuse von T. mangei Fér. ist freilich wesentlich von jenem der T. hungarica Soos und überhaupt von allen mir bekannten Arten des Genus verschieden und zeigt annähernd die Form einer phrygischen Mütze.

\section{Testacella gestroi Issel.}

Taf. 1, Fig. 5 bis 7 .

Testacella gestroi Issel, Ann. Mus. Genova, p. 277, Fig. 1 bis 5, 1873.

Ich nehme hier auch die Beschreibung dieser unserem Gebiete fremden Art auf, da durch dieselbe eine neue Gruppe der Testacelliden vertreten wird.

Tier im kontrahierten Zustand annähernd zungenförmig mit verhältnismäßig breiter, an den Rändern als scharfe Leiste vorspringender Fußsohle und flachgewölbter Oberseite; die vorliegenden, längere Zeit in Alkohol liegenden Exemplare sind auf der Oberseite schwarzbraun, unten graubraun gefärbt; die Fußsohle erscheint ungeteilt.

Die Sexualorgane mit rundlicher; ziemlich lang gestielter Samenblase; der Blasenstiel oben sehr dünn, an der Einmündung in die Vagina auffallend dicker. Der Penis ist ziemlich kurz, in der Mitte spindelförmig verdickt und durch eine Ringfurche abgesetzt. Das hintere Ende des Penis hakenförmig abgebogen und etwas angeschwollen, vor demselben ein halbkugelförmig vorspringendes Divertikel. Das fadenförmige Vas deferens mündet in das hakenförmig abgebogene Ende - des Penis und erscheint bei seinem Abgange von der Prostata wesentlich dicker. Der mittellange, aber kräftig entwickelte Musc. retractor ist zweiarmig und inseriert mit einem Arme am Ende des Penis, mit dem anderen am Divertikel (Appendix) dessełben. Die übrigen Verhältnisse wie bei T. hungarica Soos angegeben.

Gehäuse sehr ähnlich demjenigen der T. haliotidea Drap., dünnschaliger und besser durchscheinend, grünlich gelbbraun, mit langsamer zunehmenden Umgängen und stärker gebogenem Spindelrande.

$$
D=6 \cdot 2, \quad d=4 \mathrm{~mm} \text {. }
$$

Fundort: Sorgno bei Cagliari in Sardinien. Bei Testacella cataloniea Pollonera von Olot bei Barcelona scheinen ähnliche Verhältnisse der Sexualorgane wie bei $T$. gestroi Issel vorhanden zu sein; vielleicht beruhen die auf der Abbildung erkennbaren Unterschiede auf Ungenauigkeit der Zeichnung oder Präparation. Der Penis erscheint bei dieser Art länger, im vorderen Teile zylindrisch, am hinteren Ende unregelmäßig verdickt, mit endständigem Musc. retractor und unmittelbar neben der Insertion desselben mündendem, ziemlich langem Vas deferens.

Mit Rücksicht auf die bisher bekannt gewordenen Verhältnisse der Sexualorgane sowie die Form des Tieres lassen sich im Genus Testacella Cuv, zwei abweichende Gauppen unterscheiden.

Subgenus Testacella s. str.

Tier walzenspindelförmig; Sexualorgane mit mittellangem bis langem und dünnem Blasenstiel, Penis ohne Appendix, mit endständig inseriertem, langem und kräftigem Musc. retractor. Testacella hnngarica Soos, T. mangei Fér, vielleicht auch T. haliotidea Drap., T. barcinonensis Poll. = T. dubia Poll.

Subgenus Testacelloides n.

Tier zungenförmig, mit breiter, an den Rändern leistenförmig vorspringender Fußsohle; Penis mit Appendix, hackenförmig gebogenem hinterem Ende und zweiarmig inseriertem Musc. retractor.

Testacella gestroi Issel, T. catalonica Poll., T. pechiolii Bgt.?

\section{Familia ZONITIDAE.}

Tier mit dreiteiliger, berandeter Fußsohle und einem deutlichen Schleimporus (Schwanzdrüse an der verlängerten Schwanzspitze. Die Geschlechtsöffnung an der rechten Halsseite.

Der Kiefer häutig bis hornartig, glatt oder nur undeutlich und sehr fein gestreitt. 
Die Radula zeigt Übergänge vom Typus der Raublungenschnecken ohne symmetrischen Mittelzahn zu den Formen mit dreispitzigem, symmetrischem Mittelzahn, 3-5-12 zwei bis dreispitzigen Seitenzähnen und einer wechselnden Zahl stachelförmiger Randzähne; bei einer Gruppe (Hyalinia Ag.) erscheint auch der Mittelzahn auffallend klein.

Der Musc. retractor des rechten Augenträgers verläuft entweder zwischen Penis und Vagina oder frei neben den Sexualorganen.

Die Sexualorgane sind immer einfach organisiert; der Penis zumeist ohne oder nur mit schwach entwickeltem Appendix, aber immer mit einem endständig inseriertem Musc, retractor. Die kurz bis mittellang gestielte Samenblase ohne Divertikel des Blasenstiels, doch häufig mit einer schildförmigen Drüsenauf lagerung an der Basis des Blasenstiels, welche als Appendicula aufgefaßt werden kann uud vermutlich den Gland. mucosae der Heliciden entspricht.

Das Gehäuse im allgemeinen dünnschalig, durchscheinend bis durchsichtig, zumeist genabelt und stets mit einem dünnen, scharfen und geraden Mundsaum.

\section{Subfamilia Daudebardiinae.}

Tier nacktschneckenartig mit rudimentärer, vor der Schwanzspitze liegender Schale; am Rücken vier Furchen, von welchen die zwei mittleren vom Mantelrande zu den Augenträgern, die zwei seitlichen nach vorne und unten gegen den Fußrand verlaufen; die Geschlechtsöffnung befindet sich an der rechten Halsseite, der rechten Seitenfurche genähert; der Atemporus unter dem rechten Rande der Schale.

Der verhältnismäßig große Pharynx mit paarigen an den Seiten entspringenden Retraktoren, der Kiefer dünn und hautartig, die Radula nach dem Typus der Raublungenschnecken ohne symmetrischen Mittelzahn.

Die Sexualorgane mit einer verhältnismäßig großen in die Leber eingebetteten Zwitterdrüse, welche aus kugeligen Acinis zusammengesetzt ist; der lange kettengliedartig gewundene Zwittergang mündet ohne Divertikel in die große Eiweißdrüse. Die kugelige Samenblase ist stets kurz gestieit; Appendix und Appendicula fehlen stets. Der Musc. retractor des rechten Augenträgers verläuft frei neben Penis und Vagina.

Das rudimentäre Gehäuse ist im Verhältnis zum Tiere sehr klein, besitzt höchstens drei sehr rasch zunehmende Umgänge und eine sehr schiefe, weite Mündung.

\section{Genus Daudebardia Hartmann 1831 .}

Helicophanta Férussac 1822. Isselia Bourguignat 1877.

Rafina Clessin 1878. Pseudolibania De Stefani 1879.

Eudaudebardia Westerlund (part.) 1886.

Der Pharynx mit paarigen, an den Seiten entspringenden Retraktoren, welche hinter dem Schlundkopf verschmelzen, durch den Nervenschlundring treten, sodann als unpaarer Muskel den Eingeweidesack durchdringen und an der SchalenspindeI inserieren.

Die Sexualorgane mit zylindrischem, in der Mitte undeutlich abgesetztem, oft wulstig verdicktem Penis, an welchem der kräftige und lange Musc. retractor endständig inseriert; das fadenförmige, ziemlich kurze Vas deferens mündet neben dem Musc. retractor in das hintere Penisende. Uterushals und Vagina sind kurz, letztere häufig an der Einmündung des sehr kurzen Blasenstiels verdickt.

Das Gehäuse ist stets genabelt und besteht aus $2 \frac{1}{2}$ bis 3 rasch zunehmenden Umgängen, hievon entfallen $1 \frac{1}{2}$ langsamer zunehmende Umgänge auf die Embryonalschale.

Durch meinen Freund P. Hesse erhielt ich einige Exemplare der Daudebardia (Isselia) sardoa Issel aus Sardinien; diese Form wurde von Bourguignat mit Rücksicht auf das Vorhandensein einer Schwanzdrüse auch als besondere Gruppe (Isselia) von Dandebardia getrennt. Die mir vorliegenden 
Exemplare der $D$. sardoa Issel erwiesen sich jedoch als die altbekannten $D$. mifa Drap. und $D$. brevipes . Drap., welche wie an anderen Orten auch in Sardinien nebeneinander vorkommen und schon so oft verkannt wurden. Die charakteristische Schwanzdrüse habe ich aber bei allen Formen des Genus Dandebardia Hartm, auch bei $D$. rufa Drap, und D. brevipes Drap, nachgewiesen, so erscheint auch die Gruppe Isselia Bgt. überflüssig. Nachdem ich schon früher (Nachrichtsblatt d. D. Malac. Ges., 1906) die Identität von Psendolibania tarentina De Stefani mit D. rufa Drap. nachgewiesen habe, erscheint das Genus Dandebardia Hartm. auf der Apenninenhalbinsel, Sizilien und den tyrrhenischen Inseln auf die beiden Arten D. rufa Drap. und D. brevipes Drap. beschränkt.

Das Verbreitungsgebiet des Genus Daudebardia Hartm. (ex rect. mea) erstreckt sich demnach über Zentraleuropa, Italien, Sizilien, die tyrrhenischen Inseln, Algier, die Balkanhalbinsel mit den ägäischen Inseln und Kreta, die Halbinsel Krim und Kaukasien.

\section{Daudebardia rufa Drap.}

Helix mufa Draparnaud Hist., nat., 1805.

Daudebardia nivalis Benoit in: Illustr. sist. crit. iconograph, 1857.

- hassiaca Clessin, Mal. B1. 1868.

- heldi Clessin, Mal. Bl., 1872.

Isselia sardoa Is se1, Ann. Mus. Genova 1873.

Daudebardia grandis Ben oit, Bul. soc. ital., 1875.

- maravignae Mandral, Cat. Madon.

Psendolibania tarentina De Stefani, Bull, soc. mal, ital., 1879.

Das Verbreitungsgebiet dieser Art umfaßt das deutsche Mittelgebirge von der westlichen Wasserscheide des Rheins bis zur Oder, die nördlichen Karpathenländer, die nördlichen und östlichen Ausläufer der Alpen, dringt jedoch nur an einzelnen Punkten bis zum Rande des Hochgebirges vor und fehit den Zentral- und Westalpen, ebenso den Ost- und Südkarpathen. Vom Südostrande der Alpen geht dasselbe auf die Balkanhalbinsel, aber nicht nach Oberitalien über. Auf der Balkanhalbinsel kommt diese Art überall südlich der Donau vor, wurde auch in einer wenig abweichenden Lokalform noch auf den ägäischen Inseln und Kreta nachgewiesen. Ferner finden wir die typische Form noch in Unteritalien vom Monte Gargano über Apulien, Kalabrien bis nach Sardinien und Sizilien, hier auch eine Lokalform. Die Daudebardien aus Algier habe ich nicht gesehen, dieselben dürften der vorstehenden Art sehr nahe stehen. Das hier begrenzte Gebiet erscheint dadurch bemerkenswert, daß dasselbe mit den Verbreitungsgebieten solcher Gruppen der Stylomatophoren (Zonites Mont., Campylaea Beck, Alopia Ad.) im wesentlichen zusammenfällt, welche der zentraleuropäischen Region der paläarktischen Molluskenfauna eigentümlich sind. In diesem ausgedehnten Gebiete tritt diese Art nur an zerstreuten Punkten auf und wurde besonders in den kultivierten Teilen desselben an verhältnismäßig wenigen Orten gesammelt; auch ist die Individuenzahl an einer Lokalität zumeist eine geringe. So gehört D. rufa Drap. wie die übrigen Arten der Gruppe zu den Seltenheiten der Sammlungen und man findet nur schwer Gelegenheit, Exemplare von zahlreichen Fundorten miteinander vergleichen zu können. Die Weichteile der Mollusken wurden bis jetzt nur ausnahmsweise untersucht und so blieb die Unterscheidung der Daudebardien auf die Gehäuse beschränkt; diese kleinen, rudimentären Gebilde bieten aber der Beobachtung nur wenige Merkmale und erscheinen außerdem ziemlich veränderlich. Die Geschlechtsreife der Daudebardien hängt nicht mit einer bestimmten Entwicklung der Schale zusammen, wie zum Beispiel bei den Heliciden; so findet man auch unter tot gesammelten Schalen stets sehr verschiedene Wachstumsstadien. Auch andere Merkmale, wie die Färbung der Schale, die Art der Zunahme der einzelnen Umgänge, lassen individuelle Schwankungen erkennen. So erscheint es begreiflich, daß isolierte Funde von Daudebardien bei der Spärlichkeit eines entsprechenden Vergleichsmaterials oft Anlaß gaben, neue Arten, ja neue Gruppen aufzustellen.

Die von mir untersuchten Exemplare der D. nufa Drap. zeigen in den Alpen, Karpathen, Unteritalien, Sardinien und der Balkanhalbinsel eine vollkommene Übereinstimmung der anatomischen Verhältnisse; 
eine einigermaßen konstante, auch durch ihre geographische Verbreitung begründete Lokalform ist Daudebardia nufa cycladum Martens, welche in Mazedonien, Tracien und den ägäischen Inseln nachgewiesen wurde. Dandebardia lederi Bttg. aus Zis- und Thranskaukasien steht mit Rücksicht auf die Verhältnisse des Gehäuses der D. nufa Drap. so nahe, daß mich nur die Unkenntnis der anatomischen Verhältnisse bei der erstgenannten Art veranlaßt, dieselbe nicht als Form der D. mufa Drap, aufzufassen.

\section{Daudebardia brevipes Drap.}

Helix brevipes Draparnaud, Hist. nat., 1805.

Daudebardia sicula A. Bivonna, Nuovi moll. d. Palermo, 1839.

- fisceri Bourguignat, Malac. de l'Alg., 1884.

- brevipes var. carpathica A. J. Wagner, in Denkschr. Akad. Wien, 1895.

- - var. benoiti A. J. Wagner, 1. c., 1895.

- - apennina A. J. Wagner, 1. c., 1895.

Das Verbreitungsgebiet dieser Art fällt vollkommen mit jenem der D. nufa Drap. zusammen.

Daudebardia brevipes heydeni Boettger.

Taf. 2, Fig. 9.

Daudebardia heydeni Boettge r, Jahrb. d. Deutsch. Malak. Ges,. 1879.

- pavlenkoi Boettger, 1. c., 1880.

- vagneri Rosen, in Mollusken Ziskaukasien, Jahrb. d. k. Akad, St. Petersburg, Taf. 2, Fig. 5 bis 6, p. 94 (1911).

Ich bringe auf Taf. 2, Fig. 9, zum erstenmal die Abbildung der Sexualorgane einer kaukasischen Dandebardia; dieselben"entsprechen vollkommen den oben für dieses Genus angegebenen Verhältnissen und unterscheiden sich auch in keiner Weise von der typischen Form der D. brevipes Drap. Diese Übereinstimmung erstreckt sich auch auf die äußeren Merkmale des Tieres, ebenso auf die Verhältnisse des Pharynx und der Radula.

Die Gehäuse erreichen jedoch viel bedeutendere Dimensionen, als sie bei der typischen Form der D. brevipes Dr ap. bisher beobachtet wurden, sind festschaliger, rotbraun gefärbt; der letzte Umgang nimmt langsamer zu, ist verhältnismäßig schmäler und steigt vorne tiefer herab. Der Spindelrand ist häufig stärker verdickt, bedeckt den Nabel mitunter vollkommen, verbindet die Insertionen des Mundsaumes und erscheint zuweilen tütenförmig unter den Oberrand eingerollt.

$$
D=7 \cdot 5, \quad d=4 \cdot 5 m m .
$$

Fundorte: In Zis- und Transkaukasien; meine Exemplare von Maikop im Kubangebiet und vom Suram. Von Baron O. Rosen (Jekaterinodar) erhielt ich eine Anzahl von Exemplaren der vorstehenden Form vom Fundorte Maikop im Kubangebiet; von diesen Exemplaren wiesen nur die kleineren, welche der Diagnose Boettger's entsprechen normal entwickelte Sexualorgane auf; einige Exemplare des gleichen Fundortes waren jedoch auffallend groß. Ich dachte zunächst eine neue, von C. heydeni Bttg. verschiedene Form vor mir zu haben, da auch Baron Rosen berichtete, daß das lebende Tier grauviolett bis grellviolett gefärbt sei. Die anatomische Untersuchung dieser großen Exemplare (die in Spiritus stark kontrahierten Tiere waren noch immer 20 mm lang) ergab jedoch einen eigenartigen Befund. Die Verdauungsorgane und besonders der Pharynx waren besonders kräftig entwickelt, die Sexullorgane jedoch entweder vollkommen geschwunden oder nur in einem winzigen Rudimente vorhanden. Ich versuche mir diese Erscheinung in der Weise zu erklären, daß Daudebardien nach absolvierter Fortpflanzung unter günstigen Umständen weiter leben und dann auffallend groß werden; die Sexualorgane verkümmern jedoch bei solchen Exemplaren vollkommen. Solche Exemplare beschreibt Baron Rosen unter der Bezeichnung Dandebardia wagneri als neue Art, ich halte dieselben jedoch nur für eine Altersform der D. brevipes heydeni Bttg., mit welcher sie am gieichen Fundorte lebt. Das Gehäuse solcher überbildeten Exemplare weicht auch 
wesentlich von normalen Exemplaren ab; abgesehen von den bedeutenderen Dimensionen ist dasselbe festschaliger, mit einem schwielenförmig verdickten Spindelumschlag, welcher den Nabel nahezu vollkommen verdeckt und überdies tütenförmig unter den Oberrand eingerollt erscheint; auch am Gaumen finden sich mehr oder minder dicke Schmelzablagerungen. Entsprechend dem weiteren Wachstum des letzten Umganges erscheint das Gewinde im Verhältnisse zu diesem kleiner, auch steigt der letzte Umgang vorne stärker herab.

Daudebardia pavlenkoi Boettger entspricht einer Jugendform der D. brevipes heydeni $\mathrm{B} t \mathrm{tg}$.

\section{Daudebardia boettgeri Clessin.}

Taf. 1, Fig. 8 .

Dandebardia boettgeri Clessin, Malak. Bl., 1883, nec A. J. Wagner, in Denkschr. Akak. Wien, 1895.

- (Libania) boettgeri A. J. Wagner, in Nachrichtsblatt d. D. malak. Ges., v. 38, p. 184, 1906 u. in Ros sm., Icon., II, v. 13, Nr. 2208 .

Auch von dieser Art bringe ich auf Taf. 1. Fig. 8, zum erstenmal die Abbildung der Sexualorgane; dieselben entsprechen mit Rücksicht auf das terminal in den Penis mündende Vas deferens der vorstehenden Gruppe. Auch die paarigen Schlundkopfretraktoren verhalten sich wie bei $D$. rufa Drap., nur das Gehäuse zeigt eine große Übereinstimmung mit jenem von Libania saulcyi Bgt.; diese letztgenannte Art zeigt jedoch ein so abweichendes Verhalten der Sexualorgane und der Schlundkopfretraktoren, daß sie als Repräsentant einer besonderen Gruppe aufgefaßt werden muß. Dandebardia boettgeri Cless. wurde bisher nur in der Krim nachgewiesen.

Das Genus Dandebardia ex rec. mea umfaßt demnach nachstehende Formen:

$$
\begin{aligned}
& \text { Dandebardia mufa Drap. } \\
& \text { - mufa cycladum Martens. } \\
& \text { - lederi Bttg. } \\
& \text { - brevipes Drap. } \\
& \text { - brevipes heydeni Bttg. } \\
& \text { - boettgeri Cless. }
\end{aligned}
$$

vermutlich auch die Dandebardia-Formen aus Algier.

\section{Genus Libania Bourguignat (Moussonia Bgt.).}

Das Tier wie bei Dandebardia s. str., der Pharynx jedoch etwas nach links verlagert, da die paarigen Schlundkopfretraktoren beide an der linken Seitenwand inserieren.

Die Sexualorgane mit einem eigentümlich gegliederten Penis; derselbe ist im vorderen Teile spindelförmig verdickt und deutlich gegen den hinteren, dünnen Teil abgesetzt, das hintere Ende erscheint wieder blasenartig angeschwollen und hier inseriert endständig der Musc. retractor. Das mittellange Vas deferens ist in seinem oberen, von der Prostata abgehenden Teile fadenförmig dünn, das vordere in den Penis unmittelbar vor dessen blasenförmigem Ende (also nicht endständig) mündende Drittel ist jedoch zu einer länglichen Blase angeschwollen, welche dicker ist als der dünne Teil des Penis (Taf. 3, Fig. 19). Die übrigen Verhältnisse wie bei Daudebardia s. str.

Das Gehäuse ist im Verhältnis zum Tiere sehr klein, ungenabelt und besteht aus $13 / 4$ bis 2 Umgängen, von welchen $1 \frac{1}{2}$ langsam zunehmen und auf die Embryonalschale entfallen. Der letzte halbe Umgang nimmt sehr rasch und in der Weise zu, daß das Wachstum der Schale vorzüglich durch Verbreiterung der Oberseite erfolgt, während der Spindelrand auffallend zurückbleibt; an der Insertion erscheint der letztere umgeschlagen, verdickt, so daß er die Nabelgegend bedeckt und die Insertionen des Mundsaumes verbindet. 


\section{Libania saulcyi Bourguignat.}

Taf. 3, Fig. 19 bis 20

Testacella saulcyi Bourguignat, Test. noviss, et Cat, raisonné.

Daudebardia syriaca Roth, Mal. Bl., 1855.

- gaillardoli Bourguignat, Amén. Mal., I, p. 97, t. 6, Fig. 14-19.

- (Libania) bocttgeri A. J. WVagner, in Denkschr. Akad. Wien, 1895.

Dies ist die einzige Art der Gruppe, welche ich nach Exemplaren von Kandia auf Kreta (leg. Dr. Sturany) anatomisch untersucht habe. Die Verhältnisse der Sexualorgane und die Anordnung der Schlundkopfretraktoren weichen, wie oben ausgeführt, so wesentlich von den Verhältnissen ab, welche wir bei dem Genus Dandebardia s. str, beobachtet haben, daß die Trennung des Genus Libania Bgt. von Dandebardia s. str. begründet erscheint.

Das Verbreitungsgebiet dieser Art erstreckt sich über Syrien und Kleinasien bis zum Schwarzen Meer (Samsun), ferner über die ägäischen Inseln und die Insel Kreta.

Dandebardia gaillardoti Bgt. entspricht unausgewachsenen Exemplaren der vorstehenden Art.

Libania jetschini A. J. Wagner von Psirsk in Transkaukasien wurde nur mit Rücksicht auf die Form des Gehäuses dem vorstehenden Genus zugeteilt. Das Gehäuse der Dandebardia praecursor Andrae, von Kgl. Neudorf bei Oppeln in Schlesien zeigt eine auffallende, nahezu vollkommene Übereinstimmung mit jenem der Libania jetschini Wagner: so dürfte diese untermiozäne Art ebenfalls als Libania aufzufassen sein.

\section{Genus Carpathica A. J. Wagner 1895.}

Der Pharynx etwas nach links verlagert, da die beiden paarigen Retraktoren desselben an der linken Seitenwand inserieren.

Die Sexualorgane mit langem, fadenförmigem Vas deferens, welches im mittleren Drittel des Penis mündet (Taf. 3, Fig. 21). Die übrigen Verhäitnisse wie bei dem Genus Dandebardia s. str.

Das Gehäuse ist im Verhältnisse zum Tiere sehr klein und besteht höchstens aus $11 / 2$ sehr rasch zunehmenden Umgängen, von welchen ein Umgang auf die Embryonalschale entfällt. Ein Nabel ist bei der geringen Zahl der Umgänge nicht vorhanden, die entsprechende Einsenkung wird von dem schwielenförmig verdickten und umgeschlagenen Spindelrand mehr oder minder bedeckt. Im Gaumen sind schon bei jungen Exemplaren schwielenartige Auflagerungen, der sogenannte Gaumenkallus, vorhanden, dieselben lassen jedoch eine Zone in der Umgebung der Naht frei, welche durch eine im durchfallenden Lichte scharf gezeichnete, bogenförmige Linie (Kalluslinie) begrenzt wird.

Verbreitungsgebiet: Die Arten dieses Genus wurden bis jetzt nur in den Ost- und Südkarpathen, Rumänien, Serbien, Bosnien, Kroatien und Südkrain nachgewiesen, also in einem Gebiete, welchem Vertreter des Genus Dandebardia s. str. anscheinend vollkommen fehlen (nur in Kroatien nähern sich die Fundorte der D. rufa Drap. und Carpathica stussineri Wagner). Das Genus Carpathica umfaßt derzeit nachstehende Arten:

\section{Carpathica calophana Westerlund.}

Taf. 2, Fig. 18.

Dandebardia (Libania) calophana Westerlund, Fauna, I, p. 9.

Endandebardia jickelit Kimakowicz, in: Moll. Fauna. Siebenbürgens, II. Nachtrag, 1800

Verbreitungsgebiet: Ostgalizien, Nordostungarn, Siebenbürgen, 
Carpathica kimakowiczi A. J. Wagner.

Dandebardia (Carpathica) Kinakowiczi A. J. Wagner in: Denkschriften Akad. Wien, Taf. 1, Fig. 3, Taf. 2, Fig. 12, Taf. 5, Fig. $33,1895$.

Verbreitungsgebiet: Westsiebenbürgen.

\section{Carpathica langi Pfeiffer:}

Helicophanta langi Pfeiffer, Symbolae, p. 81, 1846.

Die Sexualorgane dieser Art besitzen ein endständig in den Penis mündendes Vas deferens; die parigen Schlundkopfretraktoren inserieren jedoch an der linken Seitenwand.

Verbreitungsgebiet: Banat und Ostserbien.

\section{Carpathica stussineri A. J. Wagner.}

Taf. 3, Fig, 21.

Dandebardia (Illyrica) stussineri A. J. Wagner in: Denkschriften Akad, WVien, Taf. 1, Fig. 6, Taf. 2, Fig, 13, Taf. 5, Fig. 36, 1895.

Verbreitungsgebiet: Südkrain, Kroatien, Bosnien und Serbien.

\section{Genus Cibinia n.}

Die äußeren Merkmale des Tieres und die Anordnung der Schlundkopfretraktoren wie bei dem Genus Carpathica Wagner; die Sexualorgane jedoch mit einem auffallend langen, verhältnismäßig dünnen Penis, welcher vor seinem hinteren Ende zunächst stark verdünnt, am Ende wieder blasenförmig angeschwollen erscheint. Der lange, aber dünne Musc. retractor penis ist endständig inseriert, neben ihm mündet das lange, fadenförmig dünne Vas deferens (Taf. 2, Fig, 13).

Das im Verhältnis zum Tiere auffallend kleine Gehäuse besteht nur aus einem sehr rasch zunehmenden Umgange, hievon entfallen $3 / 4$ Umgänge auf die Embryonalschale. Die übrigen Verhältnisse wie bei dem Genus Carpathica Wagner.

Cibinia transsilvanica E. A. Bielz.

Taf. 2, Fig. 13 bis 17.

Daudebardia transsitvanica E. A. Bielz in: Verhandlung d. Siebenbürg. Ver., 1859 und Fauna der Land- und SüBwassermoll. Siebenbürg. 1867.

Dandebardia (Carpatzica) transsilvanica A. J. Wagner in: Denkschriften d. k. Akad. Wien, Taf. 1, Fig. 5, Taf. 2, Fig. 11, Taf. 5, Fig. 35, 1895.

Verbreitungsgebiet: Die transsilvanischen Alpen in Siebenbürgen und Rumänien.

\section{Subfamilia Zonitinae.}

Der Kiefer dünn und hautartig bis hornartig, aber immer glatt; halbmondförmig gebogen mit einem schwachen Vorsprung am konkaven Rande.

Die Radula immer mit einem symmetrischen, zumeist dreispitzigen Mittelzahn, welcher bei einigen Gruppen konstant kleiner wie die Seitenzähne, bei anderen gleich groß ist; auf den Mittelzahn folgen 3-5-12 asymmetrische, zwei- bis dreispitzige Seitenzähne und eine wechselnde 'Zahl (15 bis 20) von stachelförmigen Randzähnen. 
Die Sexualorgane sind im allgemeinen einfach organisiert, doch werden bei den einzelnen Gruppen bereits regelmäßig schwach entwickelte Anhangsorgane, wie Appendix, Appendicula und Pfeilsack, beobachtet. Sehr verschieden sind bei den einzelnen Gruppen die Verhältnisse am Penis und dem Vas deferens. Als Penis bezeichne ich hier den vorderen Teil des männlichen Geschlechtskanals von der Einmündung in die Kloake bis zur Insertion des Musc. retractor; dieser inseriert hier also immer endständig und fehlt nur ausnahmsweise vollkommen. Abgesehen von der verschiedenen Form des Penis finden wir diesen bei einigen Arten am hinteren Ende mehr oder minder tief in zwei Zipfel gespalten, in diesem Falle den Musc. retractor zweiarmig inseriert und das Vas deferens in das eine Divertikel mündend (Taf. 6, Fig. 49 bis 51 ). In anderen Fällen ist am mittleren Drittel des Penis ein Appendix vorhanden, in welchen jedoch das Vas deferens nicht mündet (Taf..7, Fig. 61). Das Vas deferens erscheint entweder in seiner ganzen Länge gleichmäßig fadenförmig dünn und mündet dann immer endständig neben der Insertion des Musc. retractor (Taf. 4, Fig. 26) oder der vordere, in den Penis mündende Teil desselben ist wesentlich dicker und mündet dann zumeist in einiger Entfernung von der Insertion des Musc. retractor im hinteren Drittel des Penis (Taf. 7, Fig. 56), in diesem Falle erscheint das Vas deferens auch häufig durch eine bindegewebige Membran an das vordere Ende des Penis angeheftet. Eine Samenblase ist immer vorhanden, bei einer Gruppe jedoch (Crystallıs Lowe) nur rudimentär entwickelt. Ein Flagellum am Penis habe ich bei keiner der von mir untersuchten Arten gefunden, ein solches wird jedoch bei Zonites algivus L. angegeben. An der Einmündung des Blasenstiels in die Vagina finden wir bei einigen Gruppen ein gut entwickeltes, schildförmig die Vagina umgebendes Drüsenkonglomerat, bei manchen Arten erscheint dasselbe nur durch eine Verdickung der Vagina angedeutet und fehlt bei einigen Gruppen vollkommen.

Das Gehäuse ist im Verhältnisse zum Tiere so groß, daß sich letzteres vollkommen in dasselbe zurüickziehen kann; im übrigen eng bis weit und perspektivisch genabelt, dünnschalig, durchscheinend bis glasartig durchsichtig, mit 4 bis $5 \frac{1}{2}$ bis $6 \frac{1}{2}$ Umgängen; der Mundsaum gerade, dünn und scharf.

\section{Genus Aegopina Kobelt 1881}

\section{(Polita Clessin 1887, Aegopsina Bgt.)}

Tier mit dreiteiliger, berandeter Fußsohle und Schwanzdrüse; der Geschlechtsporus rechts, in der Mitte unter dem Mantelrand.

Der Kiefer hornartig fest, glatt mit einem schwachen Vorsprung am konkaven Rand.

Die Radula mit einem dreispitzigen, symmetrischen Mittelzahne, welcher so groß wie die Seitenzähne ist; auf den Mittelzahn folgen in jeder Halbreihe 3 bis 5 zweispitzige, asymmetrische Seitenzähne und eine wechselnde Zahl stachelförmiger Randzähne.

Der Musc. retractor des rechten Augenträgers verläuft frei neben den Sexualorganen.

Die Sexualorgane mit spindelförmigem, im vorderen Drittel stärker angeschwollenem Penis, welcher sich nach hinten allmählich verjüngt und so ohne deutliche Grenze in das kurze bis mittellange Vas deferens übergeht; ein Musc. retractor penis fehlt bei einigen Arten oder derselbe ist schwach entwickelt; die rundliche Samenblase ist kurz gestielt, eine Drüsenauflagerung an ihrer Einmündung in die Vagina nicht nachgewiesen. P. Hesse kennzeichnet dieses Genus außerdem durch nachstehende Merkmale: der Penisnerv entspringt am Außenrande der Oberseite des rechten Pedalganglions; der linke Nackenlappen ist in zwei Stücke geteilt.

Das Gehäuse ist klein bis mittelgroß, dünnschalig, glatt, mit feinen Zuwachsstreifen, aber ohne Spiralskulptur; die $4 \frac{1}{2}$ bis $5 \frac{1}{2}$ Umgänge nehmen ziemlich rasch zu, der letzte ist stärker erweitert.

Das Verbreitungsgebiet umfaßt Zentral- und Westeuropa.

\section{Aegopina nitens Michaud.}

$$
\text { Taf. } 7 \text {, Fig. } 59 a \text { bis } c \text {. }
$$

Helix nitens. II ichaud, Compl. moll., 1831. 
Radula: Der symmetrische Mittelzahn mit verhältnismäßig breiter, stumpfer Hauptspitze und zwei gut entwickelten Nebenspitzen; auf den Mittelzahn folgen in der Halbreihe 4 bis 5 zweispitzige Seitenzähne, welche allmählich in die stachelförmigen Randzähne übergehen ( 25 bis 30 ).

Sexualorgane: Der spindelförmige, in der Mitte stärker angeschwollene Penis geht hinten allmählich verjüngt in das kurze Vas deferens über; ein schwach entwickelter Musc. retractor penis ist vorhanden; die rundliche Samenblase mit deutlich abgesetztem, kurzem, an der Einmündung in die Vagina dickerem Blasenstiel.

Die Gehäuse dieser Art variieren an verschiedenen Lokalitäten mit Rücksicht auf ihre Dimensionen und den mehr oder minder stark erweiterten letzten Umgang, erweisen sich jedoch in den wesentlichen Merkmalen sehr konstant.

Verbreitungsgebiet: Zentral- und Westeuropa.

Aegopina nitens inermis A. J. Wagner.

Hyalina nitens inermis A. J. Wagner, Nachrichtsblatt d. D. malak. Ges., p. 113 (1907), und Rossm. Icon, v. 13, Nr. 2192.

Verbreitungsgebiet: Südbosnien, Hercegovina, Montenegro und Nordalbanien.

Aegopina hiulca (Jan.) Albers.

Taf. 4, Fig. 41 ; Taf. 7, Fig. 58.

Hyalina hiulca J an. in Albers, Helic., 1850.

Hyalina nitens var. hiulca Kob. in Rossm., Icon., I, v. 6, Nr. 1591 bis 1592.

Polita hiulca Clessin, Moll. Fauna. Österreich-Ungarns, p. 77 (1887).

Radula: Der symmetrische Mittelzahn mit einer langen, stachelförmigen Hauptspitze und zwei schwach entwickelten Nebenspitzen; auf den Mittelzahn folgen in der Halbreihe 4 zweispitzige Seitenzähne, welche allmählich in die stachelförmigen Randzähne übergehen. Die Nebenspitzen des Mittelzahnes und der Seitenzähne erscheinen hier im Verhältnisse zu den langen stachelförmigen Hauptspitzen nur schwach entwickelt und erinnert so die Radula dieser Art auffallend an die Verhältnisse der Raublungenschnecken.

Sexualorgane: Der spindelförmige, im vorderen Drittel auffallend verdickte Penis geht hinten allmählich verjüngt in das hier lange, fadenförmige Vas deferens über; ein Musc. retractor fehlt; der Blasenstiel ist sehr kurz. Aegopina hinlca Alb. unterscheidet sich, wie hier nachgewiesen wurde, auch mit Rücksicht auf die Verhältnisse der Radula und der Sexualorgane recht auffallend und konstant von Aegopina nitens Mich. Das Gehäuse dieser Art ist immer viel enger genabelt als jenes von Aegopina nitens Mich.; dasselbe erscheint ferner durchschnittlich größer, dünnschaliger, das Gewinde ist mehr erhaben, die Umgänge weniger zusammengedrückt; die Mündung gegen die Gehäuseachse mehr herabgebogen.

Das Verbreitungsgebiet dieser Art erstreckt sich über die südlichen und östlichen Ausläufer der Alpen in der Südschweiz (Tessin), der Lombardei, Venetien, Krain, Kärnten, Steiermark, Niederösterreich sowie in den angrenzenden Teilen von Westungarn und Kroatien. Aegopina hinlca Alb. ist im Gegensatze zu Aegopina nitens Mich, eine autochthone Talform, dringt nur in den größeren Tälern (Mürztal) bis an den Rand des Hochgebirges und ivurde in Höhenregionen über $1000 \mathrm{~m}$ bisher nicht beobachtet. In der Oststeiermark, den Ausläufern der Zentralalpen im Osten Niederösterreichs, in Kärnten und Westungarn wird die vorstehende Art konstant kleiner, dünnschaliger und heller gefärbt; diese konstante Lokalform entspricht der:

\section{Aegopina hiulca ressmanni Westerlund.}

Hyalina nitens var, ressmanni Westerlund, Jahrbuch d. Nat, Ges., 1883.

Polita nitens var. Szepii Clessin, Moll. Fauna Österreich-Ungarns, p. 75 (1887).

Westerlund und Clessin haben diese bis auf ihre konstant geringeren Dimensionen alle Merkmale der Aegopina hinlca aufweisende Lokalform mit Unrecht zu Aegopina nitens Mich. gestellt. 


\section{Aegopina lenticularis Held.}

Taf. 9, Fig. 68; Taf. 11, Fig. $82 a$ bis $b$.

Helix tenlicularis Held, Isis 1837.

Die beigegebenen Abbildungen der Sexualorgane, des Kiefers und der Radula wurden nach Zeichnungen Wiegmann's kopiert, welche dieser vorzügliche Anatom nach Präparaten von Exemplaren aus Jena ausgeführt hatte. Aegopina lenticularis Held wird vielfach mit Zonitoides (Hy'alina) hammonis Strö $\mathrm{m}$ = radiatulus Alder verwechselt. außerdem mit Hyalinia puva Alder identifiziert. Zonitoides hammonis Ström besitzt vor allem eine deutliche Radialskulptur, bestehend aus dichten, regelmäßigen und verhältnismäßig kräftigen Zuwachsstreifen auf der Oberseite; das höhere Gewinde besteht aus $3 \frac{3}{4}$ regelmäßig zunehmenden, höheren, gleichmäßig gerundeten Umgängen; die Mündung ist höher, der Nabel wesentlich enger. Aegopina lenticularis $\mathrm{Held}$, welche mir in übereinstimmenden Exemplaren aus den Alpen und Karpathen vorliegt, läßt sich am besten mit Aegopina nitens Mich. vergleichen; die erste Art ist immer viel kleiner, weist einen Umgang weniger, aber einen wesentlich weiteren Nabel auf, auch sind die Umgänge noch mehr zusammengedrückt; der letzte Umgang nimmt wie bei A. nitens Mich. rascher zu, ist besonders vor der Mündung doppelt so breit wie der vorletzte und die Mündung erscheint wesentlich breiter als hoch. Die Skulptur besteht nur aus sehr feinen bis undeutlichen Zuwachsstreifen; Spirallinien, wie sie Westerlund angibt, habe ich bei den Exemplaren aus den Alpen, Karpaten und Süddeutschland nicht beobachtet.

$$
D=4 \cdot 5, \quad d=4 m m .
$$

Die Radula erscheint nach der Zeichnung Wiegmann's mit jener von Ae. nitents Mich. übereinstimmend, ebenso lassen die Sexualorgane keinen wesentlichen Unterschied erkennen.

Das Verbreitungsgebiet der A. lenticularis Held umfaßt anscheinend ganz Zentraleuropa; dieselbe ist vielleicht dem ganzen paläarktischen Gebiet eigentümlich, falls Ae, pura Alder mit der vorstehenden Art identisch ist.

P. Hesse führt noch Ae. incerta Drap., Ac. olivetormm Gmel, und Ae. nitidula Drap. auf Grund der anatomischen Untersuchung bei diesem Genus an.

\section{Genus Zonites autor.}

P. Hesse weist in seiner Abhandlung über das Genus Zonites Montfort (Nachrichtsblatt d. D. mal. Ges., p. 167 [1910]) nach, daß die bisher in diesem Genus vereinigten Arten wesentliche Unterschiede in den Verhältnissen der Sexualorgane erkennen lassen, und unterscheidet dementsprechend vier scharf geschiedene Untergattungen:

Zonites Montf. S. str. (Helicodes Dumas). Typus Z. algyrus L. Penis spindelförmig, mit kurzem, dicken Flagellum. Hierher noch: Z. rollei Kob., cytherae Marts., smymnensis Roth.

Aegopis Fitz. Typus Z. verticillus Fér. Penis ohne Flagellum, jedoch mit einem endständig inserierten Musc. retractor. Hierher: Z. gemonensis Fér., acies Fér., carniolicus L. Pffr.

Paragopis P. Hesse. Typus Z. albanicus Rssm. Der Penis mit einer häutigen Hülle im vorderen Teile, in welche das Vas deferens für eine kurze Strecke eingehüllt ist. Hierher: Z. mavvitii Wstld., serajevoensis Kimak.

Aegophtalmus P. Hesse. Typus Z. graecus Kob. Penis nach hinten sich allmählich verjüngend, Retraktor fehlt, an der Genitalkloake ein Appendix.

Die von mir im Gebiete beobachteten Formen gehören nur den Gruppen Aegopis Fitz. und Paraegopis P. Hesse an; die Unterschiede dieser beiden Gruppen erwiesen sich jedoch so auffallend und konstant, daß ich dieselben als gleichwertige Genera auffasse. 


\section{Genus Aegopis Fitzinger 1833.}

(Zonites autor. part.)

Der Kiefer hornartig fest, glatt, mit einem schwachen Vorsprung am konkaven Rande.

Radula: Nach der Form und Anordnung der Zahnplatten wurden hier zwei verschiedene Typen beobachtet.

Type. 1. Der symmetrische Mittelzahn dreispitzig und so groß, wie die zweispitzigen Seitenplatten; diese beiden Zahnformen verhältnismäßig breit mit gut entwickelter Hauptspitze, kurzen, wenig vorspringenden Nebenspitzen. Auf den Mittelzahn folgen in einer Halbreihe 6 bis 12 zweispitzige Seitenzähne und 35 bis 50 stachelförmige, an Größe abnehmende Randzähne (Taf, 4, Fig. 28, Fig. 30, Fig. 32).

Type 2. Sämtliche Zähne einer Querreihe sind einspitzig und schmal; der Mittelzahn symmetrisch und so groß, wie die leicht asymmetrischen Seitenzähne ( 5 bis 6 ); auf diese folgen über 50 stachelförmige Randzähne (Taf. 5, Fig. 46). Im Gegensatze zu den bisher besprochenen Gruppen der Zonitiden finden wir hier zahlreiche stachelförmige Randzähne, bei einigen Formen überhaupt nur einspitzige Zähne.

Sexualorgane: Der verhältnismäßig große, zylindrische oder spindelförmige Penis mit einem endständig inserierten, kräftigen Musc. retractor; das lange und gleichmäßig fadenförmig dünne Vas deferens mündet unmittelbar neben der Insertion des Musc. retractor. Die ovale oder rundliche Samenblase ist von dem kurzen bis mittellangen Blasenstiel deutlich abgesetzt; der Blasenstiel ist an seinem unteren, in die Vagina mündenden Ende verdickt; diesem unteren Ende des Blasenstiels und der Vagina aufgelagert findet sich bei allen Formen dieser Gruppe ein gut entwickeltes schildförmiges Drüsenkonglomerat (glandula scutiformis). Der Musc. retractor des rechten Augenträgers verlauft frei neben den Sexualorganen.

Das verhältnismäßig große Gehäuse ist dünnschalig bis festschalig mit offenem, durchgehenden, mehr ođer minder perspektivischem Nabel; die Färbung gelblich, gelbbraun bis rostbraun, häufig mit grünlichem Stich, milchig getrübter Unterseite und opaken Anwachsstriemen; schwach durchscheinend bis durchsichtig, oben matt, unten lebhaft glänzend. Die Skulptur ist auf der Ober- und Unterseite auffallend verschieden und wird durch eine scharfe, mit dem Kiel zusammenfallende Grenzlinie geschieden; auf der Oberseite besteht die Skulptur aus dichten, ziemlich gleichmäßigen Zuwachsstreifen, welche bald sehr fein, bald kräftig bis rippchenartig erhoben sind; daneben sind sehr feine und dichte Spiralleistchen vorhanden, wodurch die Oberseite in verschiedenem Grade gegittert erscheint. Auf der Unterseite sind die Zuwachsstreifen auffallend schwächer, die Spiralleistchen fehlen zumeist vollkommen oder sind nur in der Umgebung des Nabels angedeutet. Das Gewinde ist bald breit kegelförmig, bald nahezu flach und besteht aus $5^{1 / 2}$ bis $71 / 2$ ziemlich langsam und regelmäßig zunehmenden Umgängen. Ein Kiel ist an den oberen Umgängen immer vorhanden, auf den unteren Umgängen verschwindet derselbe bei manchen Formen vollkommen. Die Mündung ist wenig schief und wird durch den vorletzten Umgang ausgeschnitten; der Mundsaum immer scharf und gerade, innen mit einer breiten, weißen, aber niedrigen, striemenartigen Kallusbildung als Ausdruck einer unvollkommenen Lippenbildung. Eine solche Lippenbildung tritt in unregelmäßigen Intervallen schon auf den oberen Umgängen auf, wodurch die für diese Gruppe charakteristischen, gelblich durchscheinenden Anwachsstriemen entstehen.

Das Verbreitungsgebiet der Aegopis-Formen erstreckt sich über die nördlichen, östlichen und südlichen Ausläufer der Ostalpen, dringt jedoch hier nur entlang der größeren Täler bis zum Rande der Hochgebirge; ferner über den Nordwesten der Balkanhalbinsel (Kroatien, Dalmatien, Bosnien, Westserbien); vielleicht gehört auch Zonites italicus $\mathrm{Kob}$. aus Unteritalien und $Z$. enboictus Kob. von der Insel Euboea zu dieser Gruppe. In den Alpen sind die Arten dieses Genus durchwegs Talformen und werden in Höhenlagen über 1000 nicht mehr angetroffen; im südlichen Velebit habe ich jedoch Aegopis croaticus laughofferi Wagner noch in Höhenlagen über $1000 \mathrm{~m}$ gesammelt. 


\section{Aegopis verticillus Férussac.}

Taf. 4, Fig. 26 bis 28.

Helix verlicillus F ćrussac, Hist, nat. moll, 1819.

Zonites verticillus var, euroa Kimakowicz, Nachrichtsblatt d. D. mal. Ges., 1899.

Die Radula mit dreispitzigem Mittelzahn, 12 bis 13 zweispitzigen Seitenzähnen und bis 40 stachelförmigen Randzähnen.

Sexualorgane: Der auffallend lange Penis ist im mittleren Teile spindelförmig verdickt; die ovale Samenblase mit kurzem, dicken Blasenstiel; die übrigen Verhältnisse typisch.

Verbreitung: Vereinzelt in Südbayern, Böhmen und Mähren, allgemein in Ober- und Niederösterreich, Steiermark, Kärnten, Krain, Kroatien und Nordbosnien, sowie in den angrenzenden Gebieten von Westungarn.

\section{Aegopis croaticus Roßmäßler.}

Taf. 4, Fig. 29 bis 30.

Helix croatica Roßmäßler, Icon., I, v. 1, Nr. 151 (part.).

Zonites croaticus septentrionalis Kobe1t, Icon., II, v, 9, Nr. 1574 bis 1576.

Die Radula mit einem dreispitzigen, symmetrischen Mittelzahn, 11 zweispitzigen Seitenzähnen, 40 bis 45 stachelförmigen Randzähnen.

Sexualorgane: Der lange zylindrische Penis ist im mittleren Drittel verdünnt; die ovale Samenblase mit kurzem, dickem Blasenstiel; die übrigen Verhältnisse typisch.

Roßmäßler führt diese Art aus Kroatien, ferner aus Tschernembl und dem Eingange der Adelsberger Grotte in Krain an; an letzterem Orte lebt aber nur Aegopis carniolicus Pfr., welche Art der Autor von seinem Ae. croaticus nicht unterscheidet. Die Abbildung in Rssm. Icon. I, v. 1, Nr. 151 stellt ein verhältnismäßig kleines und stumpfgekieltes Exemplar des Ae. croaticus dar; vollkommen ausgewachsene Gehäuse mit 7 Umgängen haben stets nur einen schwach kantigen oder vollkommen gerundeten letzten Umgang; Kobelt bezeichnet solche Exemplare als Ae.croaticus var. septentrionalis, welche also keine auf Nordkroatien beschränkte Lokalform, sondern die typische Form im ausgewachsenen Zustande darstellt. Die bei dieser Art häufig auftretenden Schwankungen in der Höhe des Gewindes und der Weite des Nabels sind als individuelle Variationen aufzufassen, da solche auch bei sonst übereinstimmenden Exemplaren des gleichen Fundortes beobachtet werden. Die Skulptur der Oberseite besteht aus dichten und feinen Zuwachsstreifen, welche nur auf dem letzten Umgange ungleichmäßig twerden; daneben sind sehr feine und dichte, nur unter der Lupe deutliche, erhobene Spirallinien vorhanden, wodurch die Oberseite sehr fein, oft undeutlich gekörnelt erscheint; auf der Unterseite sind nur ungleichmäßige, verhältnismäßig weitläufige Zuwachsstreifen vorhanden.

Das Verbreitungsgebiet dieser Art erstreckt sich vorzüglich über das Plateau von Sülkroatien und reicht nördlich im Uskokengebirge bis an die Save (Rann in Südsteiermark).

Sehr schwierig läßt sich diese Form gegen Ae. compressus Rssm, abgrenzen, mit welcher sie anatomisch übereinstimmt und mit Rücksicht auf das Gehäuse durch Übergänge verbunden ist. Im allgemeinen beobachten wir bei Ae:croaticus Rssm. ein höheres Gewinde und bei gleicher Gehäusegröße $1 / 2$ bis $3 / 4$ mehr Umgänge; diese nehmen hier auch langsamer zu und werden durch eine etwas tiefere Naht geschieden. Die Zuwachsstreifen sind ferner hier kräftiger, die Spirallinien deutlicher und immer vorhanden.

\section{Aegopis croaticus laughofferi n.}

Taf. 4 , Fig. 31 ; Taf. 11 , Fig. $78 a$ bis $b$.

Das Gehäuse mit niedrigerem, deutlich konvexem Gewinde; die flacheren Umgänge nehmen etwas rascher zu, so daß gleichgroße Gehäuse dieser Form immer $1 / 2$ Umgang weniger aufweisen, als solche 
der typischen Form; der letzte Umgang ist stärker zusammengedrückt, mit schwacher, gegen die Mündung zu undeutlicher Kante, undeutlichem bis erloschenem Kantenstreifen. Die Skulptur ist wesentlich abgeschwächt, indem die Zuwachsstreifen schwächer, die Spirallinien nahezu vollkommen erloschen sind, wodurch die Oberseite wesentlich glatter und glänzender erscheint. Die Mündung ist breiter.

$$
D=40, \quad d=35, \quad H=20 \mathrm{~mm} .
$$

Die Radula und die Sexualorgane wie bei der typischen Form.

Fundorte: Paklenica bei Starigrad und Krupa im Zrmanjatale in Norddalmatien, ferner am Mali Halan, der Visočica im Velebit südlich von Gospič; hier auch in Höhenlagen über $1000 \mathrm{~m}$.

Diese Form wird mit Ae. compressus Rssm. verwechselt, zu welchem sie freilich ebenso nahe Beziehungen hat, wie zur typischen Form des Ae. croaticus Rssm.

\section{Aegopis croaticus compressus Roßmäßler.}

Taf. 11, Fig. 79.

ITetix compressa Ro Bmäßler, Icon., I, v. 1, Nr. 150, nec Ko belt in .Iart. Chemn. Heliceen v. 5, Taf, 233, Fig. 9 bis 10, 1905. Helix lardea L. Pfeiffer, Mon. Hel. v. 1, p. 128, 1848.

Zonites lardens Ko belt, Icon., II, v. 9, Nr. 1563.

Die Abbildung in Rssm. Icon., I, v. 1, Nr. 150 entspricht einem unausgewachsenen Exemplare dieser Form; die Beschreibung und besonders die Fundortsangaben (Fiume, Frangipani) lassen keinen Zweifel darïber aufkommen, welche Form Roßmäßler seinerzeit vorgelegen hat. Kobelt bespricht in Mart. Chemn. »Heliceen, v. 5 unter der Bezeichnung Zon. compressus Rssm. eine flache Form des Ae.croaticus Rssm., anscheinend Ae.croaticus laughofferi m., während sein Z. lardeus ebendort einem ausgewachsenen Z. compressits Rssm. entspricht.

Ausgewachsene Gehäuse des Ae. compressuts Rssm. unterscheiden sich von Ae. croaticus Rssm. durch das niedrige, oft kaum erhobene Gewinde, mit höchstens 7 langsamer zunehmenden, flacheren und durch eine seichtere Naht geschiedenen Umgängen; der letzte ist stärker zusammengedrückt, an der Peripherie, auch bei ausgewachsenen Exemplaren, noch deutlich stumpf gekielt; die Mündung ist breiter, der Nabel weiter. Die Skulptur ist wesentlich schwächer und besteht aus feineren, auf den unteren Umgängen etwas ungleichmäßigen Zuwachsstreifen, während die Spirallinien sehr undeutlich sind und oft vollkommen fehlen.

$$
D=3 b, \quad l=31, \quad H=13 \mathrm{~mm} .
$$

Verbreitung: Diese Form ist mir nur aus dem kroatischen Litorale, und zwar von Buccari, Trsat, Fiume, Lukovo, Zengg, Jablanac und Carlopago bekannt.

\section{Aegopis carniolicus L. Pfeiffer.}

$$
\text { Taf. 5, Fig. } 47 \text {. }
$$

Helix camiolica L, Pfeiffer in Mon. Hel., v. 4, p. 119, 1859.

Zoniles carniolicus Ko belt in Rssm., Icon., I, v. 4, sub Nr. 1105 (part.) et in Mart. Chemn. Heliceen v. 5, S. 876, 1905.

Zonites camiolicus var. cassis Westerlund, Fauna, v. 1, p. $81,1886$.

Zonites compressus var. splendidulus Ko b. in: Mart. Chemn. Heliceen, v. 5, p. 891, 1905 et Rossm., Icon., II, v. 9, Nr. 1581.

Die Radula mit einem dreispitzigen, symmetrischen Mittelzahn, 9 zweispitzigen Seitenzähnen und über 40 stachelförmigen Randzähnen in einer Halbreihe.

An den Sexualorganen finden wir im Vergleiche mit Ae.croaticus Rssm. einen deutlich kürzeren, spindelförmigen Penis und einen etwas längeren Blasenstiel.

Auch die Gehäuse dieser Art unterscheiden sich bestimmt von solchen des Ae, croaticus Rssm. Bei Ae. carniolicus Pfr. ist das Gehäuse konstant kleiner, das Gewinde mehr abgerundet, mit 7 kleiner angelegten, langsamer zunehmenden, durch eine seichtere Naht geschiedenen Umgängen; der letzte ist stärker zusammengedrückt und an der Peripherie (auch bei 7 Umgängen) noch deutlich, wenn auch stumpfer gekielt; der Nabel ist verhältnismäßig weiter, die Mündung breiter. Die Skulptur besteht aus stärkeren, 
weitläufigeren und weniger gleichmäßigen Rippenstreifen, neben diesen sind feine, dichte, aber ebenfalls deutlichere Spirallinien vorhanden.

$$
\begin{aligned}
& D=28, \quad d=25, \quad H=13 \mathrm{~mm} ; \text { von Gospič in Kroatien. } \\
& D=25, \quad d=22, \quad H=15 \mathrm{~mm} ; \text {, von Krčmar in Kroatien. }
\end{aligned}
$$

Individuelle Variationen äußern sich hier vorzüglich durch verschiedene Dimensionen, die nicht konstante Zahl der Umgänge, die Höhe des Gewindes, Weite des Nabels, ebenso durch die mehr oder minder zahlreichen und deutlichen Anwachsstreifen.

Z. carniolicus var. cassis Wstld. entspricht Exemplaren mit höherem Gewinde und engerem Nabel, Z. camiolicus var. splendidulus Kob. solchen mit zahlreichen gut durchscheinenden Anwachsstreifen; letztere Form wird von Kobelt mit Unrecht zu Z. compressus gestellt. Beide Formen kommen am gleichen Fundorte neben typischen Exemplaren vor und werden mit solchen durch Übergänge verbunden.

Das Verbreitungsgebiet dieser Art erstreckt sich über Südkrain und das Plateau von Hochkroatien mit Ausschluß der Küstengebiete; südlich fand ich diese Art noch auf der Visočica im Velebit (1400 m), neben Ae. croaticus laughofferi m., aber nicht mehr in Dalmatien, in Westbosnien ist ihr Vorkommen wahrscheinlich.

\section{Aegopis acies Férussac.}

Taf. 4, Fig. 32; Taf. 6, Fig. 55.

Helix acies Férussac hist. moll. 1819.

- - Roßmäß1er, Icon;, I, v. 1, Nr. 152.

Zonites crypla L. Pfeiffer, Mal. B!. v. 15, p. 83, 1868.

- Kobelt, Icon., v. 4, Nr. 1106.

Die Radula mit einem dreispitzigen, symmetrischen Mittelzahn, 12 bis 13 zweispitzigen Seiten- und über 50 stachelförmigen Randzähnen.

Sexualorgane: Der Penis zylindrisch, lang, nach hinten zu allmählich verjüngt; die übrigen Verhältnisse wie bei Ae, verticillus Fér.

Das Gehäuse dieser Art ist ziemlich veränderlich, aber doch so gut gekennzeichnet, daß es sicher von allen anderen Formen der Gruppe unterschieden werden kann. Je nach der Höhe des Gewindes und dem mehr oder minder scharfen und zusammengedrückten Kiel erscheint das Gehäuse bald linsenförmig, bald breitkegelförmig mit konvexer Oberseite und flachgewölbter Basis. Die $6 \frac{1}{2}$ bis $71 / 2$ sehr flach gewölbten, durch eine seichte, kielrandige Naht geschiedenen Umgänge nehmen langsam und regelmäßig $\mathrm{zu}$; der letzte ist weniger als $1 \frac{1}{2}$ breiter wie der vorletzte. Der lichte bis weiße Kiel ist an den oberen Umgängen scharf und zusammengedrückt und wird durch eingedrückte Linien berandet; nach dem sechsten Umgange wird derselbe zunehmend stumpfer und erscheint nicht mehr berandet. Die wenig schiefe Mündung wird durch den vorletzten Umgang wenig ausgeschnitten und ist breiter als hoch; die Breite des mehr oder minder perspektivischen Nabels beträgt $1 / 5$ bis $1 / 7$ vom Durchmesser der Basis. Die Skulptur besteht auf den oberen Umgängen aus dichten, feinen und gleichmäßigen Zuwachsstreifen, welche auf den unteren Umgängen kräftiger werden, auf dem letzten in etwas ungleichmäßige Rippenstreifen übergehen; daneben sind dichte und feine Spiralleistchen vorhanden, welche auf den oberen Umgängen ebenso stark wie die radialen Zuwachsstreifen sind, gegen den Kiel zu noch schärfer werden; am letzten Umgange überwiegen jedoch die rippchenartigen Zuwachsstreifen. Auf der Unterseite sind nur weitläufige, wenig deutliche und ungleichmäßige Zuwachsstreifen vorhanden, sehr feine Spirallinien erscheinen nur bei guter Vergrößerung angedeutet. Das Verhältnis der Radial- und Spiralskulptur ist hier wie bei allen Formen der Gruppe ziemlich veränderlich. Exemplare, welche dem Z. crypta Pfr. entsprechen. also ein flacheres Gewinde, einen schärferen Kiel, nur 51/2 bis 6 Umgänge, sowie undeutliche Spirallinien auf den oberen Umgängen besitzen, sind eben nicht volikommen ausgewachsene Exemplare 
des Ae acies Fér.; die flachere Form, der schärfere Kiel, die Skulptur derselben ist nur individuelle Variation der typischen Form, mit welcher solche Exemplare auch am gleichen Fundorte vorkommen.

$$
\begin{array}{ll}
D=33, & d=30, \quad H=15 \text { bis } 18 \mathrm{~mm} . \\
D=35, & d=31, \quad H=16 \mathrm{~mm} . \\
D=37, & d=33, \quad H=21 \mathrm{~mm} .
\end{array}
$$

Das Verbreitungsgebiet dieser Art erstreckt sich über das Küstengebiet von Kroatien, die Inseln und das Festland von Dalmatien, sowie die Hercegovina.

\title{
Aegopis acies kleciachi Kobelt.
}

Zonites acies var. kleciachi Ko belt, Mart. Chemn. Heliceen, v. 5, Taf. 235, Fig, 4 bis 5, 1905.

Unterscheidet sich von der typischen Form durch das wesentlich höhere Gewinde, den stumpferen Kiel, den engeren Nabel, ist jedoch mit derselben durch Übergänge verbunden.

$$
D=30 \text { bis } 37, d=26 \text { bis } 32, \quad H=17 \text { bis } 23 m m \text {. }
$$

Fundort: In der Umgebung von Sinj in Dalmatien.

\section{Aegopis gemonensis Férussae.}

Helix gemonensis Féruss ac, Hist. moll. 1819.

Exemplare, welche der typischen Form von Gemona entsprechen, kenne ich aus dem Gebiete nur von Süidirol.

Aegopis gemonensis kusceri A. J. Wagner.

\author{
Taf. 5, Fig: 43 .
}

Zonites genonensis kusceri A. J. W a gne $\mathrm{r}$ in: Verhandlungen der k. k. zool, botan. Ges. Wien, p. 248, 1912.

Die Radula mit einem dreispitzigen, symmetrischen Mittelzahn, 9 zweispitzigen Seitenzähnen und über 30 stachelförmigen Randzähnen in einer Halbreihe.

Die Sexualorgane mit einem ziemlich langen, nach hinten verjüngtem Penis und verhältnismäßig kurzem Vas deferens; die übrigen Verhältnisse typisch.

Das Gehäuse ist dünnschaliger wie bei der typischen Form; der stumpfere Kiel geht bei Gehäusen mit $5 \frac{1}{2}$ Umgängen vor der Mündung in eine stumpfe, oft nur undeutliche Kante über. Die auffallend schwächere Skulptur besteht hier aus feineren und dichteren Zuwachsstreifen, sowie aus sehr dichten, feinen und nur unter der Lupe sichtbaren Spirallinien, so daß die Oberseite sehr fein gekörnelt erscheint. Die Unterseite ist nahezu glatt mit schwächeren Zuwachsstreifen und sehr feinen Spirallinien, welche jedoch nur in der Umgebung des Nabels schwach sichtbar sind.

$$
D=18, \quad d=16, \quad H=9 \mathrm{~mm} .
$$

Fundorte: Die Dantegrotte bei Woltschach und eine Grotte bei Ravne nächst Tolmein im Isonzotale. Typische Exemplare des Ae. gemonensis Fér. aus der Umgebung von Gemona und dem Monte Berico bei Vizenca haben auch auf dem letzten Umgange einen ziemlich scharfen, zusammengedrückten Kiel, die Zuwachsstreifen sind viel kräftiger, auch auf der Unterseite nur wenig schwächer, die Spirallinien deutlich weitläufiger, auf der Unterseite wohl schwächer, aber überall deutlich vorhanden.

\section{Aegopis tenerrimus Brancsik.}

$$
\text { Taf. 6, Fig. } 54 .
$$

Zoniles lenerrimus Brancsik. Bericht des naturwissenschaftlichen Ver. Trencsin, p. 68, Taf. 1, Fig. 3, 1888 bis 1889. - Kobelt, Rossm., Icon., II, v. 9, Nr. 1569. 
Die Radula mit einem dreispitzigen Mittelzahn, 6 bis 7 zweispitzigen Seitenzähnen und über 30 stachelförmigen Randzähnen.

Die Sexualorgane mit ziemlich langem, nach hinten allmählich verdünntem Penis, einem kurzen fadenförmigen Vas deferens und kurzem Blasenstiel; das schildförmige Drüsenkonglomerat an der Einmündung des Blasenstiels in die Vagina ist hier auffallend groß und halbkugelig vorspringend.

Verbreitungsgebiet: Südbosnien und Westserbien.

Aegopis spelaeus A. J. Wagner.

Taf. 4, Fig. 33, Taf, 5, Fig. 46, Taf. 8, Fig. 63.

Aegopis spelaeus A. J. Wagner. Sitzungsbericht d. k. Akad. Wien, 1914, Bd. 123, Abt. 1.

Die Radula mit einspitzigem, symmetrischem Mittelzahn, sowie über 60 einspitzigen Seiten- und Randzähnen in einer Halbreihe; die Spitzen aller Zähne sind lang und stachelförmig.

Sexualorgane: Der Penis ist bauchig spindelförmig mit auffallend dünnem hinterem Ende und schwach entwickeltem, endständig inseriertem Musc. retractor; das mittellange Vas deferens mündet unmittelbar neben der Insertion des Musc. retractor; der Blasenstiel ist kurz, an der Einmündung desselben in die Vagina ein gut entwickeltes, schildförmiges Drüsenkonglomerat.

Das Gehäuse flachkegelförmig mit flach gewölbter Basis, dünnschalig, glasartig durchsichtig und nur leicht milchig getrübt; glänzend und etwas irisierend. Die Skulptur besteht auf der Oberseite aus sehr feinen, ungleichmäßigen Zuwachsstreifen und sehr feinen, erhobenen Spirallinien, welche auf den oberen Umgängen dicht, auf den unteren weitläufiger erscheinen; auf der Unterseite sind nur feine Zuwachsstreifen vorhanden. Das regelmäßig flachkegelförmige Gewinde besteht aus 5 ziemlich rasch zunehmen. den, durch eine ziemlich tiefe Naht geschiedenen Umgängen; der letzte ist kaum $1 \frac{1}{2}$ breiter wie der vorletzte, zusammengedrückt, an der Peripherie im Beginne ziemlich scharf, vor der Mündung stumpfer gekielt. Der ziemlich weite, perspektivische Nabel mißt 1/6 vom Durchmesser der Basis. Die wenig schiefe Mündung wird durch den vorletzten Umgang nur wenig ausgeschnitten und ist breiter als hoch. Die Insertionen des dünnen und scharfen Mundsaumes werden durch einen sehr dünnen, nur durch den Glanz angedeuteten Kallus verbunden; Anwachsstriemen sind nicht vorhanden.

$$
D=19, \quad d=16, \quad H=9.5 \mathrm{~mm} \text {. }
$$

Fundorte: Die Höhle Mrcine bei Trebinje und Höhle Belušica in der Hercegovina; gesammelt von Kustos Dr. Karl Absolon des Landesmuseums in Brünn.

Dieses anscheinend blinde Höhlentier (ich fand nur schwache Pigmentpunkte an den Augenträgern) erscheint besonders durch das dünne, farblose, nahezu glasartige Gehäuse und die einer Raublungenschnecke entsprechende Radula ausgezeichnet; dieselbe ist ferner die größte Höhlenschnecke, welche bisher beobachtet wurde.

\section{Genus Paraegopis P. Hesse 1910.}

Radula: Auch hier wurden zwei Typen der Radula beobachtet; bei der einen Radulaform ist der symmetrische Mittelzahn dreispitzig, die Seitenzähne zweispitzig, die Randzähne stachelförmig; bei der zweiten Radulaform besitzen der Mittelzahn und 10 bis 12 Seitenzähne eine lange stachelförmige Hauptspitze, aber nur undeutliche Nebenspitzen, so daß dieselben einspitzig erscheinen; die zahlreichen Randzähne sind auch hier stachelförmig.

Sexualorgane: Der Penis ist verhältnismäßig kurz und geht hinten allmählich verjüngt in das kurze, ziemlich dicke Vas deferens über; am Übergange des Penis in das Vas deferens inseriert ein kräftiger Musc. retractor. Das Vas deferens biegt schlingenförmig gegen das vordere Ende des Penis um und wird am mittleren oder vorderen Drittel desselben durch festes Bindegewebe angeheftet. Die ovale Samenblase ist deutlich vom Blasenstiele abgesetzt; der Blasenstiel kurz bis mittellang, oben dünner, an der Einmündung 
in die Vagina dicker, jedoch ohne Spur eines schildförmigen Drüsenkonglomerates. Der Musc. retractor des rechten Augenträgers verlauft zwischen Penis und Vagina.

Das Gehäuse ist sehr ähnlich wie bei den Formen des Genus Aegopis Fitz.; die Skulptur der Oberseite besteht hier jedoch aus feinen Körnchen, welche dicht spiral und radial angeordnet sind; diese Körnelung entsteht hier wohl auch durch Kreuzung von spiralen und radialen Leistchen, doch sind diese als solche undeutlich und werden neben der Granulierung auf der Oberseite nur ungleichmäßige und weitläufige Zuwachsstreifen beobachtet. Ein scharfer Kiel ist nur bei Jugendformen mit wenigen Umgängen vorhanden, wälnrend die unteren und besonders der letzte Umgang gerundet oder schwach kantig erscheint. Das Gehäuse ist hier ferner dünnschaliger und werden radiale Anwachsstriemen nur spärlich oder gar nicht beobachtet.

Das Verbreitungsgebiet der bisher bei dieser Gruppe eingeteilten Formen umfaßt Süddalmatien, Südbosnien, Westserbien, die Hercegovina, Montenegro, Albanien und anscheinend Griechenland; nach den Merkmalen des Grhäuses gehören vielleicht auch einige kleinasiatische Formen, so Z. cilicicus Nägele, ebenso der turkestanische Z. latissimus Dohrn hierher.

\section{Paraegopis albanicus Roßmäßler.}

Taf. 4 , Fig. 34 bis 36 .

Helix albanica ROBmäßier, Icon. I, v, 1, Nr. 148.

Zonites narentanus Boettge 1, Jahrb. d. Mal. Ges. 1886.

Die Radula mit dreispitzigem, symmetrischem Mittelzahn, 8 bis 9 zweispitzigen, asymmetrischen Seitenzähnen und bis 40 stachelförmigen Randzähnen.

Der feste Kiefer ist halbmondförmig gebogen, undeutlich gestreift, mit zwei deutlichen Vorsprüngen am konkaven Rande.

Sexualorgane: Der Penis im mittleren Drittel spindelförmig angeschwollen, im hinteren Drittel auffallend verdünnt; am C̈bergange in das kurze, ziemlich dicke Vas deferens inseriert der kräftige und lange Musc. retractor; der Blasenstiel ist mittellang, die übrigen Verhältnisse typisch.

Das Verbreitungsgebiet dieser Art erstreckt sich über Süddalmatien, die Herzegovina und Montenegro, jedoch kaum mehr bis nach Albanien, da die bisher zu dieser Art gezogenen Exemplare aus der Umgebung von Skutari als wohl nahestehende, jedoch konstant abweichende Art erkannt wurden (Paraegopis skipetaricus $\mathrm{n}$.).

Zonites naventanus Boettger aus dem unteren Narentagebiet kann ich von der typischen Form nicht trennen; die geringen Abweichungen des Gewindes, welche Boettger veranlaßten, diese Form zu unterscheiden, sind nach meinem reichen Materiale doch nur individuelle Variationen und kommen im ganzen Verbreitungsgebiete der Art vor.

Paraegopis mauritii Westerlund.

Taf. 4, Fig. 37 bis 38.

Zonites mantitii Westeriund, Fauna, I, p. 77, 1886.

serajevoensis Kimakowicz, Nachrichtsblatt d. D. malak. Ges., v. 31, 1899.

Die Radula mit dreispitzigem, symmetrischen Mittelzahn, 9 zweispitzigen asymmetrischen Seitenzähnen und über 40 stachelförmigen Randzähnen.

Der Kiefer fest, glatt, mit einem deutlichen Vorsprung am konkaven Rande.

Sexualorgane: Der im mittleren Drittel spindelförmig verdickte Penis geht hinten verjüngt in das kurze und verhältnismäßig dicke Vas deferens über; am Übergange inseriert der ziemlich kurze Musc. retractor. Die ovale Samenblase mit einem mittellangen Blasenstiel, welcher oben dünn, an seiner Einmündung in die Vagina stärker angeschwollen ist, jedoch keine Auflagerung einer schildförmigen Drüse erkennen läßt; die übrigen Verhältnisse typisch. 
Verbreitung: In Südbosnien, Westserbien und dem Limgebiet.

Zonites serajevoensis Kimakowicz aus der Umgebung von Sarajevo ist nach den Merkmalen des Gehäuses von Paraegopis manvitii Wstld. aus dem Limgebiet durch keine konstanten und wesentlichen Merkmale unterschieden; das bald regelmäßig flachkegelförmige oder mehr konvexe Gewinde (Kimakowicz bezeichnet diese Verhältnisse als »dachförmig oder kugelkappenartig), der mehr oder minder weite Nabel, die verschiedene Wölbung der Umgänge kann Anlaß geben, eine Lokalform abzugrenzen, wenn diese Merkmale konstant und deutlich vorhanden sind; dies trifft im vorliegenden Falle nicht zu; Exemplare aus der Umgebung von Sarajevo, von Čajnica, Čelebič, Banja stiena, also dem Südosten Bosniens zeigen alle nur individuelle Schwankungen der angeführten Merkmale. Dies gibt auch Kimakowicz zu und versucht seine Art durch die abweichenden Verhältnisse der Sexualorgane zu begründen; diese angeblichen Unterschiede werden aber nur durch etwas mißlungene Abbildungen des vorderen Teiles der Sexualorgane demonstriert, eine Deutung derselben versucht der Autor nicht. Meine Untersuchungen der Weichteile beider hier erörterten Formen haben aber ergeben, daß dieselben auch bezüglich der Sexualorgane vollkommen miteinander übereinstimmen.

\title{
Paraegopis mauritii montenegrinus Boettger.
}

\author{
Taf. 5, Fig. 48
}

Zonites montenegrinus Boettger, in Wohlberedt, Zur Fauna Montenegros und Nordalbaniens, p. 43, Wien, 1909.

Die Verhältnisse der Radula und der Sexualorgane wie bei der typischen Form.

Das Gehäuse bei gleicher Windungszahl konstant kleiner, auch das Gewinde kleiner angelegt; die deutlicher gewölbten, durch eine etwas tiefere Naht geschiedenen Umgänge nehmen langsamer zu, der Nabel ist deutlich weiter; Anwachsstriemen sind deutlich und oft zahlreich.

$$
D=19, \quad d=17, \quad H=10 \mathrm{~mm} \text {. }
$$

Verbreitung: Durmitorgebiet in Montenegro.

Genus Meledella Sturany 1908.

\section{Meledella werneri Sturany.}

Taf. 8 , Fig. $64 a$ bis $c$.

Meledella wemeri Sturany, Mitt. d. Naturwissensch. Ver. a. d. Universität in Wien, v. 6, p. 2, 1908.

Gehäuse scheibenförmig, weit und perspektivisch genabelt, gelblichgrün und milchig getrübt, schwach durchscheinend; oben matt, unten lebhaft glänzend. Die Skulptur besteht auf der Oberseite aus dichten, radialen Rippenstreifen, welche an der Peripherie in einer scharf begrenzten Linie endigen, so daß auf der Unterseite nur feine Zuwachsstreifen vorhanden sind, welche nur im Umkreise des Nabeis deutlicher werden; feine Spirallinien sind nur bei starker Vergrößerung auf den Embryonalwindungen sichtbar, auf den übrigen Umgängen und in der Nabelgegend werden dieselben nur durch sehr feine Knötchen der Radialskulptur angedeutet. Das flachkegelförmige Gewinde besteht aus $5 \frac{1}{2}$ bis 6 ziemlich langsam zunehmenden, leicht gewölbten und durch eine seichte Naht geschiedenen Umgängen; der letzte ist gerundet und steigt vorne nicht herab. Die senkrechte Mündung wird durch den vorletzten Umgang stark ausgeschnitten, der Mundsaum ist dünn und scharf.

$$
D=14, \quad d=13 \cdot 5, \quad H=6 \cdot 3 \mathrm{~mm} .
$$

Fundort! Die Höhle Ostaševica auf der Insel Meleda.

Die anatomischen Verhältnisse dieser Höhlenschnecke sind unbekannt, da nur tote Exemplare gesammelt wurden; die Merkmale der Schalen zeigen jedoch eine große Übereinstimmung mit einigen 
Gruppen der Zonitiden. Die Form der Schale, der weite, perspektivische Nabel und die Skulptur erinnern an die Verhältnisse bei der Gruppe Aegopis Fitz., doch sind hier auch die oberen Umgänge nicht gekielt und die Spiralskulptur ist nur angedeutet.

\section{Genus Hyalinia Agassiz 1837. \\ (Hyalina Gray 1840).}

Die Radula mit dreispitzigem symmetrischen Mittelzahn, welcher wesentlich kleiner als die Seitenzähne, ja mitunter nahezu rudimentär erscheint; auf den Mittelzahn folgen in einer Halbreihe 3 bis 4 bis 5 stark asymmetrische, dreispitzige Seitenzähne und 10 bis 25 stachelförmige Randzähne; die Seiten, und Randzähne sind schmal und besonders die Hauptspitzen derselben schlank ausgezogen.

Der Kiefer ist hautartig dünn bis hornartig fest und glatt.

Sexualorgane: Der Penis ist verschieden geformt, spindelförmig, zylindrisch, ungleichmäßig verdickt, jedoch stets mit endständig inseriertem Musc. retractor. Das mittellange Vas deferens mündet im hinteren Drittel des Penis, immer in einiger Entfernung von der Insertion des Musc. retractor; der hintere, von der Prostata abgehende Teil des Vas deferens ist fadenförmig dünn, der vordere in den Penis mündende Teil desselben jedoch immer wesentlich dicker und vom dünnen Teil ziemlich scharf abgesetzt; dieser vordere Teil des Vas deferens ist gegen das vordere Ende des Penis umgebogen und hier durch Bindegewebe mehr oder minder fest angeheftet. Die ovale Samenblase ist vom mittellangen Blasenstiel oft nur undeutlich abgesetzt; der Blasenstiel erscheint an seiner Einmündung in die Vagina, ebenso die Vagina an dieser Stelle stärker, oft auffallend verdickt, indem hier eine drüsige Schichte aufgelagert ist. Diese Drüsenlage entspricht jedenfalls der schildförmigen Drüsenauflagerung, welche bei den Formen der Gruppe Aegopis Fitz. beobachtet wird, erscheint hier jedoch oft wesentlich schwächer entwickelt.

Der Musc. retractor des rechten Augenträgers verlauft zwischen Penis und Vagina.

\section{Subgenus Hyalinia s, str.}

Radula: Der kleine Mittelzahn mit langer, schlanker Hauptspitze. Der schlanke, im allgemeinen zylindrische Penis erscheint im mittleren Drittel mitunter etwas verdünnt, doch weder wulstig verdickt noch an seinem hinteren Ende gespalten.

Das Gehäuse ist offen und perspektivisch genabelt, glatt und glänzend mit feinen Zuwachsstreifen, aber stets ohne Spiralskulptur.

\section{Hyalinia (Hyalinia) cellaria Müller.}

Taf, 9, Fig. $65 a-c$.

Helix cellaria Müller, Verm. Hist., II, 1774.

- - Roßmäßler, Icon. I, v. 1, Ni. 22, v. 1I, Nr. 527.

Die Radula mit kleinem, dreispitzigem und symmetrischem Mittelzahn; auf diesen folgen in einer Halbreihe drei stark asymmetrische, dreispitzige und zunehmend größere Seitenzähne, sowie 10 stachelförmige Randzähne, welche zunächst noch größer werden, um dann gegen den Rand zu allmählich an Größe abzunehmen.

Sexualorgane: Der verhältnismäßig lange und schlanke Penis ist an seiner Einmündung in die Kloake verdickt, im mittleren Drittel etwas verdünnt und besitzt einen endständig inserierten, langen Musc. retractor. Das mittellange Vas deferens ist in seinem hinteren dünnen und im vorderen dicken Teil nahezu gleich lang und mündet im hinteren Drittel des Penis, ziemlich entfernt von der Insertion des Musc. ratractor. Die spitzovale Samenblase mit ziemlich langem und dünnem Blasenstiel, welcher in die hier auffallend verdickte Vagina mündet; die Drüsenauflagerung der Vagina ist deutlich entwickelt. 
Gehäuse: Ich beurteile das Gehäuse dieser Art zunächst nach Exemplaren von Dargun in Mecklenburg, welche dem historischen Typus entsprechen. "Das Gehäuse scheibenförmig mit kaum erhobenem Gewinde, mittelweit und perspektivisch genabelt, dünn aber ziemlich fest; gelblich homfarben, leicht milchig getrübt, glänzend, mit sehr feinen, ivenig deutlichen Zuwachsstreifen. Das flachkegelförmige Gewinde besteht aus $5^{1 / 2}$ bis 6 flach gewölbten, durch eine deutlich eingedrückte Naht geschiedenen Umgängen, welche im Anfange langsam, vom vorletzten an rascher zunehmen, so daß der letzte fast doppelt so breit wie der vorletzte erscheint; der letzte Umgang ist außerdem etwas zusammengedrückt, unten flacher, aber an der Peripherie gerundet und steigt vorne nicht herab. Die schiefe Mündung ist oval, wesentlich breiter wie hoch und wird durch den vorletzten Umgang stark ausgeschnitten. Der Mundsaum ist scharf und gerade; der Nabel mißt etwas mehr als $1 / 5$ vom Durchmesser der Basis.

$$
D=11 \cdot 5, \quad d=10, \quad H=4.5 \mathrm{~mm} .
$$

Als individuelle Variationen werden geringe Abweichungen in der Höhe des Gewindes, der Weite des Nabels, welcher außerdem bald mehr bohrlochförmig, steil abfallend, bald mehr trichterförmig erscheint, ferner bezüglich der Dimensionen, der mitunter grünlichen Färbung sowie der Art der Zunahme der Umgänge beobachtet.

Verbreitungsgebiet: Die typische Form kenne ich aus Nord-Mitteldeutschland und den Sudetenländern bis Schlesien; in Westdeutschland und den Alpenländern treten einzelne individuelle Variationen der Gehäuse als ziemlich konstante und stärker auffallende Merkmale auf, so daß hier besondere Lokalformen unterschieden werden, obwohl die anatomischen Verhältnisse vollkommen mit jenen der typischen Form übereinstimmen. Die bisher als Hyalinea cellaria Müller bezeichnete Form der östlichen Karpartenländer weicht jedoch mit Rücksicht auf die Verhältnisse der Sexualorgane so auffallend von dieser ab, daß sie als besondere Art und Gruppe aufgefaßt werden muß (Cellaviopsis denbeli Wagner).

\section{Hyalinia (Hyalinia) cellaria draparnaldi Beck.}

Taf. 9, Fig. $66 a$ bis $c$.

Helicella drapamaldi $\mathrm{Beck}$, Index 1837.

Helix lucida Drap arnaud, Tabl. moll. 1801.

- nitida Draparnaud, Hist. nat. moll. 1805.

Hyalina draparnaldi Kobelt, Icon., I, v. 6, Nr. 1607 bis 1608 .

Gehäuse größer, rötlich hornfarben mit höherem, abgerundet kegelförmigem Gewinde und verhältnis mäßig engerem, mehr trichterförmigen Nabel; die Mündung ist gegen die Gehäuseachse schiefer und mehr herabgebogen.

$$
D=15, \quad l=12 \cdot 5, \quad H=7 \cdot 5 \mathrm{~mm} .
$$

Verbreitungsgebiet: Westdeutschland und Frankreich bis zu den Pyrenäen.

Auch diese Form variiert besonders mit Rücksicht auf die Höhe des Gervindes, welches mitunter ebenso flach wie bei der typischen Form erscheint.

Hyalinia (Hyalinia) cellaria austriaca A. J. Wagnes.

Taf. 4, Fig. 39, Taf. 7, Fig. 56, Taf. 9, Fig. $67 a$ bis $b$.

Hyalina draparmaldi atstriaca A. J. Wagner, in Nachrichtsblatt d. D. malak. Ges, p. 114, 1907, und Roßm. Icon., 11, v. 13, Nr. 2193, 1907.

Das Gehäuse wesentlich größer und immer dunkler gefärbt (gelbbraun bis hellrotbraun); da Gewinde zumeist ebenso flach wie bei der typischen Form, der letzte Umgang nimmt hier jedoch rascher zu und 
erscheint vor der Mündung doppelt und mehr breiter wie der vorletzte; der Nabel ist verhältnismäßig enger, die Mündung schiefer gegen die Achse des Gehäuses und etwas herabgebogen.

$$
\begin{aligned}
& D=14, \quad d=12, \quad H=6 \mathrm{~mm} \text {, von Fischau in Niederösterreich. } \\
& D=16, \quad d=14, \quad H=7 \mathrm{~mm} \text {, von der Margareteninsel in Budapest. } \\
& D=18, \quad d=15 \cdot 5, \quad H=8 \mathrm{~mm} \text {, vom Laibacher Schloßberg. }
\end{aligned}
$$

Die Verhältnisse der Radula und der Sexualorgane wie bei der typischen Form.

Das Verbreitungsgebiet dieser Form erstreckt sich über die Ostalpen in Süddeutschland, Österreich, Westungarn, Kroatien und Norditalien; in diesem Gebiete habe ich vorstehende Form nur in den Talregionen der Vorgebirge angetroffen, dem Hochgebirge scheint dieselbe vollkommen zu fehlen. In den nördlichen Teilen ihres Verbreitungsgebietes werden mitunter Exemplare gesammelt, welche Übergänge zur typischen Form oder auch der forma draparnaldi Beck darstellen und von diesen kaum zu unterscheiden sind; besonders große, ja extrem entwickelte Exemplare kenne ich nur aus dem Südosten.

\section{Hyalinia (Hyalinia) cellaria dalmatina A. J. Wagner.}

Taf. 11, Fig. $80 a$ bis $c$.

Hyalina (Enhyalina) dalmatina A. J. W agner in: Verhandlungen der k. k. zoolog. botan. Ges. Wien, p. 247, 1912.

Gehäuse ähnlich der $H$. cellaria draparnaldi Beck, jedoch festschaliger und weniger durchscheinend, gelbbraun, häufig mit grünlichem Stich und etwas weiterem, aber mehr trichterförmigem Nabel. Die Skulptur besteht aus wesentlich schärferen und dichten Zuwachsstreifen; die stärker gewölbten Umgänge nehmen langsamer zu und werden durch eine tiefere Naht geschieden; der letzte ist oben und unten mehr gewölbt und gegen den vorletzten weniger verbreitert; die Mündung höher und nicht herabgebogen.

$$
D=15, \quad d=13, \quad H=8 m m
$$

Die Verhältnisse der Radula und der Sexualorgane sind unbekannt.

Fundorte: Ragusa, Zara und Knin in Dalmatien.

Diese Form steht auch der Hyalinia cellaria sicula Wstld. aus Sizilien nahe; meine Exemplare dieser Form von Sciacca sind durchschnittlich kleiner, heller hornfarben mit kaum erhobenem bis flachem Gewinde, weiterem Nabel und nur $4 \frac{1}{2}$ bis 5 langsamer zunehmenden, durch eine seichtere Naht geschiedenen Umgänge; der letzte ist $11 \% 2$ breiter wie der vorletzte, die Zuwachsstreifen schwächer.

Durch Hyalinia cellaria sicula Wst1d. werden auch Beziehungen der vorstehenden Formenreihe zu Hyalinia achlyophila Bgt. aus Oran vermittelt; diese Art hat ebenfalls eine mattglänzende, dicht gestreifte Oberseite, jedoch noch langsamer zunehmende Umgänge und einen weiteren Nabel.

Hyalinia (Hyalinia) villae (Mortillet) Strobel.

Taf. 12, Fig. 86 bis 88 und 92 bis 93.

Helix villac Strobel, Giorn. Mal. I, 1853 nec Desh.

- mortileti L. Pfeiffer, MIon. Hel., v. 1, p. 101.

Zonites cellarius var. etrgyrus Stabile Prosp. Lugano 1859.

Hyalina villae Kobelt, Icon., I, v. 6, Nr. 1603 bis 1605.

Gehäuse ähnlich der H. cellaria Müller, jedoch durchschnittlich größer, etwas dunkler gefärbt (gelblich hornfarben bis gelbbraun). Das niedrige bis flache Gervinde besteht aus 6 bis $6 \frac{1}{2}$ wesentlich langsamer zunehmenden, stärker gewölbten und durch eine tiefe, rinnenförmige Naht geschiedenen Umgängen; der letzte Umgang ist weniger zusammengedrückt und höchstens $11 / 2$ breiter wie der vor- 
letzte. Der annähernd gleichweite Nabel fallt senkrecht ab und erscheint mehr lochförmig, die Mündung ist im Verhältnis zur Breite höher.

$$
D=12 \text { bis } 16, d=10.5 \text { bis } 14, \quad H=6 \text { bis } 7 \mathrm{~mm} \text {. }
$$

Die Radula mit symmetrischem, dreispitzigem Mittelzahn, welcher wesentlich kleiner als die Seitenzähne ist; die Hauptspitze desselben ist schlank ausgezogen, die Seitenspitzen kurz und abgerundet; auf den Mittelzahn folgen in einer Halbreihe 3 stark asymmetrische dreispitzige Seitenzähne- und 11 stachelförmige Randzähne.

Sexualorgane: Der Penis ist viel länger und schlanker als bei der Formenreihe des $H$. cellaria Müller, der Musc. retractor endständig inseriert; ebenso ist das Vas deferens wesentlich länger, der Blasenstiel länger und dicker als bei $H$. cellaria Müller und alien oben angeführten Lokalformen derselben.

Verbreitungsgebiet: Diese Art wurde bis jetzt in zwei geographisch getrennten Gebieten der südlichen und nördlichen Kalkalpen nachgewiesen, wie dies auch bei anderen Gruppen der alpinen Mollusken beobachtet wird (Orcula conica Rssm., Pomatias hemricae Strob.!). Ich kenne dieselbe vom Mönchsberg bei Salzburg, nach Kobelt wurde dieselbe bei Bregenz in Vorarlberg und bei Miesbach in Bayern beobachtet. Viel häufiger scheint $H$. villae Strob. in den südlichen Kalkalpen aufzutreten; in meiner Sammlung liegt dieselbe von Tarvis in Kärnten, der Hadesgrotte bei Nabresina, Bozen, Meran, Salo am Gardasee, Serravalle bei Treviso, Como und Capolago in Tessin. An diesen Lokalitäten lebt H. villae Strob. in Gesellschaft der H. cellaria anstriaca Wagner, doch wurden mir keine Übergangsformen bekannt; die auffallenden anatomischen Unterschiede lassen übrigens keinen Zweifel über die Artgültigkeit dieser Art mehr aufkommen.

\section{Hyalinia (Hyalinia) rumelica P. Hesse.}

Taf, 10, Fig. $71 a$ bis $c$.

Hyalinia runelica P. Hesse, Nachrichtsblatt d. D. malak. Ges., p. 12, 1913.

Gehäuse ähnlich der.H. cellaria Müller, jedoch dunkler gelbbraun mit höherem, flachkegelförmigem Gewinde, welches aus 6 größer angelegten, langsamer und regelmäßig zunehmenden, deutlicher gewölbten Umgängen besteht; der letzte ist weniger zusammengedrückt und doppelt so breit wie der vorletzte. Der Nabel ist besonders bei jüngeren Exemplaren enger, die Mündung weniger breit aber höher; die Skulptur besteht aus deutlicheren und besonders an der Naht dichteren Zuvachsstreifen.

$$
D=14, \quad d=12 \cdot 3, \quad H=7 \mathrm{~mm} \text {. }
$$

Fundort: Umgebung von Philippopel in Bulgarien.

Die anatomischen Verhältnisse sind unbekannt; die systematische Einteilung bei dieser Gruppe erfolgte also lediglich mit Rücksicht aut das Gehäuse.

Hyalinia (Hyalinia) camelina thracica P. Hesse.

Taf. 10, Fig. $70 a$ bis $c$.

Hyalina canelina thracica P. Hesse, Nachrichtsblatt d. D. mal. Ges., p. 3, 1913.

Vom Typus und der forma frondulosa Mss, unterschieden durch größeres, flacheres, mehr zusammengedrücktes Gehäuse und einen weiteren Nabel, welcher sämtliche Umgänge erkennen läßt; am letzten Umgang eine stumpfe Kante; der Basalrand auffallend dick. Das einzige derzeit vorliegende Exemplar ist dunkel gelbbraun gefärbt; Zahl der Umgänge 6.

$$
D=10, d=4.5 \mathrm{~mm} \text {. }
$$


Fundort: Genist der Maritza bei Philippopel in Bulgarien. Die anatomischen Verhältnisse unbekannt, die Einteilung bei der vorstehenden Gruppe erfolgte nur mit Rücksicht auf das Gehäuse.

Hyalinia (Hyalinia) absoloni A. J. Wagner.

Taf, 10, Fig. $73 a$ bis $c$.

Hyalinia absoloni A. J. Wagner, Sitzungsbericht d. k. Akad. Wien, 1914, Bd. 123, Abt. 1.

Gehäuse scheibenförmig mit kaum erhobenem Gewinde und weitem perspektivischem Nabel; dünn aber ziemlich fest, durchscheinend, glänzend, mit feinen, aber deutlichen und wenig gebogenen Zuwachsstreifen, weißlich getrübt (das vorliegende Exemplar etwas verwittert). Das kaum erhobene Gewinde besteht aus $4 \frac{1}{2}$ leicht gewölbten, langsam zunehmenden, durch eine deutlich eingedrückte Naht geschiedenen Umgängen; der letzte ist doppelt so breit wie der vorletzte, zusammengedrückt, an der Peripherie gerundet und steigt vorne nicht herab. Die senkrechte, halbeiförmige Mündung ist so breit wie hoch und wird durch den vorletzten Umgang stark ausgeschnitten; der dünne, scharfe Mundsaum ist gerade, an der Spindelinsertion etwas vorgezogen. Der weite, perspektivische Nabel mißt mehr als $1 / 4$ vom Durchmesser der Basis.

$$
D=10, \quad d=9, \quad H=4 \mathrm{~mm} .
$$

Fundort: Die Eliashöhle bei Trebinje in der Hercegovina. Die analomischen Verhältnisse sind unbekannt; die Einteilung der Art erfolgte nur mit Rücksicht auf die Verhältnisse des Gehäuses.

\title{
Hyalinia (Hyalinia) nautiliformis A. J. Wagner.
}

\author{
Taf, 8 , Fig. $62 a$ bis $c$.
}

Hyalinia nattiliformis A. J. Wagner, Sitzungsbericht der k. Akad. Wien, 1914, Bd. 123, Abt. 1.

Gehäuse scheibenförmig, planorbisartig, dünnschalig, durchsichtig, farblos (das vorliegende Exemplar ist verwittert und etwas weißlich getrübt, glänzend, mit sehr feinen S-förmig gebogenen Zuwachsstreifen. Das flache, etwas unter das Niveau des letzten Umganges eingesenkte Gewinde ist bei horizontalem Anblick des Gehäuses nicht sichtbar und besteht aus 4 kaum gewölbten, durch eine ziemlich seichte Naht geschiedenen Umgängen; dieselben nehmen anfangs langsam, der 4. aber so rasch zu, daß er den vorletzten um das $2 \frac{1}{2}$ fache an Breite übertrifft; der letzte Umgang ist ferner unten deutlicher gewölbt, an der Peripherie gerundet und steigt vorne nicht herab. Die senkrechte, halbeiförmige Mündung wird durch den vorletzten Umgang stark ausgeschnitten; der dünne Mundsaum ist scharf und gerade, die Insertionen desselben nicht genähert, der Außenrand vorgezogen. Der seichte, weite und perspektivische Nabel nimmt fast $1 / 3$ vom Durchmesser der Basis ein.

$$
D=7 \cdot 3, \quad d=6 \cdot 5, \quad H=3 \mathrm{~mm} .
$$

Fundort: Die Höhle Klina pečina bei Trebinje in der Hercegovina.

Die anatomischen Verhältnisse sind nicht bekannt.

\section{Hyalinia (Hyalinia) planospira A. J. Wagner.}

Hyatina planospira A. J. Wagner, Nachrichtsblatt d, D. malak. Ges., p. 111, 1907, und Rossm. Icon., II, v. 13, Nr. 2206.

Fundorte: Höhle Krstac bei Njeguš in Montenegro und Höhle Iližina in Süddalmatien.

Die anatomischen Verhältnisse unbekannt. 
Hyalinia (Hyalinia) wagneri Köhler.

Taf. 10, Fig. $72 a$ bis $c$.

Hyalina Nagneri Köhler, Nachrichtsblatt d. D. malak. Ges., p. 81, 1912.

Gehäuse fast scheibenförmig, mit verhältnismäßig weitem, perspektivischem Nabel, gelblichweiß, leicht milchig getrübt, durchscheinend, lebhaft glänzend, mit feinen, etwas ungleichmäßigen Zuivachsstreifen. Das flachkegelförmige, kaum erhobene Gewinde besteht aus $4 \frac{1}{2}$ bis 5 ziemlich langsam und regelmäßig zunehmenden, leicht gewölbten und durch eine seichte Naht geschiedenen Umgängen; der letzte steigt vome kaum merklich oder gar nicht herab und ist nahezu doppelt so breit wie der vorletzte.

Die ovale, durch den vorletzten Umgang ausgeschnittene Mündung ist schief, der Mundsaum scharf und gerade, der Nabel mißt fast $1 / 4$ vom Durchmesser der Basis.

$$
D=7, \quad d=6, \quad H=3 m m \text {. }
$$

Fundort: Die Umgebung der Stadt Lesina auf Lesina. Die anatomischen Verhältnisse sind nicht bekannt.

\section{Hyalinia (Hyalinia) wagneri sinjana A. J. Wagner.}

Taf. 9, Fig. $69 a$ bis $c$.

Hyalina wagneri sinjana A. J. Wagner, Sitzungsb. d. k. Akad. Wien, 1914, Bd, 123, Abt. 1.

Das Gehäuse größer, gelbbraun gefärbt, mit höherem Gewinde.

$$
D=8, \quad d=7, \quad H=3.8 \mathrm{~mm} .
$$

Fundort: Höhle be1 Sinj in Dalmatien.

In diese Gruppe gehört nach dem anatomischen Befunde auch Hyalinia (Hyalinia) diaphanella Kryn. aus der Krim.

\section{Subgenus Morlina 11.}

Das Gehäuse dünnschalig, glatt und glänzend, mit sehr feinen bis undeutlichen Zuwachsstreifen, aber ohne Spirallinien; der Nabel sehr eng bis stichförmig.

Die anatomischen Verhältnisse sind mir nur von wenigen Formen bekannt, dieselben lassen bemerkenswerte Unterschiede gegenüber den anderen Gruppen des Genus erkennen.

\section{Hyalinia (Morlina) glabra Férussac.}

Taf. 7 , Fig. $57 a$ bis $b$.

Helix glabra Férus sa c, Tabl. syst, 1822.

- - Roßmäßler, Icon., I, v. 2, N1. 528.

Radula: Der Mittelzahn ist hier sehr klein, nahezu rudimentär, mit einer kurzen Hauptspitze und abgerundeten Nebenspitzen; auf denselben folgen in einer Halbreihe 5 stark asymmetrische, dreispitzige Seitenzähne und 25 stachelförmige Randzähne. Mit Rücksicht auf die Dimensionen erscheinen hier die Seitenzähne am größten, die Randzähne allmählich kleiner.

Sexualorgane: Der Penis ist unregelmäßig wulstig verdickt, das hintere Ende angeschwollen, mit einem endständig inserierten Musc. retractor. Das mittellange Vas deferens ist im hinteren Teile fadenförmig dünn, im vorderen wesentlich dicker und mündet im hinteren Drittel des Penis, ziemlich entfernt von der Insertion des Musc. retractor; dasselbe ist wohl gegen das vordere Penisende gebogen, jedoch dort nur schwach oder gar nicht durch Bindegewebe angeheftet. Die ovale Samenblase ist von dem ziemlich kurzen Blasenstiel wenig deutlich abgesetzt; der Blasenstiel erscheint an seiner Einmündung in die Vagina nicht verdickt, die Vagina an dieser Stelle nur wenig angeschwollen; eine Drüsenauflagerung wurde hier nicht nachgewiesen. 
Verbreitungsgebiet: Diese Art ist anscheinend über die ganze zentraleuropäische Region verbreitet und wurde nur in Krain, Südkroatien und Dalmatien nicht nachgewiesen. In diesem weiten Gebiete erscheint das Gehäuse wenig veränderlich; auf Kalkboden ist dasselbe festschaliger und dunkler gelbbraun gefärbt, meine Exemplare aus Südtirol und Steiermark weisen ein niedrigeres Gewinde und etwas rascher zunehmende Umgänge auf; an einzelnen Lokalitäten in Ungarn und Siebenbürgen kommen auch auffallend groBe Exemplare vor (var. Inmgarica Wstld. und var. striaria Wstld.). Bemerkenswerte Lokalformen wurden ferner besonders auf der Balkanhalbinsel beobachtet.

Hyalina (Morlina) glabra bojanae A. J. Wagner.

Hyalina bojancte A. J. IVagner, Nachrichtsblatt d. D. malak. Ges., p. 112, 1907, und Rossm., Icon., II, v. 13, Nr. 2207.

Fundort: Umgebung von Skutari in Albanien.

\section{Hyalinia (Morlina) glabra riloensis 17.}

Taf. 11, Fig. 81 a bis $c$.

Gehäuse verhältnismäßig groß, aber sehr dünnschalig, grünlich gelb, lebhaft glänzend mit sehr feinen Zuwachsstreifen; die $5 \frac{1}{2}$ bis 6 deutlicher gewölbten Umgänge werden durch eine tiefere Naht geschieden.

$$
D=18, \quad d=15, \quad H=9 \mathrm{~mm} \text {. }
$$

Fundort: Rilogebirge in Bulgarien.

\section{Hyalinia (Morlina) montivaga Kimakowicz.}

Taf. 12, Fig. 90 bis 92 .

Hyalina nitidissina var. montivaga Kimakowicz, Beitrag III zur Moll. Fauna Siebenbürgens, p. 161, 1890.

Gehäuse ähnlich der $H$. nitidissima Mss. aus dem Parnaß, jedoch wesentlich kleiner, mit $4 \mathbf{1} / 2$ rascher zunehmenden, weniger gewölbten Umgängen; der letzte ist stärker zusammengedrückt und nahezu dreimal so breit wie der vorletzte, die Mündung verhältnismäßig breiter, der Nabel enger.

$$
D=11, \quad d=9, \quad H=5 m m \text {. }
$$

Verbreitungsgebiet: Siebenbürgen, Banat, Serbien und Bosnien.

Die anatomischen Verhältnisse unbekannt.

\section{Hyalinia (Morlina) depressa Sterki.}

Hyalina depressa Ste rki, Nachrichtsblatt d. D. malak. Ges., p. 104, 1880.

- - Kobelt, in Rossm., Icon., II, v. 1, Nr. 35.

- tschapecki Westerlund, Fauna, I, Suppl., p. 7, 1890.

- nitidissima var, domestica Kimakowicz, Beitrag III zur Moll. Fauna Siebenbürgens, p. 161, 1890.

Verbreitungsgebiet: Die Alpen-, Karpathen- und die nördlichen Balkanländer.

\section{Hyalina (Morlina) dautzenbergi A. J. Wagner.}

Taf. 11, Fig. 75 .

Hyalina dautanbergi A. J. WVagner, Nachrichtsbiatt d. D. malak. Ges., p. 110, 1907, und Rossm., Icon., II, v. 13, Nr. 2205.

Radula: Der dreispitzige Mittelzahn klein und rudimentär wie bei H. glabra Fér.; auf diesen folgen in einer Halbreihe 3 dreispitzige, stark asymmetrische Seitenzähne und 9 stachelförmige Randzähne.

Verbreitungsgebiet: Süddalmatien, Hercegovina und Montenegro. 
Subgenus Retinella Shuttleworth.

Hyalinia (Retinella) mingrelica Mousson.

Taf 6, Fig. 52 bis 53 .

Zoniles mingrelicus Mousson, Coq. Schläfli, II, p. 294, 1863.

Hyalina mingrelica Kobe1t, in Rossm. Icon., I, v. 6, Ni. 1596.

- pontica Boettger, Jahrb. d. D. malak. Ges., 1881. teste Rosen.

Radula: Der symmetrische dreispitzige Mittelzahn ist kleiner als die Seitenzähne, seine Hauptspitze auffallend lang und schmal, die Seitenspitzen kurz und abgerundet; auf den Mittelzahn folgen in einer Halbreihe 2 stark asymmetrische dreispitzige und 1 zweispitziger Seitenzahn, auf diesen 20 stachelförmige Randzähne. Den Dimensionen nach sind die mittleren Seitenzähne am größten.

Sexualorgane: Der verhältnismäßig kurze, zylindrische Penis ist in der Mitte eingeschnürt; der Musc. retractor ist lang, dünn und endständig inseriert. Das ziemlich lange Vas deferens mündet im hinteren Drittel des Penis; das vordere Drittel desselben ist wesentlich dicker und wird am vorderen Drittel des Penis durch Bindegewebe angeheftet, nur der hintere Teil des Vas deferens erscheint fadenförmig dünn. Die längliche Samenblase ist mittellang gestielt; die Basis des Blasenstiels, ebenso der angrenzende Teil der Vagina werden von einer drüsigen Auflagerung eingeschlossen und erscheinen verdickt.

Das verhältnismäßig große Gehäuse ist ziemlich dünnschalig und durchscheinend, der Nabel eng. aber durchgehend, die 6\% Umgänge nehmen langsam und regelmäßig zu. Die Skulptur erinnert an die Verhältnisse bei der Gruppe Aegopis Fitz. und besteht auf der Oberseite aus deutlichen und dichten Zuwachsstreifen, welche durch feine Spirallinien gekreuzt werden; auf der stärker glänzenden Unterseite sind nur sehr feine Zuwachsstreifen vorhanden. Die untersuchten Exemplare vom Maikop im Kubangebiet.

Das Verbreitungsgebiet dieser Gruppe dürfte auf Cis- und Transkaukasien, die Krim und den Nordosten von Kleinasien zu beschränken sein, da die anatomische Untersuchung einiger westlicher Formen, welche bisher hier eingeteilt wurden, wesentlich abweichende Verhältnisse der Radula und der Sexualorgane ergeben hat.

\section{Genus Sehistophallus n.}

Radula: Der symmetrische dreispitzige Mitteizahn ist nur wenig kleiner oder nahezu so groß wie die Seitenzähne; auf den Mittelzahn folgen in einer Halbreihe 3 bis 4 stark asymmetrische, zwei und dreispitzige Seitenzähne, welche gegen die Randzähne verhältnismäßig klein sind; die folgenden Randzähne sind stachelförmig und verhältnismäßig groß.

Sexualorgane: Der Penis ist am hinteren Ende in zwei kurze, ungleiche Zipfel gespalten, an welchen der ebenfalls gespaltene, also zweiarmige Musc. retractor inseriert; in den vorderen, größeren Zipfel mündet das in diesem Teil wesentlich dickere Vas deferens, erscheint sodann gegen das vordere Ende des Penis gerichtet und hier durch Bindegewebe angeheftet; der übrige Teil des Vas deferens ist fadenförmig dünn und lang. Die ovale Samenblase ist vom Blasenstiel wenig deutlich abgesetzt; der mittellange Blasenstiel ist im oberen Teile dünn, an seinem unteren Teile erscheint derselbe ebenso wie der anliegende Teil der Vagina auffallend verdickt, indem hier eine drüsige Auflagerung gut entwickelt ist.

Die Gehäuse wie bei Hyalinia Agassiz; bei einigen Formen werden auf der Oberseite feine Spirallinien sichtbar.

Verbreitungsgebiet: Formen dieser Gruppe wurden bisher nur in Siebenbürgen und Bulgarien nachgewiesen, ich vermute dieselben ferner im ganzen östlichen Balkangebiet, der Krim und Kleinasien. 
Subgenus Schistophallus s. str.

Schistophallus (Schistophallus) oskari Kimakowicz.

Taf. 11, Fig. 76 .

Hyalina (Retinella) oskari Kinakowicz, Beitrag zur Moll. Fauna Siebenbürgens, p. 9, 1883.

- (Retinella) oskari Kob., in Rossm., Icon., II, v. 9, Nr. 1609.

- natolica Bielz, Fauna Siebenbürgens, p. 42, 1867.

Das Gehäuse verhältnismäßig groß, dünn aber fest und durchscheinend, oben hell hornfarben, unten milchig getrübt; wachsglänzend mit sehr feinen, ziemlich gleichmäßigen Zuwachsstreifen, welche auf den oberen Umgängen und entlang der Naht deutlicher sind, daneben werden unter der Luppe auch sehr feine und dichte Spirallinien sichtbar. Das flachkegelförmige, kaum erhobene Gewinde besteht aus $5 \frac{1}{2}$ bis 6 ziemlich regelmäßig und rasch zunehmenden, schwach gewölbten und durch eine leicht eingedrückte Naht geschiedenen Umgängen; der letzte ist beiderseits gleichmäßig gerundet und doppelt so breit wie der vorletzte. Die schiefe Mündung wird durch den vorletzten Umgang ausgeschnitten und ist breiter als hoch; der Mundsaum scharf und gerade; der Nabel stichförmig.

$$
I=18, \quad l=1+5, \quad H=8 \mathrm{~mm} .
$$

Fundorte: Die Bogater Schlucht und Coltiu Pesteri im Persányer Höhenzug bei Kronstadt in Siebenbürgen.

\section{Schistophallus (Schistophallus) oskari tumidus Kimakowicz.}

Taf. 4, Fig. 42. Taf. 6, Fig. 49 bis 50, Taf. 11, Fig. $77 a$ bis $c$.

Hyalina (Retinella) oskari var. tumida Kimakowicz, Beitrag III zur Moll. Fauna Siebenbürgens, p. 176, 1890.

Radula: Der symmetrische Mittelzahn ist kaum kleiner als die benachbarten Seitenzähne, die Hauptspitze desselben ist ziemlich lang und schmal, aber stumpf, die zwei Seitenspitzen niedrig bis undeutlich. Auf den Mittelzahn folgen in einer Halbreihe 3 dreispitzige und ein zweispitziger Seitenzahn, welche asymmetrisch sind und an Größe zunehmen; die 13 stachelförmigen Randzähne sind auffallend groß.

Sexualorgane: Der verhältnismäßig lange Penis ist im mittleren Drittel verdünnt, am hinteren Ende keulenförmig verdickt und in zwei Zipfel gespalten, an welchen der lange und zweiarmige Musc. retractor inseriert. Das sehr-lange Vas deferens mündet in den größeren Zipfel des Penis, erscheint dann nach vorne umgebogen und am vorderen Penisende durch festes Bindegewebe angeheftet; dieser vordere Teil des Vas deferens ist verdickt, der übrige sehr lange Teil desselben fadenförmig dünn. Die übrigen Verhältnisse typisch.

Das Gehäuse erscheint wesentlich von jenem der typischen Form unterschieden; das höhere, konvexe Gewinde besteht aus 6 bis $6 \frac{1}{2}$ deutlicher gewölbten und langsamer zunehmenden Umgängen; der letzte ist weniger zusammengedrückt und nur $1 \frac{1}{2}$ breiter wie der vorletzte, die Mündung mehr gerundet und nahezu so hoch als breit. Die Zuwachsstreifen und besonders die Spirallinien sind schwächer, die Färbung rotbraun.

$$
D=10 \cdot 5, \quad l=16, \quad H=1(1) \cdot \mathrm{m} m \mathrm{~m} .
$$

Fundort: Der Zeidner Berg bei Kronstadt in Siebenbürgen, an der Lokalität »Scara».

Mit Rücksicht auf die Verhältnisse des Gehäuses steht diese Art der H. malinonvskii Pfr. aus der Dobrudscha und der H. krynickii Cless. aus der Krim auffallend nahe; es liegt also die Vermutung nahe, daß diese anatomisch noch nicht untersuchten Arten ebenfalls zu dieser Gruppe gehören. Auch $H$. kobelti Lindholm zeigt nach P. Hesse Verhältnisse der Sexualorgane, wie sie dieser Gruppe eigentümlich sind, nur die Radula dieser Art besitzt einen rudimentären Mittelzahn. 


\section{Subgenus Cellariopsis 17.}

\section{Schistophallus (Cellariopsis) deubeli n.}

Taf. 6, Fig. 51 ; Taf. 7, Fig. 60; Taf. 12, Fig: 85 a bis $c$.

Hyalina cellaria Bielz, Fauna Sieben bürgens 1867.

Hyalinia (Polita) cellaria Kimakowicz, Beitrag zur Moll. Fauna Siebenbürgens, p. 164, 1890

Radula: Der symmetrische Mitlelzahn ist kleiner wie die Seitenzähne, die Hauptspitze desselben ist lang und schlank, die beiden Nebenspitzen kurz, aber ebenfalls gut entwickelt; auf den Mittelzahn folgen in einer Halbreihe 3 dreispitzige, stark asymmetrische Seitenzähne und 15 stachelförmige Randzähne, von welchen die inneren am größten sind.

Sexualorgane: Der ziemlich kurze Penis ist im hinteren Teile auffallend angeschwollen und hier in zwei ungleiche Zipfel gespalten; an dem kleineren Zipfel inseriert der Musc, retractor, entsendet aber auch einige Fasern zum ziveiten größeren Zipfel, in welchen das in diesem Teile dickere Vas deferens einmündet; der vordere Teil des Vas deferens ist ferner gegen das vordere Ende des Penis gebogen und hier durch Bindegewebe angeheftet, der übrige, längere Teil desselben fadenförmig dünn. Die übrigen Verhältnisse typisch.

Das Gehäuse ist scheibenförmig mit flachkegelförmigem, sehr niedrigem, etwas konvexem Gewinde, flacher Basis und ziemlich engem, lochförmigem oder etwas trichterförmig erweitertem Nabel; gelblich hornfarben mit grünlichem Stich und milchig getrübter Unterseite; durchscheinend, lebhaft glänzend, mit sehr feinen bis undeutlichen Zuwachsstreifen. Das Gewinde besteht aus 5 bis $5 \frac{1}{2}$ kaum gewölbten, durch eine seichte Naht geschiedenen, ziemlich langsam zunehmenden Umgängen; der letzte ist zusammengedrückt, oben mehr gewölbt und höchstens $1 \frac{1}{2}$ breiter wie der vorletzte. Die ovale Mündung wird durch den vorletzten Umgang ausgeschnitten und ist breiter als hoch, der Mundsaum scharf und gerade.

$$
\begin{aligned}
& D=9, \quad d=8, \quad H=+m m . \\
& I)=11, \quad d=10, \quad H=5 m m .
\end{aligned}
$$

Verbreitungsgebiet: Die Ostkarpathen in Ungarn und Siebenbürgen. Mit Rücksicht auf die Verhältnisse des Gehäuses steht diese Art der H. planaria Cless. aus der Krim und der H. camelina Bgt. aus dem östlichen Balkangebiet und Vorderasien am nächsten, doch sind die anatomischen Verhältnisse dieser Formen noch unbekannt.

\section{Genus Crystallus Low e 1854.}

Der Kiefer dünn und zart, halbmondförmig mit einem schwachen Vorsprung am konkaven Rande, glatt.

Radula: Der dreispitzige, symmetrische Mittelzahn ist von gleicher Größe wie die drei asymmetrischen, ebenfalls dreispitzigen Seitenzähne; 10 bis 15 Randzähne sind stachelförmig.

Sexualorgane: Der Penis mit endständig inseriertem Musc. retractor; nach einer Zeichnung Wiegmann's findet sich bei $\mathrm{Cr}$. diaphamıs Stud, ein halbkugelig vorspringendes Divertikel am Penis. Das Vas deferens ist mittellang und in seinem ganzen Verlaufe fadenförmig; die Samenblase rudimentär entwickelt und kurz gestielt; die Vagina in der Mitte auffallend verdickt. Der Musc. retractor des rechten Augenträgers verlauft zwischen Penis und Vagina.

Das Gesäuse klein, glasartig durchsichtig, farblos oder gelblich, glänzend und sehr fein gestreift, jedoch ohne Spirallinien; offen, eng bis stichförmig genabelt oder ungenabelt;, mit zahlreichen (4 bis 8 ) langsam und regelmäßig zunehmenden Umgängen, in welche sich das Tier vollkommen zurückziehen kann; die Mündung durch den vorletzten Umgang ausgeschnitten, der Mundsaum dünn, scharf und gerade.

Das Verbreitungsgebiet umfaßt das ganze paläarktische Gebiet. 
Subgenus Crystallus s. str.

Crystallus spelaeus A. J. Wagner.

Taf. 11, Fìg. $74 a$ bis $c$

Crystallus spelaeits A. J. Wagner, Sitzungsbericht der k. Akad. Wien, 1914, Bd. 123, Abt. 1.

Das Gehäuse sehr ähnlich dem Cr. crystallinus Müller, jedoch bei der gleichen Windungszahl (5) wesentlich größer, festschaliger, mit nahezu flachem Gewinde und verhältnismäßig engerem lochförmig abfallendem Nabel.

$$
D=5, \quad d=4 \cdot 7, \quad H=2 \cdot 4 \text { mun. }
$$

Fundort: Höhle Crnulja ponor im Popovo polje, Hercegovina.

\section{Crystallus crystallinus Müller.}

Taf. 12, Fig. 94.

Helix crystallina Mül1er, Verm. hist. II, 1774.

Sexualorgane: Der spindelförmige Penis mit endständig inseriertem Musc. retractor, neben diesem mündet das mittellange, fadenförmige Vas deferens. Die Vagina ist im mittleren Teile zu einer eiförmigen Biase angeschwollen, in welche die rudimentäre, sehr kleine und kaum gestielte Samenblase mündet.

Verbreitungsgebiet: Europa.

\section{Crystallus jetschini Kimakowicz.}

Hyalina (Vitrea) jetschinti Kimakowicz in: Beitrag z. Molluskenfauna Siebenbürgens, 2. Nachtrag, p. 171, 1890.

Verbreitungsgebiet: Banat in Südungarn, Domoglet bei Mehadia.

Crystallus illyricus A. J. Wagner.

Crystallus illyrictes A. J. Wagner, Nachrichtsblatt d. D. mal. Ges., p. 103, 1907 und Rossm., Icon., II, v. 13, Nr. 2199.

Verbreitungsgebiet: Süddalmatien, Hercegovina, Bosnien, Serbien, Montenegro, Albanien.

Crystallus contractus subcontractus A. J. Wagner.

Crystallus contractus subcontractus A. J. W a gner, Nachrichtsblatt d. D. mal. Ges., p. 104, 1907 und Rossm. Icon. II, v. 13, Nir. 2196.

Verbreitungsgebiet: Das ganze Gebiet Österreichs und Ungarns mit Ausnahme von Süddalmatien.

\section{Crystallus contractus botterii Pfeiffer.}

Helix crystallina var, botterii Pfeiffer, Mon. Helic., III, p. 66, 1853 und Rossm., Icon., II, v. 13, Nr. 2197.

Verbreitungsgebiet: Süddalmatien und Montenegro.

\section{Crystallus kutschigi Walderdorff.}

Hyalina kutschigi Walderdorf, Verhandl. d. k. k. zoolog. botan. Ges. Wien, p. 504, 1864 und Rossm., Icon., II, v. 13, Nr. 2201.

Verbreitungsgebiet: Süddalmatien und Hercegovina. 
Crystallus kutschigi zavalae A. J. Wagner:

Crystallus kutscligi zavalae A. J. Wagner, Nachrichtsblatt d. D. mal. Ges., p. 105, 1907 und Rossm., Icon., II, v. 13, Nr. 2202 .

Verbreitungsgebiet: Zavala in der Herzegovina.

Crystallus sturanyi A. J. Wagner.

Crystallus sturanyi A. J. W agner, Nachrichtsblatt d. D. malak. Ges., p. 106, 1907, und Rossm., Icon., II, v. 13, N1. 2200.

Verbreitungsgebiet: Montenegro, Bosnien, Serbien und Bulgarien.

\section{Crystallus subrimatus Reinhardt.}

Hyalina subrimata Rein hardt, Sitzungsb. Ges. naturf. Freunde, Berlin, p. 39, 1871.

Verbreitungsgebiet: Die Alpen-, Sudeten-, Karpathen- und nördlichen Balkanländer:

\section{Crystallus subrimatus litoralis Clessin.}

Hyatina (Vitrea) litoralis Clessin, Mal. B1., p. 131, t. 2, f. $9,1877$.

Verbreitungsgebiet: Das Küstenland, Krain, Kroatien, Bosnien, Dalmatien, Montenegro und Südtirol.

Crystallus subrimatus inflatus A. J. Wagner.

Crystallus subrimatus inflahus A. J. Wagner, Nachrichtsblatt d. D. mal. Ges., p. 107, 1904, und Rossm. Icon., II, v. 13, Nr. 2204

Verbreitungsgebiet: Süddalmatien, Montenegro und Albanien.

\section{Crystallus diaphanus Studer.}

Helix diaphana Studer, Kurz. Verz., p. 44, 1820.

- Tyalina Férussae, Tabl., p. 45, 1822.

- contorta Held, 1837.

Verbreitungsgebiet: Die Alpen, das deutsche Mittelgebirge, die Karpathen und die nördlichen Balkanländer.

\section{Crystallus transsilvanicus Clessin.}

Hyalina transsilvanica C1essin, Mal, B1., v. 24, p. 133, t. 2, f. 12, 1877.

Verbreitungsgebiet: Die Karpathen.

Crystallus erjaveci Biusina.

Helicella erjaveci Brusina, Contr. mal. Croat., p. 18, 1870.

Verbreitungsgebiet: Das Küstenland, Krain und Kroatien.

\section{Crystallus subcarinatus Clessin.}

Hyalina (Vitrea) subcarinata Clessin, Mal. B1., v. 24, p. 129, t. 1, f. 5, 1877.

- jickelii C1essin, Mal. Bl., v. 24, p. 130, t. 2, f. 8, 1877.

Verbreitungsgebiet: Die Südkarpathen. 
Subgenus Hydatinus Westerlund 1886.

Crystallus (Hydatinus) hydatinus Roßmäßler.

Helix Fyydalina RoBmäB1er, Icon., 1, v. 2, Nr. 529.

Terbreitungsgebiet: Kroatien, Dalmatien und Montenegro.

Crystallus (Hydatinus) sphaeroconus A. J. Wagner:

Crystallus (Hydatinus) sphacroconus A. J. Wagner, Nachrichtsblatt d. D. mal. Ges, p. 109, 1907 und Rossm., Icon., II, v. $13, \mathrm{Nr} .2203$.

Verbreitungsgebiet: Nordalbanien.

Crystallus (Hydatinus) eudaedaleus Bourguignat.

Zonites endadalens Bourguignat, Aménités mal, I, p. 189, t. 20, Fig. 1 bis 3, und Rossm., Icon., I, v. 7, Nr. 1946.

Verbreitungsgebiet: Lesina, die Jonischen Inseln und Griechenland.

Crystallus (Hydatinus) opinatus Clessin.

Hyalina (Vitrea) opinata C1essin, Moll. Fauna Österreich-Ungarns, p. 89, f. 29, 1887.

- - plutonia Kimakowicz, Beitrag zur Moll. Fauna Siebenbuirgens, 2. Nachtrag, p. 174, 1890.

Verbreitungsgebiet: Das Gebiet der Monarchie und die nördlichen Balkanländer.

Crystallus (Hydatinus) maritae Kimakowicz.

Hyalinia (Vitrea) maritae Kimakowicz, Beitrag zur Moll. Fauna Siebenbürgens, 2. Nachtrag, p. 173, 1890.

Verbreitungsgebiet: Südkarpathen.

Crystallus (Hydatinus) maritae clathratus Kimakowicz.

Hyalinia (Vitrea) maritae var. clathrata Kimakowicz, Beitrag zur Moll. Fauna Siebenbürgens, 2. Nachtrag, p. $174,1890$.

Fundorte: Tordaer Felsspalte und Attelsloch bei Schäßburg in Siebenbürgen.

\section{Familia VITRINIDAE.}

\section{Subfamilia Vitrininae.}

Das kriechende Tier ist sehr schlank, die Sohle in drei Längsfelder geteilt und berandet, die Schwanzspitze ohne Schwanzdrüse. Am Mantelrande sind zwei Nacken und zwei Schalenlappen vorhanden; die Atemöffnung befindet sich auf der rechten Seite an der Basis des Mantellappens, die Geschlechtsöffnung rechts in der Mitte des Halses.

Verdauungstrakt:- Der zylindrische Oesophagus ohne Kropf und Vormagen erweitert sich zu einem gleichlangen, sackförmigen Magen, der sich in einen dünnen zylindrischen Enddarm mit den typischen Windungen fortsetzt. Der halbmond- oder hufeisenförmige Kiefer ist glatt mit einem Vorsprung am konkaven Rande (Taf, 11, Fig. 83b, Fig. 84; Taf. 15, Fig. 129). „Wiegmann«.

Die Radula mit 71 bis 88 Querreihen und im Maximum mit 31-1--31 Längsreihen »Wiegmann«. Der symmetrische Mittelzahn ist stets deutlich dreispitzig und so groß wie die Seitenzähne; die Hauptspitze ist schlank ausgezogen, länger wie die Basalplatte, an der Basis etwas schmäler, vorne zugespitzt; die zwei Nebenspitzen sind viel kürzer, aber deutlich vorspringend. Auf den Mittelzahn folgen in einer 
Halbreihe eine wechselnde Zahl asymmetrischer Seitenzähne, von welchen die inneren (10 bis 12) deutlich dreispitzig sind, während die äußeren zweispitzig werden und allmählich in die stachelförmigen Randzähne übergehen; die stachelförmigen Randzähne sind entweder einspitzig oder fein sägenartig gezähnt und mehrspitzig.

Die Niere typisch wie bei den Heliciden "Wiegmann".

Der Nervenschlundring mit auffallend großem Hirnganglienknoten und kurzer Cerebralkommissur unterscheidet sich von den Heliciden besonders dadurch, daß die Visceralganglien deutlicher von den Pedalganglien gesondert sind und der Ring ein weiteres Lumen besitzt „Wiegmann"

Sexualorgane: Die Zwitterdrüse ist aus kugeligen Acinis zusammengesetzt und in der Leber eingebettet. Der zumeist gestreckte oder nur weit gewundene, verhältnismäßig kurze Zwittergang besitzt ein deutliches Divertikel; die Eiweißdrüse ist verhältnismäßig groß, das Uterus-Prostatakonvolut veit gewunden. Die kleine, kugelige Samenblase ist kurz bis sehr kurz gestielt; der Blasenstiel ist deutlich von der Samenblase abgesetzt, stets ohne Divertikel und an seiner Einmündung in die Vagina nicht wesentlich dicker. In die Vagina mündet gegenüber der Einmündung des Penis in die Kloake bei einer Gruppe eine weibliche Anhangdrüse (Appendicula); dieselbe besteht aus einem in der Ruhelage eingestülpten Blindsack, welcher in eine gebogene und an der Spitze durchbohrte hornartig feste Spitze auslauft. Taf. 15, Fig. 141 stellt dieses Organ eingestülpt, Fig. 141 vorgestülpt dar. Diese Appendicula wird mit dem Pfeilsack der Heliciden verglichen und erfüllt vielleicht eine ähnliche Funktion als Reizorgan. Sehr verschiedene Verhältnisse werden bei den einzelnen Gruppen am Penis beobachtet; derselbe ist im allgemeinen keulenförmig, kurz und dick; ein endständig inserierter Musc. retractor ist bald vorhanden oder derselbe fehlt vollkommen. Das kurze, fadenförmige Vas deferens verlauft entweder frei zum hinteren Ende des Penis und mündet neben dem Musc. retractor, oder dasselbe verlauft zunächst zum vorderen Ende des Penis, wird daselbst von einer Bindegewebsmembrane eingehüllt und gelangt so bedeckt zum hinteren Penisende. Der Musc. retractor des rechten Augenträgers verlauft bald zwischen Penis und Vagina, bald frei neben den Sexualorganen.

Das Gehäuse ist immer sehr zart, oft hautartig dünn und biegsam, durchsichtig und glänzend mit sehr feinen bis undeutlichen Zuwachsstreifen; dasselbe gestattet dem Tiere nur ausnahmsweise sich vollkommen in das Gehäuse zurückzuziehen, zumeist ist ein ähnliches Verhältnis wie bei Dandebardia vorhanden. Das Gehäuse ist ferner stets ungenabelt und besteht aus $1^{1} / 2$ bis $3^{1} / 2$ sehr rasch zunehmenden Umgängen; im übrigen ist das Wachstum des Gehäuses hier ähnlich wie bei Daudebardia, indem der Spindel- und Basalrand der Mündung gegen den Oberrand mehr oder minder auffallend zurückbleiben, so daß das Gehäuse schildförmig erscheint; am Spindelrand ist häufig ein mehr oder minder breiter, hautartig dünner Saum vorhanden, welcher bei den einzelnen Arten konstant erscheint.

Das Verbreitungsgebiet der hier besprochenen Gruppen dieser Familie umfaßt das ganze paläarktische Gebiet; als autochthone Höhenformen treten dieseiben auch heute vorzüglich in den Gebirgen auf, wo sie in die obersten Höhenlagen vordringen, welche überhaupt noch Mollusken beherbergen. Die bei den einzelnen Arten wesentlich abweichenden Verhältnisse der Sexualorgane begründen bei gleichzeitiger Berücksichtigung der Sshalenmerkmale und der Radula nachstehende Gruppeneinteilung.

\section{Genus Vitrina Draparnaud 1801.}

Die Radula mit stachelförmigen einspitzigen äußeren Randzähnen.

Sexualorgane: Die Vagina stets ohne Appendicula (Pfeilsack), der Penis mit endständigem Musc. retractor. Der Musc, retractor des rechten Augenträgers verlauft zwischen Penis und Vagina.

Das Gehäuse mit $2^{1} / 2$ bis $3^{1} / 2$ rasch zunehmenden Umgängen, in welche sich das Tier nur teilweise zurückziehen kann. 
Vitrina diaphana Draparnaud.

Taf. 13 , Fig. 106 bis 110 .

Vitrina diaphana Draparnaud, Hist. p. 120, Taf. 8, Fig. 38 bis 39, 1805.

Die Radula mit 1 symmetrischen, dreispitzigen Mittelzahn, 10 dreispitzigen, stark asymmetrischen Seitenzähnen und 22 bis 25 stachelförmigen Randzähnen, von welchen nur die zwei innersten undeutlich zweispitzig erscheinen (in einer Halbreihe).

Sexualorgane: Der dicke, keulenförmige Penis mit einem kräftigen, endständig inserierten Musc. retractor; das kurze Vas deferens legt sich dem vorderen Ende des Penis an und verlauft hier unter der bindegewebigen Hülle zum hinteren Ende desselben. Die rundliche Samenblase mit dünnem, ziemlich kurzem Blasenstiel; die übrigen Verhältnisse typisch.

Gehäuse: Sehr dünn und zart, gelblich gefärbt, durchsichtig und glänzend mit undeutlichen Zuwachsstreifen; die Oberseite flachkonvex mit kaum vorspringendem Gewinde, welches aus $2 \frac{1}{2}$ rasch zunehmenden Umgängen besteht; der Oberrand der Mündung konvex vorgezogen, der Spindelrand stark konkav gebogen mit einem breiten Hautsaum.

$$
D=6 \cdot 5, \quad d=5 \cdot 2, \quad H=3 \cdot 2 m m .
$$

Bezüglich der übrigen Verhältnisse des Gehäuses verweise ich hier und bei den weiteren Formen dieser Gruppen auf die beigegebenen Abbildungen.

Verbreitungsgebiet: Die typische Form der V. diaphana Drap. ist mir nur aus West-, Süd- und Mitteldeutschland bis Patschkau in Schlesien, also dem deutschen Mittelgebirge, ferner aus den Alpenländern bekannt. In den Karpathen (schon im oberen Oder- und Weichseltale) habe ich dieselbe nicht beobachtet, ebenso sind mir aus den Südostalpen nur vereinzelte Fundorte bekannt geworden (Alpe Krn in den Julischen Alpen, Mali Halan im Velebit). In diesem Gebiete tritt $V$. diaphana Drap. vorzüglich in den unteren Höhenlagen auf; schon in Höhenlagen über $1000 \mathrm{~m}$ nimmt die Individuenzahl ab, während gleichzeitig andere Arten auftreten, um dieselbe bald vollkommen zu ersetzen.

Vitrina glacialis Forbes.

Taf. 14, Fig. 115 bis 117.

Vitrina glacialis Forbes, Magas. Zool. Bot. 1837.

- _ Kobelt in Rossm., Icon, I, v. 5, Nr. 1401.

Gehäuse sehr ähnlich der Vitrina diaphana Drap,, die $2 \frac{1}{2}$ Umgänge nehmen jedoch rascher zu, so daß der Umriß des Gehäuses weniger gerundet, annähernd halbkreisförmig erscheint; die Oberseite ist flacher, das Gewinde im Verhältnis zur Mündung kleiner; der Ober- und Außenrand der Mündung sind stärker vorgezogen, der Spindelrand weniger konkav gebogen; der Hautsaum am Spindelrand ist nicht wesentlich schmäler als bei $V$. diaphana Drap., nimmt aber nur einen geringeren Teil von der Unterseite des Gehäuses ein.

$$
D=0, \quad a=4, \quad H=2 \cdot 5 \mathrm{~mm} .
$$

Die anatomischen Verhältnisse sind unbekannt.

Fundorte: Vitrina glacialis Forbes ist mir nur aus Tirol bekannt (Schwarzenbach bei Luttach, Kanserbach), wo sie nur in den oberen Höhenregionen auftritt und vermutlich eine Höhenform der $V$. diaphana Drap. darstellt; Kobelt und Koch führen dieselbe auch aus der Schweiz an.

Vitrina charpentieri Stabile.

Taf. 14, Fig. 124 bis 127, Taf. 15, Fig. 128 bis 129.

Vilrina charpentieri Stabile, Rev. Mag. p. 419, Taf. 15, Fig. 1 bis 5, 1859.

Kobelt in: Rossm., Icon., I, v. 5, Nr. 1408.

- nivalis Charpentier in sched. 
Vitrina kochi Andrae, Der Diluvialsand von Hangenbieten, p. 52, Taf. 1, Fig, 60 bis 63, Straßburg 1884.

- - Clessin, Fauna Österreich-Ungarns, p. 60, 1887.

Der symmetrische dreispitzige Mittelzahn mit gut entwickelten Nebenspitzen; auf diesen folgen in einer Halbreihe 12 asymmetrische dreispitzige Seitenzähne und 20 bis 23 stachelförmige Randzähne, von welchen die innersten schwach zweispitzig erscheinen.

Sexualorgane: Der Penis ist im Vergleiche mit $V$. diaphana D rap. wesentlich kleiner und kürzer, die übrigen Verhältnisse typisch.

Das Gehäuse ähnlich wie bei $V$. diaphana Drap., jedoch durchschnittlich kleiner, im Umrisse mehr oval; die 21/2 Umgänge nehmen rascher zu, dementsprechend erscheint das Gewinde im Verhältnisse zur Mündung kleiner; der Spindelrand der Mündung ist weniger konkav gebogen, der Hautsaum sehr schmal.

$$
D=6, \quad d=4 \cdot 5, \quad H=3 \mathrm{~mm} .
$$

Das Verbreitungsgebiet dieser Art scheint sehr ausgedehnt zu sein; ich kenne dieselbe in vollkommen übereinstimmenden Exemplaren aus der Umgebung von Bex in der Schweiz, vom Hochtor, Hochschwab, Rax in Steiermark, vom Schneeberg in Niederösterreich, aus dem Tatragebirge, den schlesischen Beskiden und dem Reichensteiner Gebirge bei Patschkau in Preußisch-Schlesien. In den Alpen und der Tatra wurde $V$. charpentieri Stab. vorzüglich in den oberen Höhenlagen beobachtet, in den schlesischen Beskiden tritt dieselbe jedoch regelmäßig auch in Höhenlagen um $1000 \mathrm{~m}$, ja vereinzelt in der Talregion auf. Ich beurteile diese Art zunächst nach Originalexemplaren Charpentiers aus der Umgebung von Bex, welche dieser Autor mit der Bezeichnung Vitrina nivalis dem Wiener Hofmuseum übergeben hat.

\section{Genus Phenacolimax Stabile 1859.}

Radula: Die Randzähne sind nur zum Teile stachelförmig; die inneren derselben infolge Spaltung der Hauptspitze zweispitzig und schmäler als die Seitenzähne; die äußeren durch das Auftreten von kleinen Nebenspitzen am Außenrande mehrspitzig und zumeist kürzer, nicht mehr stachelförmig; mitunter sehr klein bis rudimentär.

Sexualorgane: Der schlank zylindrische oder mehr keulenförmige Penis mit einem endständig inserierten Musc. retractor; das kurze, fadenförmige Vas deferens legt sich dem vorderen Teile des Penis an und verlauft dann demselben dicht anliegend gegen das hintere Ende, wo es neben dem Musc. retractor mündet.

Der Musc. retractor des rechten Augenträgers verlauft frei neben den Sexualorganen.

Das Gehäuse ist im Verhältnisse zum Tiere so groß, daß sich dasselbe nahezu vollkommen in das Gehäuse zurückziehen kann. Die Zahl der Umgänge ist hier immer größer wie bei den Formen des Genus Vitrina Drap., auch nehmen dieselben langsamer zu, so daß der letzte Umgang und die Mündung nicht so auffallend das Gewinde überwiegen; der Hautsaum am Spindelrande ist immer schmal.

\section{Phenacolimax pellucidus Müller.}

Taf. 4, Fig. 40, Taf. 13, Fig. 95 bis 99.

Hellix pellucida Müller, Verm. Hist., II, 1774.

Die Radula mit dreispitzigem symmetrischem Mittelzahn und 8 asymmetrischen, dreispitzigen Seiten. zäbnen; auf diese folgen in einer Halbreihe 22 bis 23 schmälere Randzähne, bei welchen zunächst eine Spaltung der Hauptspitze erfolgt, so daß dieselben zweispitzig erscheinen; bei den äußeren Randzähnen treten außerdem am Außenrande kleine Nebenspitzen auf, wodurch dieselben sägenartig gezähnt, also mehrspitzig werden.

Sexualorgane: Der schlank zylindrische Penis mit einem endständig inserierten Musc. retractor; die übrigen Verhältnisse typisch. 
Gehäuse gelblich oder grünlich, durchsichtig oder leicht getrübt; glänzend mit sehr feinen Zuwachsstreifen. Das breit kegelförmige Gewinde besteht aus $3^{1 / 2}$ ziemlich rasch zunehmenden Umgängen; der letzte ist mehr als doppelt so breit wie der vorletzte und steigt vorne langsam herab. Der Oberrand der Mündung ist etwas konvex vorgezogen, der Basalrand flach konkav mit sehr schmalem Hautsaum.

$$
D=5, \quad d=4 \cdot 2, \quad H=3 \mathrm{~mm} .
$$

Verbreitungsgebiet: Das ganze paläarktische Gebiet, sowohl in der Talregion, als in den unteren und oberen Höhenlagen der Gebirge.

\section{Phenacolimax reitteri Boettger.}

Taf. 14, Fig. 118 bis 123 .

Vitrina reitteri Boettge r, Ber. d. Offenb. Ver., p. 102, 1880.

- carniolica Boettger, Nachrichtsblatt d. D. malak. Ges., p. 184, 1884.

Die Radula mit dreispitzigem symmetrischem Mittelzahn und 9 asymmetrischen dreispitzigen Seitenzähnen; auf diese folgen in einer Halbreihe 25 Randzähne, von welchen die inneren (15) infolge Spaltung der Hauptspitze zweispitzig und schmal sind, während die äußeren durch Auftreten von äußeren Nebenspitzen mehrspitzig erscheinen, aber abnehmend kleiner und kürzer werden.

Sexualorgane: Der keulenförmige Penis mit endständig inseriertem Musc. retractor; die übrigen Verhältnisse typisch.

Gehäuse dünnschalig, gelblich hornfarben, durchsichtig oder nur leicht getrübt, glänzend, mit feinen aber deutlichen Zuwachsstreifen. Das flachkegelförmige, deutlich vorspringende Gewinde besteht aus 3 bis $3 \frac{1}{2}$ rasch zunehmenden Umgängen; der letzte nimmt gegen die Mündung rascher zu und steigt vorne langsam herab; Exemplare mit 3 oder $3^{\frac{1}{2}} / 2$ Umgängen zeigen aus diesem Grunde wesentlich verschiedene Verbältnisse, indem mit der rascheren Zunahme des letzten Umganges das Gewinde flacher, die Mündung größer und weiter erscheint (Taf. 14, Fig. 118 und Fig. 121). Der Oberrand der Mündung ist konvex vorgezogen, der Basalrand seicht konkav mit einem sehr schmalen Hautsaum.

$$
D=9 \cdot 2, \quad d=7 \cdot 4, \quad H=4 \cdot 6 \mathrm{~mm} .
$$

Verbreitungsgebiet: Die Südostalpen und der Westen der Balkanhalbinsel; Krain, Kroatien, Bosnien, Hercegovina, Montenegro, Albanien und Mazedonien.

Vitrina carniolica Bttg. entspricht unausgewachsenen Exemplaren dieser Art.

\section{Phenacolimax retyezati $n$.}

Taf. 14, Fig. 111 bis 113.

Gehäuse ähnlich dem Phenacolimax reitteri Bttg.; das niedrigere, nahezu flache Gewinde besteht aus $2^{3 / 4}$ rascher zunehmenden Umgängen, so daß das Gewinde im Verhältnis zur Mündung kleiner erscheint; der Hautsaum am Spindelrande der Mündung ist schmal.

$$
D=6 \cdot 6, \quad d=5, \quad H=4 m m .
$$

Fundort: Am Berge Retyezat in den Südwestkarpathen.

\section{Phenacolimax bielzi Kimakowicz.}

Taf. 13, Fig. 103 bis 105.

Phenacotinnax bielzi Kimakowicz, Beitrag zur Moll. Fauna Siebenbürgens, p. 159, 1890.

Vitrina diaphana Bielz, Fauna, p. 35, 1867.

Gehäuse sehr ähnlich dem Phenacolimax reitteri Bttg., jedoch kleiner, mit 3 langsamer zunehmenden Umgängen und einem breit kegelförmigen Gewinde, wie es nur unausgewachsene Gehäuse des 
Ph. reitteri Bttg. aufweisen. Die Mündung ist im Verhältnis zum Gewinde weniger breit und erweitert, der Oberrand derselben stärker konvex, der Spindelrand tiefer konkav, der Hautsaum sehr schmal.

$$
D=5 \cdot 2 \text { bis } 5 \cdot 6, \quad d=4 \cdot 2 \text { bis } 4 \cdot 5, \quad H=3 \mathrm{~mm} .
$$

Verbreitungsgebiet: Die Ostkarpathen in Ostungarn, Ostgalizien, der Bukowina und Siebenbürgen.

\section{Phenacolimax nivalis Dum. et Mort.}

Taf. 14, Fig. $114 a$ bis $c$.

Vitrina nivalis Dum. et Mort., Hist. moll. Savoie 1852, nec Charpentier.

- Pollonera, Mon. in Atti Ac. Torino, Fig. 14 bis 16, 1884.

- $\quad$ Westerlund, Fauna, I, p. 16, 1886.

Gehäuse sehr dünnschalig, gelblich mit grünlichem Stich, glänzend und durchsichtig, mit schwachen, nur an der Naht deutlicheren Zuwachsstreifen. Das kaum erhobene Gewinde besteht aus 23/4 ziemlich rasch zunehmenden Umgängen; der Oberrand der Mündung ist konvex vorgezogen, der Spindelrand leicht konkav mit einem sehr schmalen Hautsaum.

$$
D=10, \quad d=8, \quad H=3 \cdot 4 m m
$$

Die anatomischen Verhältnisse sind unbekannt.

Fundorte: In den oberen Höhenlagen der Westalpen; meine Exemplare aus den Walliser, Grajischen und Kottischen Alpen.

Von Vitrina diaphana Drap. unterscheidet sich vorstehende Art durch das mehr gedrückte, oben flachere Gehäuse, die größere Zahl der langsamer und regelmäßiger zunehmenden Umgänge (1/4 Umgang mehr), das im Verhältnis zur Mündung größere Gewinde und besonders durch den weniger konkav gebogenen Spindelrand mit einem wesentlich schmäleren Hautsaum.

Nahe Beziehungen zeigt Vitrina nivalis Dum. et Mort. zu einer Vitrina des mittleren und unteren Rheintales, welche Clessin als V. elliptica Brown, Kobelt als V. major Fér. bezeichnen. Mit letzterer Art, welche ich nach Exemplaren aus der Bretagne beurteile, hat die Form des Rheintales aber gewiß nichts zu tun; $V$. elliptica Brown wird aber als Synonym der $V$. major Fér. $=V$. draparnaldi Beck bezeichnet; ich schlage aus diesem Grunde zur Fixierung dieser bemerkenswerten Form eine neue Bezeichnung vor.

\section{Phenacolimax austrasiae $n$.}

Vitrita elliptica Clessin, d. Excursions Moll. Fauna, p. 70, 1884.

- major Kobelt, in Rossm., Icon., I, v. 5, Nr. 1404.

Gehäuse ähnlich der V. nivalis Dum. et Mort., jedoch weniger abgeflacht, mit deutlicher vorspringendem Gewinde, welches aus 31/4 langsamer zunehmenden Umgängen besteht; der Hautsaum am Spindelrande ebenso schmal.

$$
D=7, \quad d=5 \cdot 5, \quad H=3 \cdot 5 .
$$

Verbreitungsgebiet: Im mittleren und unteren Rheintal, sowie den angrenzenden Gebieten von Westdeutschland und Ostfrankreich; meine Exemplare aus der Umgebung von Bonn und Neuwied. V. major Fér. ist nach Exemplaren aus der Bretagne festschaliger, zumeist leicht getrübt und deutlich gestreift; das Gewinde besteht aus $3 \frac{1}{2}$ langsamer und regelmäßiger zunehmenden Umgängen; dẹ Oberrand der Mündung ist gerade, bei $P h$. austrasiae n. konvex vorgezogen. 


\section{Phenacolimax annularis Studer.}

Taf. 13, Fig. 100 bis 102.

Hyatina anmularis Studer, Verz., p. 11, 1820.

Vitrina plicosa Bielz, Fauna Siebenbürgens, p. 34, 1867.

- annularis Kob., in Rossm., Icon., I, v, 5, Nr. 1406.

Das Gehäuse von jenem des Ph. pellucidus Müller durch das höhere kegelförmige Gewinde mit $3^{1} / 2$ gewölbten, wesentlich langsamer zunehmenden Umgängen, die stärkeren ungleichmäßigen Zuwachsstreifen sowie die mehr gerundete, weniger breite Mündung unterschieden.

Verbreitungsgebiet: Ph. annularis Stud. wurde in allen Gebirgen Europas gesammelt, wo sie zumeist in den oberen Höhenlagen, mitunter aber auch in der Talregion auftritt, so in der Tordaer Schlucht bei Klausenburg in Siebenbürgen und auf der Halbinsel Krim.

\section{Genus Semilimax Stabile 1859.}

Die Radula zeigt ähnliche Verhältnisse wie bei dem Genus Vitrina Drap., die stachelförmigen Randzähne lassen jedoch besonders bei den inneren Gliedern eine schwache Nebenspitze am Außenrande erkennen.

Sexualorgane: Der kurze dicke Penis besitzt zumeist keinen Musc. retractor; das kurze Vas deferens mündet am hinteren Ende des Penis; in das vordere Ende der Vagina mündet ein pfeilsackähnliches Anhangsorgan (Appendicula); die rundliche Samenblase ist sehr kurz gestielt.

Der Musc. retractor des rechten Augenträgers verlauft frei neben den Sexualorganen.

Das zarte und sehr dünne Gehäuse ist im Verhältnis zum Tiere so klein, daß sich dasselbe nicht in das Gehäuse zurückziehen kann; das im Verhältnis zur Mündung sehr kleine Gewinde besteht höchstens aus zwei sehr rasch zunehmenden Umgängen, welche in der Weise wachsen, daß vorzüglich die Oberseite zunimmt, während die Unterseite auffallend zurückbleibt; dementsprechend erscheint hier das Gehäuse schildförmig und ähnlich rudimentär wie bei Daudebardia.

\section{Semilimax elongatus Draparnaud.}

Taf. 11 , Fig. $83 a$ bis $b$; Taf. 15, Fig. 130 bis 133.

Vitrina elongala Dra p., Hist. moll., 1805.

Die Radula mit einem symmetrischen, dreispitzigen Mittelzahn und 11 dreispitzigen Seitenzähnen, welche vom 10. an in die mehr stachelförmigen Randzähne übergehen; auf die Seitenzähne folgen in einer Halbreihe 28 Randzähne, welche zunächst noch eine schwache äußere Nebenspitze erkennen lassen, während die innere Nebenspitze verschwindet; die äußeren Randzähne sind einspitzig, aber abnehmend kleiner.

Sexualorgane: Der Penis ist kurz birnförmig, ohne Musc. retractor, in das etwas verschmälerte hintere Ende desselben tritt das Vas deferens ein; gegenüber der Einmündung des Penis in die lange Kloake mündet das keulenförmige, am hinteren Ende zuweilen hackenförmig umgebogene weibliche Anhangsorgan, welches aus einem vorstülpbaren Blindsack besteht; derselbe endet mit einer hornartig festen, hackenförmig gebogenen und durchbohrten Spitze und wird von einer doppelten sackförmigen Hülle umgeben; die rundliche Samenblaśe ist sehr kurz gestielt.

Das schildförmige im Umriß ovale Gehäuse besteht aus $1 \frac{1}{2}$ bis $1 \frac{1}{4}$ sehr rasch zunehmenden Umgängen; das kaum vorspringende Gewinde ist mehr als zweimal kleiner wie der letzte Umgang vor der Mündung; die weite ovale Mündung mit konvexem Oberrand und konkavem Spindelrand, am Spindelrand ein breiter Hautsaum.

$$
D=5 \cdot 2, \quad l=3 \cdot 5, \quad H 2 \cdot 2 m m .
$$


Verbreitungsgebiet: Ich kenne S. elongatus Drap. aus Süddeutschland, den österreichischen Alpenländern, aber bisher nur von wenigen Lokalitäten der Karpathen (Borszek in Siebenbürgen), ferner aus der Umgebung von Agram in Kroatien, sowohl in den oberen Höhenlagen der Gebirge als in der Talregion.

\section{Semilimax kotulae Westerlund.}

Taf. 15, Fig. 134 bis 135.

Vitrina kotulae Westerlund, Jahrb. d. D. Mal. Ges., p. 54, 1883.

Gehäuse ähnlich dem Semilimax elongatus Drap.; der Umriß des Gehäuses ist jedoch mehr gerundet, indem die $1 \frac{1}{2}$ bis $1 \frac{3}{4}$ Umgänge langsamer zunehmen und der letzte Umgang nur zweimal so breit wie das Gewinde ist. Der Oberrand der Mündung ist stärker konvex vorgezogen, der Spindelrand auffallend konkav ausgeschnitten, so daß man von unten bis zur Embryonalschale Einblick erhält; der Hautsaum am Spindelrande ist breit.

$$
D=5, \quad d=4 m m .
$$

Verbreitungsgebiet: Die Nordkarparthen in Ostschlesien, Galizien und Nordungarn; in den oberen und unteren Höhenlagen der Gebirge.

\section{Semilimax truncatus Boettger:}

Taf. 15, Fig. 136 bis 141.

Vitrina truncata Boettger, Nachrichtsblatt d. D, malak. Ges, p. 184, 1884.

- carinthiaca Westerlund, Fauna, I, p. 18, 1886.

Die Radula mit einem symmetrischen, dreispitzigen Mittelzahn und 11 asymmetrischen, dreispitzigen Seitenzähnen; auf diese folgen in einer Halbreihe über 25 stachelförmige Randzähne, von welchen die inneren eine schwache äußere Nebenspitze besitzen.

Die Sexualorgane zeigen im Vergleiche mit S. elongatus Drap. einen verhältnismäßig größeren birnförmigen Penis, eine länger gestielte Samenblase und eine längere Vagina, sonst aber die gleichen Verhältnisse.

Das Gehäuse ist sehr ähnlich demjenigen von S. elongatus Drap., erreicht jedoch immer größere Dimensionen; die zwei Umgänge nehmen langsamer zu, der Oberrand der Mündung ist gleichmäßiger im Bogen vorgezogen, der Spindelrand weniger ausgeschnitten und seichter konkav gebogen; die Basalfläche des Gehäuses ist hier breiter, der Hautsaum am Spindelrande jedoch wesentlich schmäler.

$$
D=6 \cdot 2, \quad d=4 \cdot 2, \quad H=2 \cdot 6 \mathrm{~mm} \text {. }
$$

Verbreitungsgebiet: Steiermark, Kärnten, Krain und das Küstenland.

\section{Semilimax brevis Férussac.}

Taf. 11, Fig. 84; Taf. 15, Fig. 142 bis 145.

Helicolimax brevis Férussac. Hist. moll, 1822.

Vitrina brevis Kobelt in Rossm., Icon., I, v. 5, Nr. 1402.

Die Radula mit symmetrischem, dreispitzigem Mittelzahn, auf diesen folgen in einer Halbreihe 11 asymmetrische und dreispitzige Seitenzähne, sowie über 20 stachelförmige Randzähne, von welchen die inneren noch eine schwache, äußere Nebenspitze besitzen.

Sexualorgane: Der keulenförmige, an seinem hinteren Ende blasenförmig verdickte und winkelig abgebogene Penis besitzt einen dünnen, langen und endständig inserierten Musc, retractor; das Vas deferens legt sich dem vorderen Ende des Penis an und verlauft von da unter einer bindegewebigen Membrane 
zum hinteren Ende desselben, wo es dem Musc. retractor genähert mündet; die kleine Samenblase ist sehr kurz gestielt; in das vordere Ende der Vagina mündet ein pfeilsackähnliches Anhangsorgan wie bei den anderen Arten dieser Gruppe.

Das Gehäuse ist sehr ähnlich jenem des S. elongatus Drap.; der Umriß desselben jedoch mehr rundlich oval mit deutlicher vorspringendem Gewinde, welches aus $13 / 4$ langsamer zunehmenden Umgängen besteht; dementsprechend ist der letzte Umgang nur um $1 / 3$ breiter wie das Gewinde und die Mündung weniger erweitert. Die Unterseite des Gehäuses ist so breit wie bei S. elongatus Drap., der Hautsaum am Spindeirande jedoch viel schmäler, die Oberseite des Gehäuses stärker gewölbt.

$$
D=6, \quad d=5, \quad H=3 \cdot 2 .
$$

Verbreitungsgebiet: Ich kenne diese Art, welche sich besonders durch die eigentümlichen Verhältnisse der Sexualorgane von den anderen Arten dieser Gruppe sicher unterscheiden läßt, nur aus Württemberg, Baden, der Lombardei und der Umgebung von Triest.

\section{Familia HELICIDAE.}

\section{Subfamilia Fruticicolinae.}

Der Kiefer hornartig fest, gürtelförmig und mehr oder minder halbkreisförmig gebogen; auf der Fläche sind dichtere oder weitläufigere Querstreifen oder Leistchen vorhanden, welchen an den Rändern Einkerbungen entsprechen, so daß dieselben feingezähnt erscheinen und die Zusammensetzung des Kiefers aus einzelnen Plättchen mehr oder minder deutlich erkennen lassen (Taf. 22, Fig. 182 b, Taf. 24, Fig. 187, 188 b, $189 a$ ).

Die Radula weist im allgemeinen kurze und verhältnismäßig kleine Zahnplatten auf, welche in zahlreichen Längs- und Querreihen angeordnet sind. Der symmetrische Mittelzahn ist so groß wie die benachbarten Seitenzähne, mit einer gut entwickelten Hauptspitze, aber 2 kurzen Nebenspitzen, welche mitunter nur angedeutet sind, so daß derselbe entweder deutlich dreispitzig oder einspitzig erscheint. Auf den Mittelzahn folgen in jeder Halbreihe 15 bis 35 Seiten- und Randzähne; dieselben sind zweispitzig mit langer Hauptspitze und kurzer äußerer Nebenspitze; vom 10. bis 15. Seitenzahn erfolgt bei einigen Arten eine Spaltung der Hauptspitze, ebenso treten bei den äußersten Randzähnen mitunter einige schwache Nebenspitzen auf, so daß dieselben mehrspitzig erscheinen. Die dem Mittelzahn benachbarten Seitenzähne besitzen schwächer entwickelte, oft undeutliche Nebenspitzen, dieselben gehen allmählich in die Randzähne über, bei welchen auch die Nebenspitzen gut entwickelt sind; eine deutliche Grenze zwischen Seiten- und Randzähnen ist aber hier nicht vorhanden. Mit Rücksicht auf die Dimensionen der einzelnen Zähne erscheinen der Mittelzahn und die inneren Seitenzähne stets am größten, die äußeren Seitenzähne werden allmählich kleiner und die äußersten Randzähne erscheinen zumeist sehr klein und rudimentär entwickelt.

Sexualorgane: Die Zwitterdrüse ist in den hinteren, spiralaufgerollten Leberlappen eingebettet und reicht bis in die obersten Windungen, dieselbe besteht aus zahlreichen Büscheln, welche einreihig in den Zwittergang münden (Taf. 24, Fig. 189 b). Der Zwittergang ist oft auffallend dick und lang und stellt ein engaufgewundenes Gekröse dar; das Divertikel ist undeutlich. Der Uterusschlauch ist eng gewunden und von der Prostata deutlich abgesetzt. Die kugelige, ovale, oft unregelmäßig geformte Samenblase ist zumeist deutlich vom Blasenstiele abgesetzt, der Blasenstiel mittellang bis lang und stets ohne Divertikel. Unterhalb des Blasenstieles münden in die Vagina einfache oder verästelte Glandulae mucosae, welche entweder paarig ader virtelständig angeordnet sind. Pfeilsäcke sind zumeist mehrfach vorhanden; gewöhnlich $1-2-4$, im letzteren Falle werden jedoch nur zwei entwickelte Pfeile gefunden. Bei einer Gruppe werden anstatt der: Pfeilsäcke pfeilsackähnliche Appendiculae beobachtet (Enomphatia Wstld.). 
Der verhältnismäßig lange Penis besteht aus einem vorderen, spindelförmig oder keulenförmig verdickten und einem hinteren, zylindrischen, dünneren Teile, welcher als Epiphallus bezeichnet wird; der Epiphallus geht in ein kurzes bis sehr langes Flagellum über; am Übergange des Penis in den Epiphallus inseriert der Musc. retractor. Das fadenförmige Vas deferens ist an der Einmündung in den Epiphallus deutlich abgesetzt.

Der Musc, retractor des rechten Augenträgers verlauft zwischen Penis und Vagina.

Das Gehäuse ist offen bis bedeckt genabelt, dünn bis festschalig, zumeist hornfarben mit heller bindenartiger Zone an der Peripherie, seltener kalkartig getrübt mit zwei dunklen Bändern. Die Skulptur besteht nebst deutlichen bis rippchenartigen Zuwachsstreifen aus einer mehr oder minder deutlichen Körnelung oder Runzelung der Oberfläche; daneben sind häufig feine Schuppen oder hinfällige Borsten vorhanden. Das Gewinde besteht aus 5 bis 6 regelmäßig zunehmenden Umgängen, der Mundsaum ist zumeist deutlich ausgebreitet und innen lippenartig verdickt.

Das Verbreitungsgebiet der Fruticicolinen umfaßt das ganze paläarktische Gebiet, wo sie als autochthone Höhenformen auch heute besonders in den Gebirgen in größter Formen- und Individuenzahl auftreten; nur wenige Arten gelangten entlang der Wasserläufe auch in die Ebenen und sind heute über sehr weite Gebiete verbreitet (Fruticicola hispida L., Monacha rubiginosa A. Schm.), die meisten Arten sind auf einzelne Gebirge oder Gebirgsteile beschränkt.

Die wechselnden Verhältnisse der Sexualorgane, welche bei den einzelnen Arten dieser Subfamilie beobachtet werden, bedingen die Zusammenfassung ähnlicher Formen in engere, natürliche Gruppen. Diese Merkmale der Sexualorgane erweisen sich für die einzelnen Gruppen als sehr konstant und charakteristisch. Unsicher und wenig charakteristisch erscheinen dafür die Merkmale der Gehäuse. Bei einigen Gruppen finden wir in den Eigentümlichkeiten der Skulptur wohl genügend auffallende und den Verhältnissen der Weichteile zumeist entsprechende Merkmale, wie Borsten und Schuppen; diese Gebilde sind jedoch sehr hinfällig und oft schwer nachzuweisen, so daß die Feststellung der Gruppe einwandfrei doch nur auf Grund der Untersuchung der Sexualorgane erfolgen kann. Bemerkenswert ist ferner das Auftreten von Konvergenzerscheinungen bei Aiten verschiedener Gruppen; so besitzen Formen der Fruticicola erjaveci Brus. und Monacha umbrosa C. Pfr,oder der Fruticicola zelebori Pfr. und Semifruticicola serbica Wagner nahezu übereinstimmende Gehäuse, aber wesentlich abweichende Verhältnisse der inneren Organe.

Nahe Beziehungen zeigen ferner die Formen dieser Subfamilie zu jenen der Xerophilinen; so erscheinen die Verhältnisse der Gehäuse, des Gebisses und der Sexualorgane bei den genannten Subtamilien im Gegensatze zu anderen Gruppen der Heliciden (Campylaeinae, Helicinae) auffallend ähnlich und lassen eine nähere Verwandtschaft derselben erkennen. Einen wesentlichen und konstanten Unterschied zwischen den genannten Subfamilien bildet nur die Lage des den Sexualorganen benachbarten Musc. retractor des entsprechenden Augenträgers, welcher bei den Formen der Fruticicolinae zwischen Penis und Vagina, bei den Xerophilinen stets frei neben denselben verlauft; alle übrigen sonst hervorgehobenen Unterschiede, wie das Vorhandensein oder Fehlen eines Musc. retractor penis, das hornfarbene, durchscheinende (Fruticicolinae) oder kalkartig weiße und dunkel gebänderte Gehäuse (Xeropliilinae) sind nicht konstant und werden überdies bei Formen beider Subfamilien beobachtet. Dem entgegengesetzt finden wir die eigentümlichen Verhältnisse der Sexualorgane bei den Fruticicolinen, so die Anordnung der Gland. mucos., die Mehrzahl und Anordnung der Pfeilsäcke in auffallend ähnlicher Weise auch bei den Xerophilinen.

Genus Fruticicola ex rect. mea.

(Frulicicola Held ex parte, Perforatella Schlüter ex parte, Xerocampylaea Kobelt, Trichia Hartm. ex parte).

Sexualorgane: Der spindelförmige Penis mit einem wesentlich dünneren Epiphallus von annähernd gleicher Länge; das Flagellum kurz bis mittellang; der Musc. retractor inseriert am Übergange des Penis in den Epiphallus. Die Vagina mit 4 paarweise und symmetrisch angeordneten Pfeilsäcken, von welchen 
nur die 2 äußeren Pfeile enthalten. Die in der Anzahl von 6, 8, 10 oder 12 vorhandenen Gland. mucosae sind nicht oder nur undeutlich (am Grunde) verästelt. Die ovale Samenblase mit mittellangem Blasenstiel. Die zwei Pfeile sind spitz und kaum gebogen, am unteren Ende oft etwas ringförmig eingeschnürt und leicht gerieft.

Das Gehäuse ist dünn- bis festschalig, durchscheinend hornfarben mit einer helleren Zone an der Peripherie oder weißlich opak mit 1 bis 2 dunklen Bändern; häufig sind Borsten vorhanden oder die Oberfläche erscheint gekörnelt mit deutlichen bis rippchenartigen Zuwachsstreifen, aber stets ohne Spiralskulptur; am Basalrande der Mündung ist häufig eine zahnartige Verdickung des Lippenkallus vorhanden.

Verbreitungsgebiet: Von den in Zentraleuropa beobachteten Formen dieses Genus sind nur einzelne Arten über einen großen Teil West- und Osteuropas verbreitet (Fruticicola hispida L, Fr. rufescens montana C. Pfr., Fr. sericea Drap.), zum großen Teile sind dieselben auf engere Bezirke innerhalb der Alpen, Karpathen oder der Balkangebirge beschränkt und diesen eigentümlich. Die Arten dieses Genus sind wohl sämtlich autochthone Höhenformen und finden sich auch heute in größter Verbreitung und Individuenzahl in den höheren Lagen der Gebirge, wo sie auch die Eiszeiten überdauert haben; nach eingetretener Änderung des Klimas wanderten diese Arten entlang der Hänge und Wasserläufe talwärts und gelangten so bis in das Hügel- und Flachland, wo sie aber auch heute vorzüglich in der Nähe der Wasserläufe beobachtet werden und so charakteristische Formen der Auen darstellen. Mit dieser Änderung des Wohnortes und der Lebensverhältnisse traten Erscheinungen der Anpassung auf, welche sich auch durch Änderung der äußeren Merkmale, besonders solcher der Gehäuse bemerkbar machen; so sehen wir bei den Arten dieses Genus eine auffallende individuelle Variation und schließlich auch bemerkenswerte Lokalformen auftreten. Die Merkmale solcher Lokalformen erscheinen jedoch noch wenig konstant und wir finden auch auf einem engbegrenzten Gebiet neben extrem entwickelten Formen die entsprechenden Übergänge. Da wie oben ausgeführt schon die scharfe Abgrenzung von Gruppen und Arten bei diesem Genus Schwierigkeiten bereitet und nur unter gleichzeitiger Berücksichtigung der Gehäuse sowie der Verhältnisse der Sexualorgane sicher durchführbar ist, erscheint das systematische Registrieren der zahlreichen individuellen Variationen sehr schwierig und auch zwecklos. In solchen Fällen erscheint mit der Feststellung der Variationsgrenzen einer Art die Aufgabe der Systematik erfüllt und nur jene Formen, welche in einem größeren Gebiete durch konstante Merkmale auffallen, sind durch eigene Bezeichnungen zu fixieren, doch genügt auch in solchen Fällen die Bezeichnung Höhenform (oreinos) oder Talform, da auf diese Weise das Auftreten oder Überwiegen gewisser Merkmale angedeutet wird. Die Höhenformen dieses Genus in Höhenlagen über $1000 m$ zeichnen sich im allgemeinen durch geringere, jedoch auch auf engbegrenztem Fundorte sehr wechselnde Dimensionen, eine lebhaftere, dunklere Färbung sowie eine kräftigere Skulptur aus; freilich erscheint die Epidermis bei Höhenformen schon am lebenden Tier mehr oder minder verwittert, so daß die genannten Merkmale undeutlich werden.

In der alpinen Region scheinen die Dimensionen, welche die Gehäuse mancher Höhenformen erreichen, wesentlich durch die jeweilige Dauer der Sommerperioden bedingt zu sein; in kurzen Sommerperioden wird das Wachstum solcher Formen vorzeitig abgeschlossen, was besonders durch die Bildung eines charakteristischen Mundsaumes auch bei Exemplaren mit einer geringeren Windungszahl zum Ausdruck gelangt. Solche Exemplare sind zum Teile auch schon geschlechtsreif und ist diese Erscheinung als Anpassung an die ungleichen Sommerperioden aufzufassen, welche das Aussterben der Art hintanhaltet.

Mit abnehmender Seehöhe werden die Gehäuse einer bestimmten Art im allgemeinen größer, die Färbung heller, die Skulptur gleichmäßiger und feiner; die Oberfläche des Gehäuses ist hier widerstandsfähiger oder wird weniger durch Witterungseinflüsse in Anspruch genommen; so findet man hier zarte Cuticulargebilde, wie Haare, Borsten und Schuppen besser entwickelt und weniger hinfällig.

Im Nachfolgenden werden die im Gebiete von Österreich und Ungarn sowie in den angrenzenden Balkanländern beobachteten Formen des Genus Fruticicola ex rect. mea angeführt. 


\section{Subgenus Fruticicola s. str. \\ Formenreihe der Fruticicola erjaveci Brusina.}

Verbreitungsgebiet: Westliche Balkanländer von der Save bis nach Mazedonien.

\section{Fruticicola erjaveci Brusina.}

Taf. 16, Fig. $146 a$ bis g.

Fruticicola erjaveci Brusin a, Contribution à la Malacologie de la Croatie, p. 26, 1870.

Trichia erjaveci Kobelt, in Rossm., Icon., 1I, v. 5, Nr. 726, 1891.

- blaui Kobelt, in Rossm., Icon., II, v. 5, Nr. 727, 1891.

Die Radula mit dreispitzigem Mittelzahn und 30 Seiten- und Randzähnen; der Mittelzahn mit schlanker Hauptspitze und schwach entwickelten Nebenspitzen; die Seiten- und Randzähne zweispitzig, nur die äußersten Randzähne durch das Auftreten von Nebenspitzen dreizähnig.

Der Kiefer mit zahlreichen queren Leistchen.

Sexualorgane: Der Penis ist bauchig spindelförmig mit einem verhältnismäßig dünnen, aber längeren Epiphallus und einem kurzen Flagellum; die ovale Samenblase mit einem mittellangen Blasenstiel; die Gland. mucos. bestehen aus 8 bis 12 ungeteilten Schläuchen; die übrigen Verhältnisse typisch.

Das Gehäuse ist breit kegelförmig mit flach gewölbter Basis, ziemlich dünnschalig aber fest; gelblich weiß, mehr oder minder milchig opak, mattglänzend und durchscheinend. Die Skulptur besteht neben feinen und ungleichmäßigen Zuwachsstreifen aus einer sehr feinen Körnelung, der letzte Umgang ist mitunter vor der Mündung schwach gehämmert. Das breit- bis flachkegelförmige Gewinde besteht aus 5 bis 6 gewölbten, ziemlich langsam und regelmäßig zunehmenden Umgängen, welche durch eine ziemlich tiefe Naht geschieden werden; der letzte ist gerundet oder undeutlich kantig und steigt vorne ziemlich tief herab. Die querovale Mündung wird durch den vorletzten Umgang wenig ausgeschnitten und ist breiter als hoch; der weiße, dünne Mundsaum ist ziemlich entfernt vom Rande mit einer mehr oder minder dicken Lippe versehen, welche am Basalrande mitunter stärker schwielenartig vorspringt; die Insertionen des Mundsaumes sind mehr oder minder genähert, der Oberrand gerade, der Außen- und Basalrand erweitert und leicht umgeschlagen, der Spindelrand an der Insertion nur sehr kurz über den Nabel zurückgeschlagen. Der mittelweite, perspeltivische Nabel ist bald enger, bald weiter, erreicht jedoch nur ausnahmsweise $1 / 4$ vom Durchmesser der Basis.

$$
D=13,10,15, \quad d=11,8 \cdot 5,12, \quad H=8,5,8 \mathrm{~mm} .
$$

Das Verbreitungsgebiet dieser Art beginnt südlich der Save, erreicht also noch die Südostalpen und erstreckt sich anscheinend über den ganzen Westen der Balkanhalbinsel ausschließlich der dalmatinischalbanischen Küstenzone, also von Kroatien über Bosnien, die Hercegovina und Montenegro bis nach Mazedonien; in diesem Gebiete wurde Fr. erjaveci Brus. sowohl in den Höhen-, als Talregionen beobachtet und erscheint dementsprechend mit Rücksicht auf das Gehäuse in zahlreichen Lokalformen.

Bei der Beurteilung dieser Lokalformen gehe ich von Exemplaren aus der Umgebung von Agram aus, welche als historischer Typus aufzufassen sind; dieselben stellen eine verhältnismäßig große, einfärbig lichte Talform mit zumeist flachkegelförmigem, niedrigen Gewinde, einer schwachen Streifung und Körnelung, sowie einem verhältnismäßig weiten Nabel dar. Auch bei dieser Form finden wir die Verhältnisse des Gehäuses mit Rücksicht auf seine Dimensionen, die Höhe des Gewindes, die Zahl der Umgänge, den vor der Mündung mehr oder minder tief herabsteigenden letzten Umgang, die Weite des Nabels sehr veränderlich und veranlassen mich, diesen Merkmalen bei der Abgrenzung der zahlreichen Lokalformen eine geringe Bedeutung zuzuerkennen.

Der typischen Form aus der Umgebung von Agram entsprechen Exemplare von den Lokalitäten: Kostajnica, Krušedol und Brušane in Kroatien. Aus der Umgebung von Travnik und Sarajevo in Bosnien 
besitze ich ferner Exemplare, welche sich von der typischen Form durch die dunklere hornbraune bis rotbraune Färbung mit einer hellen Zone an der Peripherie, den außen gelbbraun durchscheinenden Lippenkallus, sowie mitunter bedeutendere Dimensionen unterscheiden.

$$
D=16, \quad d=13 \cdot 5, \quad H=9 \mathrm{~mm} .
$$

Der Nabel ist bei einzelnen Exemplaren wohl enger, im allgemeinen aber so variabel wie beim Typus; diese Form entspricht wohl der Fruticicola blani Kobelt, welche ich mit Rücksicht auf die geringen und durch Übergänge vermittelten Unterschiede mit der typischen Form vereine.

\section{Fruticicola erjaveci hirei Clessin.}

Taf. 16, Fig. $147 a$ bis $c$, Fig. 148; Taf. 17, Fig. $149 a$ bis $c$.

Helix hirci Clessin, Mal. BI. N. F., IV., p. 198, 1883.

Das Gehäuse ist konstant viel enger genabelt wie bei der typischen Form, der letzte Umgang weniger zusammengedrückt, vorne weniger herabsteigend; die Mündung weniger schief und höher, oft so breit als hoch; der Mundsaum kürzer ausgebreitet, schwächer gelippt, die Insertionen desselben weniger genähert; die Oberfläche ist rauher, indem die Zuwachsstreifen und die Hämmerung stärker, die Körnelung aber schwächer erscheint. Die Färbung ist gelbbraun mit einer hellen Binde an der Peripherie, das Gewinde oft mehr erhoben, die Umgänge zahlreicher und langsamer zunehmend.

$$
\begin{array}{llll}
D=14, & d=12, & H=8-10 \mathrm{~mm} ; \text { vom Berge Risnjak, } 1400 \mathrm{~m} . \\
D=15, & d=13, & H=9 \cdot 5-10 \mathrm{~mm} ; \text { vom Berge Grleš. } \\
D=16 \cdot 5, & d=14, & H=10.5 \mathrm{~mm} ; \text { von Pazarisk. } \\
D=11-14, & d=9 \cdot 5-12, & H=7-10 \mathrm{~mm} ; \text { von der Kapela bei Jezerane. } \\
D=12-15 \cdot 5, & d=10 \cdot 5-13, & H=8-10.5 \mathrm{~mm} ; \text { von der Visočica im Velebit. }
\end{array}
$$

Fundorte: Die Berge Risnjak, Grleš, Veliki Obruč, Veliki Papuk in der großen Kapela, die kleine Kapela bei Jezerane, Metla bei Trnovac, Visočica und Badanj im Velebit, Postak, Ciginovac an den Plitvicer Seen. Fruticicola erjaveci hirci Clessin ist eine Höhenform der Fr. erjaveci Brus., welche in höheren Lagen Kroatiens (bis $1600 \mathrm{~m}$ ) auftritt und sich hier durch konstante Merkmale von der typischen Form unterscheidet, dabei zeigen jedoch die Exemplare der verschiedenen Lokalitäten nicht unbeträchtliche Unterschiede; so besitzt die Form von der Visočica im südlichen Velebit (Taf. 17, Fig. 149) einen sehr engen Nabel, eine gedrückt kugelige Form, entfernte Insertionen des Mundsaumes, daß anscheinend eine von Fr. erjaveci Brus. vollkommen abweichende Form vorliegt. Die mir bekannt gewordenen Übergänge veranlassen mich jedoch, alle diese Lokalformen als Höhenform der Fr. erjaveci aufzufassen und unter der vorstehenden Bezeichnung zusammenzufassen.

\section{Fruticicola erjaveci osoria Brancsik.}

Taf. 17, Fig. $152 a$ bis c, Fig. $153 a$ bis $c$.

Helix osoria Brancsik, Naturw. Verein des Trencsiner Komitats, p. 69, t. 2, Fig. 4, 1889.

- haueri Brancsik, 1. c., t. 2, Fig. 3.

- tanora (Servain) Kobelt, in Rossm., Icon., II, v. 5, Ni. 728, 1891.

mortella (Servain) Kobelt, in. Rossm., Icon., II, v. 5, Nr. 729, 1891.

- cavarella (Servain) Westeriund, Fauna, II, p. 45, 1889.

Gehäuse festschaliger als bei der typischen Form und lebhafter gefärbt, gelbbraun bis rotbraun mit einer hellen Zone an der Peripherie. Das abgerundet kegelförmige, mehr oder minder erhobene Gewinde besteht aus 5 bis $6 \frac{1}{4}$ langsamer zunehmenden, flacher gewölbten und durch eine seichtere Naht geschieđenen Umgängen; der letzte ist gerundet oder nur undeutlich kantig und steigt vorne langsamer und weniger herab. Der Mundsaum ist kürzer ausgebreitet, kaum umgeschlagen, mit einem dünneren oft nahezu 
obsoleten Lippenkallus, die Insertionen desselben sind weniger genähert. Der Nabel ist stets viel enger und mißt nur $1 / 7$ bis $1 / 10$ vom Durchmesser der Basis.

$$
\begin{array}{lll}
D=10-12, & d=8-10, & H=6-7 \mathrm{~mm} ; \text { aus dem Miljackatal. } \\
D=9-17, & d=7 \cdot 5-14, & H=5 \cdot 8-10 \mathrm{~m} ; \text { von der Treskavica. } \\
D=10, & d=8 \cdot 5, & H=6 \mathrm{~mm} ; \text { von der Bjelasnica. }
\end{array}
$$

Die Verhältnisse der Radula und der Weichteile wie bei der typischen Form.

Fundorte: Das Miljackatal bei Sarajevo, Treskavica, Bjelasnica, Tisovica am Prenj, Igman, Metalkasattel bei Čajnica in Bosnien und Ljubetin in der Sar planina nördlich von Üsküb in Altserbien.

In höheren Lagen bleiben die Gehäuse der Fr. erjaveci osoria Brancs. kleiner, das Gewinde ist zumeist niedriger, die Zuwachsstreifen stärker; ich bezeichne diese Höhenform als:

\section{Fruticicola erjaveci osoria oreinos n.}

Taf. 18, Fig. $154 a$ bis $d$.

Fundorte: Ljubična und Radovina bei Celebič in Bosnien. Diese Form bildet einen Übergang zu der Höhenform des Durmitorgebietes.

\section{Fruticicola erjaveci costulata Wohlberedt.}

Taf. 18, Fig. 156 a bis $c$.

Fruticicola haueri var. costulata Wohlberedt, Fauna Montenegros und Nordalbaniens, p. 46, 1909.

Gehäuse immer viel kleiner mit konvexem, breit kegelförmigem Gewinde und kräftigen bis rippchenartigen Zuwachsstreifen; die 51/2 Umgänge nehmen langsamer zu, der letzte steigt vorne wenig und langsam herab. Der Mundsaum ist kurz oder kaum ausgebreitet, die Insertionen desselben entfernt.

$$
D=6 \cdot 5-8 \cdot 5, \quad d=5 \cdot 5-7 \cdot 5, \quad H=4 \cdot 5 \mathrm{~mm} .
$$

Fundorte: Bubatov Kuk, Volujak (2000 m), Prutaš (1800 bis 2000 m) und Begova brda im Durmitorgebiet Montenegros.

Fruticicola erjaveci leptolasia A. J. Wagner.

Taf. 17, Fig. $150 a$ bis $c$; Taf. 18 , Fig. $155 a$ bis $c$.

Fruticicola erjaveci leptolasia A. J. W agner. in Verbandl. d. k. k. zoolog. botan. Ges. Wien, p. 4, 1912.

Das Gehäuse kleiner, dünnschaliger, rötlich hornfarben mit einer hellen Zone an der Peripherie; die Oberfläche ist sehr fein gekörnelt, daneben sind Haarnarben sowie kurze und sehr hinfällige Borsten vorhanden. Das breit kegelförmige, häufig leicht konvexe Gewinde besteht aus $4^{1} / 2$ bis $5^{1 / 2}$ Umgängen; der Nabel ist sehr eng bis stichförmig.

$$
D=7-11 \cdot 5, \quad d=6-10, \quad H=4 \cdot 5-7.5 \mathrm{~mm} .
$$

Fundorte: Am Vlasič bei Travnik und in der Umgebung von Jablanica in Bosnien.

\section{Fruticicola erjaveci flörickei Kobelt}

Taf. 18 , Fig. $157 a$ bis f, Fig. $158 a$ bis $b$, Fig. $159 a$ bis $b$; Taf, 19, Fig. 160 a bis $c$

Enwmphalia flörickei Kobelt, in Rossm., Icon., II, v. 9, Nr. 1622, 1623, 1901.

Das Gehäuse ist durchschnittlich festschaliger und größer wie bei Fr. erjaveci Brus., mit einer rauhen und unebenen Oberfläche, indem neben ungleichmäßigen Rippenstreifen auch eine deutliche Hämmerung und Körnelung sowie kurze, eingedrückte Querlinien sichtbar sind; gelblichweiß, gelbbraun 
bis rotbraun mit hellen bis weißen Zonen an der Naht und Peripherie. Das zumeist flachkegelförmige und leicht konvexe Gewinde besteht aus 6 bis $6 \frac{1}{2}$ langsamer zunehmenden Umgängen; der letzte ist gerundet oder undeutlich kantig und steigt vorne weniger herab, ebenso sind die Insertionen des Mundsaumes weniger genähert. Der ziemlich veränderliche Nabel mißt $1 / 5$ bis $1 / 7$ vom Durchmesser der Basis.

$$
\begin{array}{llll}
D=17, & d=14, & H=9 \mathrm{~mm} ; \text { von der Skakala am Durmitur. } \\
D=12-16, & d=10 \cdot 2-13 \cdot 5, & H=7 \cdot 5-9 \cdot 5 \mathrm{~mm} ; \text { von Bušat im Komgebiet. } \\
D=11 \cdot 5, & d=9 \cdot 6, & & H=7 \mathrm{~mm} ; \text { von Kolašin. } \\
D=15, & d=13 \cdot 5, & H=9.5 \mathrm{~mm} ; \text { vom Durmitor. }
\end{array}
$$

Die Verhältnisse der Radula und der Sexualorgane entsprechen vollkommen der Fr. erjaveci Brus. von Agram.

Verbreitungsgebiet: Exemplare, welche der Beschreibung und Abbildung Kobelt's vollkommen entsprechen, kenne ich von den Lokalitäten: Bušat im Komgebiet, Koritnikgebirge, Skakala (1500 m) und Skrečko jezero $(1750 \mathrm{~m}$ ) vom Durmitor; Exemplare von Kolašin in Montenegro sind kleiner, enger genabelt, mit schwächeren Rippenstreifen und undeutlicher Hämmerung; am Durmitor und der benachbarten Bjalašica bei Gačko in der Hercegovina finden sich neben typischen Exemplaren auch enger genabelte, glattere Gehäuse, welche auffallend der Fr. erjaveci hirci Clessin gleichen und ohne Kenntnis des Fundortes kaum von dieser Form zu unterscheiden sind.

Die einzelnen Formen der Fruticicola erjaveci Brus, werden in nahe Beziehungen zu Arten der Gruppen Monacha Hartm., Theba Risso, Euomphalia Wstld. gebracht, mit welchen sie lediglich mit Rücksicht auf die Gehäuse so auffallend übereinstimmen, daß eben nur der Vergleich der Sexualorgane eine sichere Unterscheidung ermöglicht.

Eine auffallende Konvergenz der Schalenmerkmale wird zwischen nachstehenden Formen beobachtet: Fruticicola erjaveci Brus. typus und Monacha mmbrosa C. Pfr. Die Gehäuse der letzteren Art sind im allgemeinen dünnschaliger, besitzen eine geringere Zahl rascher zunehmender Umgänge, einen durchschnittlich weiteren Nabel, mehr entfernte Insertionen des Mundsaumes, einen deutlicher gekielten letzten Umgang; alle diese Merkmale sind jedoch bei beiden Formen sehr veränderlich und lassen mitunter vollkommen im Stich; um so auffallender sind die Unterschiede in den Verhältnissen der Sexualorgane, da Monacha imbrosa C. Pfr. nur einen Pfeilsack mit einem gekrümmten Pfeil, einen langen schlanken Penis und Epithallus mit einem sehr langen peitschenartigen Flagellum und einen langen Blasenstiel aufweist.

Fruticicola erjaveci hirci Clessin und Euomphalia strigella Drap.

- erjaveci osoria Brancs. und Monacha fallax A. J. Wagner.

- evjaveci flörickei Kob. und Theba orsinii Porro (nach P. Hesse).

\section{Fruticicola rufescens montana C. Pfeiffer.}

Taf. 16, Fig. $151 a-d$.

Helix montana C. Pfeiffer, Naturgesch., III, p. 23, t. 6, Fig. 9, 1828.

striolata C. Pfeiffer, Naturgesch., III, p. 28, t. 6, Fig. 8, 1828.

- circinata Roßmäßler, Icon., I, v. 1, Nr. 12.

Frnticicola mufescerts var, damubialis Ciessin, Deutsche Excursions-Mollusken-Fauna, p. 157, 1884.

Die Sexualorgane zeigen eine wesentliche Übereinstimmung mit jenen der Fr, erjaveci Brus., nur das Flagellum und der Blasenstiel erscheinen etwas länger. Auch die Gehäuse sind jenen der Fr. erjaveci 
Brus, ähnlich, besitzen jedoch keine Spur der für diese Art charakteristischen feinen Körnelung, dafür aber deutlichere und dichtere Zuwachsstreifen. Das Gewinde weist bei gleich großen Gehäusen einen halben Umgang mehr auf, auch nehmen die Umgänge deutlich langsamer zu; der Nabel ist durchschnittlich enger und die Insertionen des Mundsaumes mehr entfernt. Diese Art zeigt also sehr nahe Beziehungen zu Fr. crjaveci Brus., läßt sich jedoch von derselben stets und besonders durch die Skulptur unterscheiden.

Fruticicola rufescens montana C. Pfr. gehört zu einer westeuropäischen Formenreihe, welche mit Rücksicht auf die Merkmale des Gehäuses ebenso veränderlich ist wie Fr. erjaveci Brus.; das Verbreitungsgebiet dieser Formenreibe umfaßt England, Frankreich, West- und Süddeutschland, die Schweiz, Salzburg und Oberösterreich und reicht entlang der Donauauen noch bis Wien und Preßburg. In Niederösterreich ist diese Art auf die Donauauen beschränkt und findet sich auf den benachbarten Höhen, so dem Wiener Wald, nicht mehr; im Gebiete der Traun, Salzach und im Inntal scheint dieselbe jedoch weit verbreitet zu sein und wurde von Professor Geyer aus Stuttgart sogar in einer Höhenform am Schafberg bei $1700 m$ gesammelt. Die Gehäuse dieser Höhenform sind kleiner, rotbraun gefärbt und kräftiger bis rippchenartig gestreift; Fr. rufescens montana oreinos n.

\section{Fruticicola villosa Draparnaud.}

Helix villosa Drap., Hist, nat. moll., 1805.

- - RoBmäBler, Icon., I, v. 2, Nr. 421.

Die anatomischen Verhältnisse dieser Art sind mir unbekannt und erfolgt ihre Einteilung bei dieser Gruppe nur mit Rücksicht auf das Gehäuse.

Verbreitungsgebiet: Fruticicola villosa Drap. kommt vorzüglich im Gebiete der Westalpen vor und erreicht nur in Vorarlberg und dem oberen Lechtale das Gebiet der Monarchie; in Kärnten wurde diese Art durch H. v. Gallenstein nicht nachgewiesen, so dürften die älteren Angaben über dieses Vorkommen unrichtig sein.

Fruticicola villosula Roßmäßler.

Helix villosa var. villosula Roßmäß1er. Icon., I, v. 2, sub Nr. 421.

- pietruskyana C. Pfeiffe, i! Mart. Chemn., ed. II, t. 148, Fig. 11.

Trichia pietruskyana Kobelt, in Rossm., Icon., 1I, v. 5, Nr. 752.

Die anatomischen Verhältnisse dieser Art sind unbekannt, die Einteilung bei der vorstehenden Gruppe erfolgte nur mit Rücksicht auf die Verhältnisse des Gehäuses.

Verbreitungsgebiet: Die West- und Nordkarpathen in Mähren, Nordungarn und Galizien.

\section{Fruticicola hispida Lin né.}

Taf. 19, Fig. 164.

Helix hispida Linné, Syst, nat, X, p. 771, 1758.

Die Radula mit einem dreispitzigen, symmetrischen Mittelzahn sowie 23 zweispitzigen Seiten- und Randzähnen in einer Halbreihe.

Sexualorgane: Der Penis, Epiphallus und das Flagellum von annähernd gleicher Länge; die ovale Samenblase mit dünnem, mittellangem Blasenstiel: die Gland. mucos. bestehen aus 8 Schläuchen; die übrigen Verhältnisse typisch.

Verbreitungsgebiet: Das ganze paläarktische Gebiet. Von den zahlreichen Lokalformen, welche mit Rücksicht auf die ziemlich veränderlichen Verhältnisse des Gehäuses unterschieden werden, erwähne ich hier nur eine Höhenform der nördlichen Kalkalpen. 


\section{Fruticicola hispida oreinos n.}

Gehäuse kleiner aber festschaliger, mit einem kräftigen, außen gelblichweiß durchscheinenden Lippenkallus, welcher am Basalrande zahnartig vorspringt; glänzend, sehr fein gekörnelt, mit kräftigen, ungleichmäßigen Zuwachsstreifen, aber stets ohne Borsten; der letzte Umgang mit einer deutlichen Kante.

$$
D=6-7, \quad d=5 \cdot 6, \quad H=3-3 \cdot 5 \mathrm{~mm} .
$$

Fundort: Hochschwab in Höhenlagen um $2000 \mathrm{~m}$.

\section{Fruticicola coelata Studer.}

Helix coelata Studer, Syst. Verz., p. 12, 1820.

Fruticicola coelata $\mathrm{Cles}$ in, Deutsche Excursions-Mollusken-Fauna, p. 154, 1884.

Die anatomischen Verhältnisse sind mir unbekannt.

Verbreitungsgebiet: Das Gebiet der Westalpen in Frankreich, der Schweiz und Süddeutschland; innerhalb der Monarchie habe ich diese Art nur im Trauntal bei Aussee und Gmunden nachgewiesen.

\section{Fruticicola sericea Draparnaud.}

Taf. 19, Fig. 165

Helix sericea Draparnaud, Tabl. p. 85, 1801, Hist. moll, Taf. 7, Fig. 16 bis $17,1805$.

Die Radula mit einem symmetrischen dreispitzigen Mittelzahn und 24 zweispitzigen Seiten- und Randzähnen in einer Halbreihe.

Sexualorgane: Der Penis, Epiphallus und das Flagellum sind annähernd gleich lang, der Blasenstiel mittellang; die Gland. mucos. bestehen aus 6 Schläuchen; die übrigen Verhältnisse sind typisch.

Verbreitungsgebiet: Eine genaue Abgrenzung des Verbreitungsgebietes dieser Art wird besonders durch den Umstand erschwert, daß die Gehäuse derselben auffallend jenen der Monacha mibiginosa A. Schm. gleichen und nur der Vergleich der Sexualorgane die Unterscheidung mit Sicherheit ermöglicht. Nach meinen Beobachtungen gehört Fruticicola sericea Drap. vorzüglich der westeuropäischen Region an und erreicht das Gebiet der Monarchie nur in Tirol und vielleicht in Salzburg und Oberösterreich. In Tirol kenne ich diese Art sowohl aus der Talregion (var. liberța Wstld. von Innsbruck), als aus höheren Gebirgslagen, so von Ried, Nanders $(1300 \mathrm{~m}$ ), Trins im Gschnitztal (an diesen Lokalitäten als Forma oreinos). Aus den Ostalpen ist mir noch keine sichere Fundortsangabe bekannt geworden und im Donautale habe ich nur Frnticicola lubomirskii Slosarski nachgewiesen, welche die vorstehende Art in den Karpathen ersetzt.

\section{Fruticicola lubomirskii Slosarski.}

Helix lubomirskii Slosarski, Materiały do Fauny malakologicznei Królewstwa polskiego, 1881. clessini Ulicny, Malak. BI., v. 7, p. 1 bis $8,1884$.

Verbreitungsgebiet: Die West-, Nord- und Ostkarpathen vom Donautale in Niederösterreich über Mähren, Schlesien, Galizien, Nordungarn bis nach Siebenbürgen; ferner die Sudeten in Böhmen und Schlesien.

\section{Fruticicola waldemari A. J. Wagner.}

Taf. 19, Fig. $163 a$ bis $c$.

Frulicicola waldemari A. J. Wagner, Verhandlungen der k. k. zoolog.-botan. Ges., p. 250, WVien, 1912.

Gehäuse flach kegelförmig mit gewölbter Basis, dünnschalig, durchscheinend und leicht glänzend, gelblich weiß oder gelbbraun mit einer hellen Zone an der Peripherie, mitunter etwas milchig getrübt. Die 
Skulptur besteht nebst feinen, etwas ungleichmäßigen Zuwachsstreifen atıs sehr feinen, nur unter der Lupe sichtbaren Runzeln der Epidermis ohne Spur von Haarnarben. Das flach kegelförmige Gewinde besteht aus 5 bis $5 \frac{1}{2}$ flach gewölbten, ziemlich rasch zunehmenden Umgängen, welche durch eine ziemlich seichte Naht geschieden werden; der letzte ist fast doppelt so breit wie der vorletzte, im Beginne stumpfkantig, vor der Mündung nahezu gerundet und steigt vorne langsam, aber nicht sehr tief herab. Die breitovale, schiefe Mündung wird durch den vorletzten Umgang wenig ausgeschnitten. Der dünne, innen sehr schwach gelippte Mundsaum ist sehr kurz ausgebreitet, oben gerade, die Insertionen desselben wenig genähert. Der enge bis stichförmige Nabel wird durch den Spindelumschlag teilweise bedeckt.

$$
D=11-13, \quad d=9-11, \quad H=7-8 m m .
$$

Die anatomischen Verhältnisse sind unbekannt.

Fundorte: Die Umgebung von Sarajevo, Jajce und Bočac in Bosnien.

Von der ähnlichen Fr. hubomirskii Slos, unterscheidet sich vorstehende Art durch ihre bedeutenderen Dimensionen, das niedrigere Gewinde, die rascher zunehmenden, weniger gewölbten Umgänge, den kantigen, vorne tiefer herabsteigenden letzten Umgang und die feingerunzelte, aber haarlose Epidermis.

\section{Fruticicola zelebori Pfeiffer.}

Taf. 19, Fig. $161 a$ bis $f$ und Fig. $162 a$ bis $c$.

Helix zelebori Pfeiffer in: Zeitsclur. f. Mal. p. 186, 1853.

Xerocampylaea zelebori Kobelt, Rossm. Icon, I, v. 6, Nr. 1562, 1563, 1878.

Helix zelebori autor, part.

Die Radula mit dreispitzigem symmetrischen Mittelzahn und 35 zweispitzigen Seiten- und Randzähnen in einer Halbreihe; die äußersten, rudimentären Randzähne erscheinen durch das Auftreten einer zweiten Nebenspitze dreispitzig. Der Kiefer typisch.

Sexualorgane: Der bauchig spindelförmige Penis mit einem wenig dünneren Epiphallus und kurzem Flagellum ist kürzer als bei Fr. erjaveci Brus.; der Blasenstiel mittellang, die Gland. mucos. bestehen aus 8 Schläuchen; die übrigen'Verhältnisse sind typisch.

Das Gehäuse flachkegelförmig oder gedrückt kugelig, eng bis stichförmig genabelt, ziemlich dünnschalig glänzend mit feinen, etwas ungleichen Zuwachsstreifen; die Grundfarbe ist milchweiß oder gelblich opak, mit zwei gelbbraunen bis dunkelkastanienbraunen, durchscheinenden und scharfbegrenzten Bändern über und unter der Peripherie; mitunter wird das untere Band dünner und schwächer oder verschwindet vollkommen. Das regelmäßig kegelförmige Gewinde ist breit bis flachkegelförmig und besteht aus 5 bis $5^{3} / 4$ ziemlich rasch zunehmenden, gewölbten und durch eine deutlich eingedrückte Naht geschiedenen Umgängen; der letzte ist vorne doppelt so breit wie der vorletzte, gleichmäßig gerundet und steigt vorne langsam, aber ziemlich tief herab. Die schiefe, breitovale Mündung wird durch den vorletzten Umgang wenig ausgeschnitten und ist im Gaumen weiß mit lebhaft durchscheinenden Bändern. Der dünne, scharfe Mundsaum ist oben gerade, nur entsprechend dem Basalrande kurz ausgebreitet, an der Spindelinsertion umgeschlagen und den Nabel mehr oder minder verdeckend; innen mit einem dünnen weißen Lippenkallus; die Insertionen des Mundsaumes sind ziemlich genähert.

$$
D=10-14, \quad d=8-11, \quad H=6-9 \mathrm{~mm} .
$$

Verbreitungsgebiet: Ich beurteile diese Art zunächst nach Exemplaren aus der Umgebung von Višegrad im Drinatal in Südostbosnien, welche auch Kobelt als historischen Typus betrachtet; die entsprechende Form kenne ich ferner aus der Umgebung von Sarajevo, aus Serbien und dem Banat. An diescn Lokalitäten beobachtete ich nur geringe Abweichungen des Gehäuses mit Rücksicht auf die Höhe des Gewindes, die mehr oder minder rasch zunehmenden Umgänge und die Nabelweite. Die Angaben über das Vorkommen der Fr. zelebori Pfr. in Südwestbosnien und Montenegro beziehen sich auf Formen 
welche wohl ein auffallend ähnliches Gehäuse, aber vollkommen abweichende Verhältnisse der Sexualorgane aufweisen und einer anderen Gruppe der Fruticicolinen angehören.

Subgenus Perforatella Schlüter 1838.

(Trochiscus Clessin.)

Das Gehäuse sehr eng, stichförmig bis bedeckt genabelt mit $5 \frac{1}{2}$ bis 7 langsam zunehmenden Umgängen und einem kräftig entwickelten Lippenkallus in der Mündung, welcher entsprechend dem Basalrande häufig zahnartig vorspringt. Die Skulptur besteht nebst feinen Zuwachsstreifen zumeist aus dichten und kurzen Borsten.

Die Radula und die Verhältnisse der Sexualorgane sind typisch.

\section{Fruticicola (Perforatella) unidentata Draparnaud.}

Taf, 20, Fig, $168 a$ bis $\varepsilon$.

Helix unidentata Draparnaud, Hist. moll, 1805.

- cobresiana Alten 1812.

- monodon Férussac.

Der Kiefer ist gürtelförmig, ziemlich dünn und biegsam mit über 20 Querleistchen, welchen an den Rändern Einkerbungen entsprechen.

Die Radula mit einem dreispitzigen, symmetrischen Mittelzahn und 22 zweispitzigen Seiten^ und Randzähnen.

Sexualorgane: Der bauchig spindelförmige Penis mit einem dünneren, etwas längeren Epiphallus und einem ziemlich langen, dünnen Flagellum. Die ovale Samenblase ist vom mittellangen, dünnen Blasenstiel nicht deutlich abgesetzt; die Gland. mucosae bestehen aus 8 Schläuchen.

Das Verbreitungsgebiet dieser Art erstreckt sich über das deutsche Mittelgebirge und die Nordkarpathen, ferner über die Ostalpen in Süddeutschland, Ober- und Niederösterreich, Nordtirol, Steiermark, Krain, Kärnten, die angrenzenden Gebiete von Westungarn und Nordkroatien. Wie weit diese Art in den Westalpen vordringt, ist mir nicht bekannt. Fruticicola unidentata Drap. ist eine autochthone Höhenform der Alpen und Nordkarpathen, wo sie regelmäßig und zahlreich auch in Höhenlagen von $2000 m$ auftritt und dann die für Höhenformen charakteristischen Merkmale des Gehäuses aufweist.

Exemplare von den oberen Höhenlagen des Schneeberges in Niederösterreich, der Raxalpe, dem Hochschwab (1800 bis $2000 \mathrm{~m}$ ) zeigen im allgemeinen geringere, aber sehr wechselnde Dimensionen, ein bald hohes, bald niedriges Gewinde mit $5^{1} / 2$ bis 6 Umgängen; die Borsten sind kürzer, dichter und sehr hinfällig, so daß auch lebende Exemplare häufig glatt erscheinen; der Nabel ist verhältnismäßig weiter wie bei der typischen Form, der Basalzahn des Lippenkallus nur schwach entwickelt und häufig obsolet.

\section{Fruticicola (Perforatella) unidentata alpestris Clessin.}

Taf. 20. Fig. $169 a$ bis $b$.

Helix midentata var, alpestris Clessin, Malak. Blätter, v. 25, p. 84, Taf. 3, Fig. 12, 1878.

Unter dieser Bezeichnung fasse ich alle Höhenformen dieser Art aus den Alpen und Karpathen zusammen, welche sich durch die oben angeführten Merkmale kennzeichnen lassen.

$$
\begin{array}{lll}
D=5, & d=4 \cdot 5, & H=3 \mathrm{~mm}, \\
D=7 \cdot 5, & d=6 \cdot 5, & H=4.5 \mathrm{~mm}, \\
D=7, & d=6, & H=4-5 \mathrm{~mm} .
\end{array}
$$


Entsprechend dem großen Verbreitungsgebiete und den wechselnden Verhältnissen, unter welchen Fr. midentata Drap. heute angetroffen wird, erscheinen die Gehäuse dieser Art auch in den Talregionen ziemlich veränderlich, was besonders durch die wechselnden Dimensionen, die verschiedene Höhe und Form des Gewindes, die Zahl der Umgänge, die Weite des Nabels, die Dichte und Länge der Borsten, sowie die Form der Mündung und des Lippenkallus zum Ausdruck kommt; die wesentlichen Merkmale der Art sind dabei aber so charakteristisch, daß eine Verwechslung mit anderen Arten dieser Gruppe leicht zu vermeiden ist.

Die Abbildung auf Taf. 20, Fig. $168 a$ bis $c$ ist nach einem Originalexemplar Draparnaud's aus dem Wiener Hofmuseum angefertigt, stellt also den historischen Typus dar. Diese typische Form hat jedenfalls die größte Verbreitung und findet sich besonders in den unteren Höhenlagen und der Talregion am Rande der nördlichen Kalkalpen, ebenso im deutschen Mittelgebirge und den Nordkarpathen; in den Nordkarpathen habe ich die typische Form jedoch nur auf die Talregion beschränkt gefunden, indem hier die Forma alpestris bereits in Höhenlagen unter $1000 m$ beobachtet wird.

\section{Fruticicola (Perforatella) edentula Draparnaud.}

Taf. 20, Fig. $167 a$ bis $b$.

Helix edentula Draparnaud, Hist. moll. Taf. 7, Fig. 14, 1805.

- depilata Draparnaud, Tableau syst. p. 72, 1801, nec. C. Pfr.

Auch diese Form wurde nach dem im Wiener Hofmuseum befindlichen Originalexemplare Draparnaud's angefertigt; dieselbe unterscheidet sich von Fr. midentata Drap. durch die flacher gewölbte Unterseite, dementsprechend eine engere, mehr sichelförmige Mündung; der engere Nabel wird durch den Spindelumschlag nahezu vollkommen bedeckt, der Basalzahn des Lippenkallus ist obsolet.

$$
D=8, d=7, \quad H=5.6 \mathrm{~mm} .
$$

Die Herkunft dieser Form ist nicht bekannt; Kobelt, Clessin und Westerlund kennen dieselbe nicht und beschreiben unter der Bezeichnung H. edentula Drap. andere Formen der Fr. midentata Drap. Eine auffallende Übereinstimmung mit Fr. edentula Drap. zeigen jedoch Exemplare der Fr. unidentata var. anodonta Tschapek aus dem Murtal in Steiermark; diese Form ziehe ich jedoch zur Formenreihe der Fruticicola leucozona C. Pfr. Schon Roßmäßler vergleicht Fr. edentula Drap. mit Fr. delopida Jan., welche ebenfalls zur Formenreihe der Fr. lencozona C. Pfr. gehört (Rossm. Icon., I, v. 1, p. 66), es ist also nicht ausgeschlossen, daß Draparnaud die vorstehende Form, wie ja bekanntlich auch weiteres Studienmaterial, aus Österreich und Steiermark erhalten hat (Cylindrus obtusus Drap.!).

\section{Fruticicola (Perforatella) subleucozona Westerlund.}

Taf. 20, Fig. $166 a$ bis $e$.

Perforatella unidentata var. sublencozona Westerlund, Fauna II, p. 32, 1889.

Sexualorgane: Der bauchig spindelförmige Penis mit einem dünneren, annähernd gleichlangen Epiphallus und einem ziemlich kurzen Flagellum; die übrigen Verhältnisse wie bei Fr. midentata Drap.

Das Gehäuse ähnlich der Fr. minidentata Drap., jedoch durchschnittlich kleiner, mit einem lochförmigen, verhältnismäßig weiteren Nabel und konstant niedrigerem, leicht konvexem Gewinde, welches aus $5 \frac{1}{2}$ bis 6 langsam zunehmenden Umgängen besteht; der letzte ist besonders auf der Unterseite flacher gewölbt, die Mündung enger und mehr sichelförmig. Die Skulptur besteht aus wesentlich weitläufigeren und längeren Borsten; der Lippenkallus ist niemals am Basalrande zahnartig verdickt.

$$
D=6 \cdot 5, \quad d=6, \quad H=4 \cdot 3 \mathrm{~mm} .
$$

Fundorte: In den Schluchten und Graben der Floning und des Rennfeldes bei Bruck/Mur, aber nicht mehr im Kalkgebiet des Hochschwab, wo ohne Übergänge Fr. minidentata Drap. auftritt. Diese Art zeigt 
nahe Beziehungen zu Fr. unidentata Drap. und Fr. leucozona C. Pfr., grenzt auch an die Verbreitungsgebiete dieser Arten, doch sind mir derzeit keine Übergangsformen bekannt geworden, ebenso ist der anatomische Befund nicht vollkommen übereinstimmend.

\section{Fruticicola (Perforatella) leucozona C. Pfeiffer. \\ Taf. 20, Fig. 170, Fig. $171 a$ bis $b$, Taf. 21, Fig. $172 a$ bis $f$.}

Helix lencozona C. Pfeiffer, Naturgesch., III, p. 34, t. 6, f. $19,1828$.

- - Roßmäßler, Icon., I, v. 2, Nr. 435 bis $436,1838$.

Der Kiefer gürtelförmig mit 20 bis 25 feinen Querleistchen, welchen an den Rändern Einkerbungen entsprechen.

Die Radula mit undeutlich dreispitzigem, symmetrischem Mittelzahn und 25 bis 30 zweispitzigen Seiten- und Randzähnen in einer Halbreihe.

Sexualorgane: Der spindelförmige Penis mit dünnerem, aber gleichlangem Epiphallus und ziemlich langem, peitschenförmigem Flagellum. Die ovale Samenblase ist von dem mittellangen Blasenstiel undeutlich abgesetzt; die Glandulae mucosae bestehen aus 8 Schläuchen; die übrigen Verhältnisse typisch.

Das Verbreitungsgebiet erstreckt sich über die östlichen Ausläufer der Zentralalpenzone in Ost- und Südsteiermark, sowie die südliche Kalkalpenzone in der Lombardei, Südtirol, Venetien, dem österreichischen Küstenland, Kärnten, Krain und Kroatien; wenig abweichende Lokalformen wurden in Bosnien, Setbien und in den Südkarpathen Siebenbürgens nachgewiesen.

Die Gehäuse dieser Art sind, wie schon Roßmäßler hervorhebt, sehr veränderlich und stellen eine Formenreihe dar, in welcher heute verschiedene Arten und zahlreiche Lokalformen unterschieden, zum Teile auch bei verschiedenen Gruppen untergebracht werden.

Gehäuse der typischen Form besitzen weder Haarnarben noch Borsten, dafür zeigt die Epidermis frischer Exemplare einen matten, reifartigen Anflug. Das aus 6 bis $61 / 2$ langsam zunehmenden Umgängen bestehende Gewinde ist auch bei Exemplaren einer eng begrenzten Lokalität bald kegelförmig erhoben, bald niedrig; der letzte Umgang kaum breiter wie der vorletzte, unten flacher, an der Peripherie gerundet oder stumpfkantig, vorne kaum oder nicht herabsteigend. Ebenso veränderlich erscheint der Nabel, welcher bald eng lochförmig aber offen, bald ritzförmig oder vollkommen bedeckt erscheint. Die Mündung wird durch den vorletzten Umgang wenig ausgeschnitten; der Mundsaum ist kaum erweitert, fast gerade, innen aber mit einem dicken, weißen Lippenkallus versehen, welcher sich unmittelbar vom Rande erhebt und nur entsprechend dem Oberrand etwas von demselben zurücktritt; am Basalrand ist der Lippenkallus häufig knotenförmig oder wulstig aber niemals zahnartig verdickt.

$$
\begin{aligned}
& D=7 \cdot 5, \quad d=6 \cdot 5, \quad H=5 \mathrm{~mm} \text { von Villach in Kärnten. } \\
& D=8, \quad d=7 \cdot 2, \quad H=5 \mathrm{~mm} \quad \text { " } \quad \text { " } \quad \text { " } \\
& D=9, \quad d=8 \cdot 5, \quad H=6 \mathrm{~mm} \quad \text { " } \quad \text { " } \quad \text { " } \\
& D=11, \quad d=10 \cdot 2, \quad H=7-8 \mathrm{~mm} \text { von Idria. }
\end{aligned}
$$

Verbreitungsgebiet: Die auf diese Weise begrenzte typische Form habe ich in den Tal- und unteren Höhenregionen von Südsteiermark, Kärnten, Krain, Nordkroatien, dem Küstenlande und in vollkommen übereinstimmenden Exemplaren auch am Monte Presolano in der Lombardei beobachtet; Gredler führt dieselbe auch aus Tirol an.

Fruticicola (Perforatella) leucozona ovirensis Rossmässler.

Taf. 21, Fig. $173 a$ bis $b$, Fig. 174.

Helix lencozona var. ovirensis Rossmässter, Icon., I, v. 2, Nr. 434.

Das Gehäuse durchschnittlich kleiner, mit verhältnismäßig weiterem Nabel, deutlicheren Zuwichsstreifen sowie häufig mit Haarnarben oder kurzen und hinfälligen. Borsten der Epidermis. Das zumeist 
niedrigere Gewinde besteht nur aus $5 \frac{1}{2}$ bis 6 Umgängen; der letzte ist weniger zusammengedrückt und häufig gerundet.

Fundorte: Die oberen Höhenregionen in Kärnten, Krain und dem Küstenlande, so am Hoch Obir, Dobratsch, der Bevčica, dem Grintove und Matajur. Fruticicola lencozona ovirensis Rssm. entspricht der Höhenform dieser Formenreihe und erscheint besonders dadurch bemerkenswert, daß ein Teil der Exemplare Haarnarben oder Borsten aufweist, wodurch ein Übergang zu der konstant borstigen Fruticicola lencozona lurida $\mathrm{C} . \mathrm{Pfr}$. vermittelt wird.

\section{Fruticicola (Perforatella) leucozona lurida C. Pfeiffer.}

Taf. 21, Fig. $175 a$ bis $b$, Fig. 176 und $177 a$ bis $i$.

Helix 7urida C. Pfe iffer, Naturgesch., III, p. 33, t. 6, f. 14 bis $15,1828$.

- - Rossm., Icon., I, v. 1, Nr. 360, 1837.

- filicina L. Pfeiffer, Symb., I, p. 39, 1841 und Mon., Hel. viv., v. 1, p. 141, 1848.

- Inrida var. separanda Roßmäß1er, Icon., I, v. 1, Nr. 360.

Die Radula und die Verhältnisse der Sexualorgane entsprechen vollkommen jenen der Fruticicola lencozona C. Pfr.

Die Gehäuse erreichen vielfach bedeutendere Dimensionen als Fr. lencozona C. Pfr., sind jedoch dünnschaliger, ebenso ist der Lippenkallus zumeist dünner und auch am Basalrand etwas vom Rande entfernter. Die Skulptur besteht nebst feinen und ziemlich dichten Zuwachsstreifen aus ziemlich dichten Borsten, welche jedoch sehr verschieden entwickelt sind, bald sehr kurz und dicht, bald länger und weitläufiger; 'mitunter werden Exemplare beobachtet, bei welchen die Borsten nur vereinzelt vorhanden oder durch schwache Narben angedeutet sind, also auch diesbezüglich Übergänge zur typischen Form der Fr. lencozona C. Pfr. darstellen. Bezüglich der weiteren Merkmale ist vorstehende Form ebenso veränderlich wie Fr. lencozona C. Pfr. Die Höhe des Gewindes schwankt selbst bei Exemplaren des gleichen Fundortes bedeutend, ebenso die Zahl der Umgänge von $5 \frac{1}{2}$ bis $6^{1} / 2$. Der Nabel ist zumeist etwas weiter wie bei der typischen Form, die'Färbung bei Exemplaren aus höheren Lagen dunkler bis rotbraun, bei den Formen der Auen bräunlichgelb bis gelblichweiß.

Die Unterscheidung von konstanten Lokalformen wird um so schwieriger, je zahlreicher die Exemplare und Fundorte vorliegen; nach meiner Beobachtung geht die Höhenform dieser Art, Fr. leücozona ovirensis Rssm., indem sie in die Talregionen herabwandert entweder, in die glatte Fr. leucozona C. Pfr. oder die borstige Fr. luvida C. Pfr. über; diese beiden Hauptformen erscheinen auch räumlich geschieden, zeigen aber eine auffallende individuelle Variation, welche Anlaß gegeben hat, extrem entwickelte Exemplare als konstante neue Arten zu beschreiben. Der historische Typus der Fr. lurida C. Pfr. soll bedeckt durchbohrt sein, würde also der Abbildung auf Taf. 21, Fig, $175 a$ bis $b$ entsprechen (von Lokve in Kroatien); die offen durchbohrte Form aus den Saveauen bei Agram, Taf, 21, Fig. $177 a$ bis $c$, kann als Fr. filicina L. Pfr. aufgefaßt werden, ebenso die kleine, dünnschalige Form, mit schwächerem Lippenkallus, Taf. 21, Fig. 176, als Fr. separanda Rssm., ebenfalls aus den Saveauen bei tgram. Diese hier abgebildeten Exemplare entsprechen jedoch keinen konstanten Lokalformen, sondern wurden als extreme Entwicklungsformen ausgewählt, um die Veränderlichkeit der Fr. lencozona luwida C. Pfr. zu demonstrieren; dieselben leben neben weiteren Übergangsformen mit der typischen Form am gleichen, engbegrenzten Fundort.

$$
\begin{array}{llll}
D=12 \cdot 5, & d=11 \cdot 5, & H=9 \mathrm{~mm}, \text { aus dem Wocheinertal in den Julischen Alpen. } \\
D=13 \cdot 5, & d=12 \cdot 5, & H=7.5 \mathrm{~mm}, \text { Kankertal in Kärnten. } \\
D=11-135, & d=9 \cdot 5-11 \cdot 5, & H=7 \mathrm{~mm}, \text { Agram. } \\
D=11 \cdot 5, & d=10 \cdot 5, & & H=7.5 \mathrm{~mm}, \text { Laibach. } \\
D=9, & d=7 \cdot 6, & H=6.5 \mathrm{~mm}, \text { Wolschach, Isonzotal. } \\
D=10 \cdot 5, & d=9 \cdot 5, & H=6.5 \mathrm{~mm}, \text { Bärenschütz, oberes Murtal in Steiermark. }
\end{array}
$$


Das Verbreitungsgebiet der Fr. lencozona lurida C. Pfr. umfaßt die Ausläufer der Ostalpen in der Ost- und Südsteiermark, ferner die Tal- und unteren Höhenregionen in Kärnten, Südtirol, dem Küstenland, Krain und Kroatien.

\section{Fruticicola (Perforatella) leucozona bosnensis Möllendorff.}

Taf. 21, Fig. $178 a$ bis $b$.

Helix biclzi var. bosnensis Möllendorff, Beitrag zur Fauna Bosniens, 1873.

Das Gehäuse sehr ähnlich der Fr. leucozona lurida C. Pfr., jedoch festschaliger, mit durchschnittlich niedrigerem Gewinde und etwas weiterem Nabel; der letzte Umgang zeigt häufig eine stumpfe Kante und der Lippenkallus wird so kräftig, wie bei der typischen Form der Fr. lettcozona Pfr.

$$
D=9-12 \cdot 5, \quad l=8-11, \quad H=5-7 \mathrm{~mm} .
$$

Verbreitungsgebiet: Bosnien und Serbien.

\section{Fruticicola (Perforatella) leucozona Bielzi Bielz.}

Taf, 21, Fig. $179 a$ bis $b$.

Helix bielzi B ielz, Verhandl. d. siebenbürg. Ver, 1860, und Fauna d. Land- und Süßwassermoll. Siebenbürg., p. $63,1867$.

Das Gehäuse sehr ähnlich der Fr. lencozona lurida C. Pfr., der engere Nabel ist jedoch konstant durch den Spindelumschlag bis auf einen feinen Ritz bedeckt; die Borsten sind kurz und dicht angeordnet, der Mundsaum und Lippenkallus wie bei der typischen Form der Fr. lencozona C. Pfr.

$$
D=10, \quad d=9, \quad H=6-7 \mathrm{~mm} \text {. }
$$

Verbreitungsgebiet: Die Ostkarpathen in Galizien, der Bukowina, Siebenbürgen und Ungarn.

Fruticicola (Perforatella) leucozona anodonta Tschapek.

Helix unidentata var, anodonta Tschapek, Jahrb. d. D. Mal. Ges., 1886.

Das Gehäuse ähnlich der Fr. lencozona C. Pfr., jedoch konstant viel kleiner mit einem ritzförmigen, durch den Spindelumschlag nahezu vollkommen bedeckten Nabel, sowie kurzen, dichten aber hinfälligen Borsten.

$$
D=6 \cdot 5-7 \cdot 5, \quad d=6-7, \quad H=4 \cdot 5-5 \mathrm{~mm} .
$$

Verbreitungsgebiet; Das mittlere Murtal und Raabtal in der Oststeiermark.

Diese durch ihre konstant sehr geringen Dimensionen bemerkenswerte Lokalform kann wohl bei oberflächlicher Betrachtung mit Fr. midentata Drap, verwechselt werden, unterscheidet sich jedoch von derselben durch ihre rascher zunehmenden Umgänge, besonders aber durch die Beschaffenheit und Form der Mündung und des Mündungskallus.

\section{Genus Semifruticicola n.}

Der gürtelförmige Kiefer mit feinen, ziemlich weitläufigen Querleistchen (18), welchen an den Rändern Einkerbungen entsprechen.

Die Radula mit deutlich dreispitzigem, symmetrischem Mittelzahn und 30 zweispitzigen Seiten- und Randzähnen; die äußersten Randzähne durch das Auftreten von weiteren Nebenspitzen auch mehrspitzig.

Sexualorgane: Der spindelförmige Penis mit einem dünneren, annähernd gleich langen Epiphallus, aber sehr kurzem Flagellum; der Musc. retractor inseriert am Übergange des Penis in den Epiphallus. Die ovale Samenblase mit ziemlich kurzem Blasenstiel. Die eiförmig verdickte Vagina mit zwei ungleichen, 
aber symmetrisch angeordneten Pfeilsäcken, welche nur mit ihren hinteren, abgerundeten Enden frei hervorragen und je einen Pfeil enthalten. Die Pfeile verhältnismäßig lang und spitz, leicht gebogen, an der Basis undeutlich eingeschnürt und schwach gerieft. Die Gland. mucosae bestehen aus 8 Schläuchen.

Verbreitungsgebiet: Südbosnien, Montenegro und Nordalbanien.

\title{
Semifruticicola serbica n.
}

Xerocampylaca zelebori autor. part.

Taf, 22, Fig. 180

Die Verhältnisse des Kiefers, der Radula und der Sexualorgane werden unter den Merkmalen des Genus angeführt.

Das Gehäuse flachkegelförmig, ziemlich eng, aber perspektivisch genabelt, dünnschalig aber fest, leicht glänzend mit kräftigen, etwas ungleichmäßigen Zuwachsstreifen; die Grundfarbe kalkartig weiß bis gelbbraun und opak, mit zwei gelbbraunen bis dunkelbraunen und durchscheinenden Binden über und unter der Peripherie; die beiden Binden sind häufig nur gegen die zwischenliegende Zone der hellen Grundfarbe deutlich begrenzt, nach oben und unten mehr oder minder verwaschen, so daß die Oberseite bis zur Naht, besonders aber die Unterseite gegenüber der hellen Peripherialzone dunkler erscheinen; ebenso sind die oberen Umgänge dunkler gefärbt. Das regelmäßig flachkegelförmige Gewinde besteht aus $5 \frac{1}{2}$ ziemlich rasch zunehmenden, gewölbten und durch eine deutlich eingedrückte Naht geschiedenen Umgängen; der letzte ist doppelt so breit wie der vorletzte und steigt vorne langsam, aber ziemlich tief herab. Die ovale Mündung ist breiter als hoch; der dünne und scharfe Mundsaum nur am Außen- und Basalrand kurz ausgebreitet; ein schmaler, weißer Lippenkallus erhebt sich erst in einiger Entfernung vom Rande; die Insertionen des Mundsaumes sind ziemlich genähert, der Spindelrand umgeschlagen, wodurch jedoch nur ein geringer Teil des Nabels bedeckt wird.

$$
D=13 \cdot 5-15, \quad d=11-12, \quad H=7 \cdot 5-8 \cdot 5 \mathrm{~mm} \text {. }
$$

Verbreitungsgebiet: Diese Art wurde bis jetzt in Südwestbosnien, der Hercegovina und in Montenegro nachgewiesen, da dieselbe jedoch leicht mit Fruticicola zelebori Pfr. verwechselt wird, dürfte ihr Verbreitungsgebiet ausgedehnter sein. Im Wiener Hofmuseum liegt die Art von nachstehenden Lokalitäten: Prosječenica vrata bei Grab an der Sutjeska nächst Čemerno, Bjelasnica bei Sarajevo, Sucha a. d. Sutjeska, Bjelašica bei Gačko, Begova brda (2000 m) am Süd-Durmitor; an letztgenannter Lokalität sind die Gehäuse kalkartig weiß mit schärfer begrenzten, dunkelbraunen Bändern und kräftigen Rippenstreifen.

Die Gehäuse der Semifruticicola serbica m. zeigen eine auffallende Übereinstimmung mit solchen der Fruticicola zelebori Pfr. und können von diesen oft nur durch ihre kräftigere Skulptur, besonders die Rippenstreifen, unterschieden werden; entscheidend bleibt allein der Vergleich der Sexualorgane.

\section{Semifruticicola serbica costulata Brancsik.}

\author{
Taf. 21, Fig. $181 a$ bis $c$.
}

Helix zelebori var. costulata Brancsik in: Soc. nat Trencsin, v. 19 bis 20, p. 87, 1897.

Das Gehäuse kleiner, verhältnismäßig ıveiter genabeit, festerschalig; weißlich oder rötlich opak mit einem bläulichen oder violetten Anflug und schmäleren Bändern, welche häufig vollkommen erlöschen. Das mehr erhobene Gewinde besteht aus 5 bis $5 \frac{1}{2}$ langsamer zunehmenden, stärker gervölbten Umgängen; die besonders auf der Oberseite kräftigere Skulptur besteht aus rippenartigen Zuwachsstreifen.

$$
D=12, \quad d=10 \cdot 5, \quad H=7.5 \mathrm{~mm} \text {. }
$$

Fundorte: Der Bubatov kuk (2000 m) und Volujak in Montenegro, Lebršnik bei Ćemerno in Bosnien, das Koritnik Gebirge im Ljumagebiet Nordalbaniens.

Einfärbige Exemplare dieser Form erinnern auffallend an kleine Exemplare der Fruticicola evjaveci flörickei Kobelt, mit welcher sie an einzelnen Lokalitäten (Bjelašica bei Gačko) gleichzeitig auftreten. 


\section{Genus Monacha Hartmann 1840.}

Der Kiefer und die Radula zeigen Verhältnisse wie bei den Gruppen Fruticicola Held und Semifruticicola A. J. Wagner.

Der nur im vorderen Drittel leicht verdickte Penis ist verhältnismäßig lang und schlank, mit einem wenig dühneren, gleichlangen Epiphallus und einem langen bis sehr langen, peitschenförmigen Flagellum; der Musc. retractor inseriert am Übergange des Penis in den Epiphallus. Die ovale oder rundliche Samenblase ist von dem langen bis sehr langen Blasenstiel gut abgesetzt. Die Gland. mucos. bestehen aus zwei bis vier Paaren tief gabelspaltiger Schläuche. Der Pfeilsack ist stets einfach und verhältnismäßig groß mit einem langen, spitzen und spiralgebogenen Pfeile.

Das Gehäuse ist dünn bis zartschalig, hornfarben bis rotbraun und durchscheinend, selten opak. Die Skulptur besteht nebst feinen Zuwachsstreifen aus einer feinen Körnelung der Epidermis und sehr feinen, zumeist nur unter der Lupe sichtbaren Schüppchen, welche leicht abgerieben werden und frischen Gehäusen ein mattes, bereiftes. Aussehen verleihen; nur ausnahmsweise sind auch kurze Borsten vorhanden.

\section{Monacha fallax $n$.}

Taf. 23, Fig. $185 a$ bis $d$, Taf. 24, Fig. 187.

Der Kiefer gürtelförmig mit ziemlich weitläufigen (über 20) Querleistchen, welchen an den Rändern feine Einkerbungen entsprechen.

Die Radula mit einem symmetrischen, dreispitzigen Mittelzahn und 25 ziveispitzigen Seiten- und Randzähnen in einer Halbreihe.

Sexualorgane: Der Penis mit verhältnismäßig kurzem. Flagellum; der Blasenstiel mittellang; die Gland. mucosae bestehen aus 8 Drüsenschläuchen; die übrigen Verhältnisse sind typisch.

Das Gehäuse ist flachkegelförmig mit ziemlich engem, perspektivischem Nabel, hellbräunlichgelb oder gelblichweiß und milchig opak; am letzten Umgang sind mitunter hellere Zonen an der Peripherie und Naht angedeutet. Die Skulptur besteht nebst feinen und dichten Zuwachsstreifen aus einer sehr feinen Körnelung und Runzelung der Epidermis, wodurch das Gehäuse mattglänzend erscheint. Das flachkegelförmige Gewinde besteht aus 5 bis $5 \frac{1}{2}$ ziemlich langsam zunehmenden, gewölbten und durch eine deutlich eingedrückte Naht geschiedenen Umgängen; der letzte ist an der Peripherie gerundet und steigt vorne langsam und wenig herab. Die ovale Mündung ist schief und breiter als hoch, der Mundsaum am Oberrande fast gerade, am Außen- und Basalrande ausgebreitet; der weiße, zumeist wenig erhobene Lippenkallus ist dem Basal- und Außenrande genähert, vom Oberrande weiter entfernt; die Insertionen des Mundsaumes sind entfernt; der Nabel mißt durchschnittlich 1/6 vom Durchmesser der Basis.

$$
D=8 \cdot 5-12 \cdot 5, \quad d=7-105 . \quad H=5 \cdot 5-7 \cdot 5 \mathrm{~mm} .
$$

Fundort: Trebovič bei Sarajevo.

Die Gehäuse dieser Art zeigen bis auf eine deutlichere Körnelung der Epidermis eine so vollkommene Übereinstimmung mit jenen der Fruticicola erjaveci osoria Bráncs,, daß nur der Vergleich der Sexualorgane eine sichere Unterscheidung ermöglicht.

\section{Monacha incarnata Müller.}

Taf. 22, Fig. $182 a$ bis $d$.

Helix incarnata Nüiller, Verm. Hist., II, 1774.

Der gürtelförmige Kiefer mit ziemlich dichten Querleistchen (über 20), welchen an den Rändern feine Einkerbungen entsprechen. 
Die Radula mit symmetrischem, dreispitzigem Mittelzahn und 30 zweispitzigen Seiten- und Randzähnen.

Sexualorgane: Der zylindrische, im vorderen Drittel kaum verdickte Penis mit einem wenig dünneren aber längeren Epiphallus und einem mittellangen Flagellum; die rundliche Samenblase mit einem langen, schlanken Blasenstiel; die Gland. mucos. bestehen aus 4 Paaren bis fast zum Stiele gespaltener Schläıche; der Pfeil ist deutlich spiral gedreht und gebogen, lang und schlank, am vorderen Ende mit scharfen, flügelartig vorspringenden Leistchen. Die übrigen Verhältnisse sind typisch.

Das Verbreitungsgebiet dieser Art umfaßt den größten Teil Europas.

\section{Monacha vicina Roßmäßler.}

Taf. 23, Fig. 183.

Helix vicina Roßmäß1er, Icon., I, v. 2, Nr. 689, 1842.

Der Kiefer und die Radula wie bei M. incarnata Müller.

Die Sexualorgane unterscheiden sich von jenen der M. incarnata Müller durch den vorne deutlicher spindelförmig verdickten Penis mit längerem Flagellum, einen kürzeren Blasenstiel und die weniger tief gespaltenen Gland. mucos.

Verbreitungsgebiet: Nur in den Sudeten und Karpathenländern.

\section{Monacha umbrosa C. Pfeiffer.}

Taf. 23, Fig. 184.

Helix umbrosa C. Pfeiffer, Naturgesch., III, p. 27, t. 6, Fig. 7, 1828.

- - Roßmäßler, Icon., I, v. 1, Nr. 13, 1837.

Der Kiefer ist gürtelförmig mit über 20 Querleistchen, welchen an den Rändern deutliche Einkerbungen entsprechen.

Die Radula mit dreispitzigem, symmetrischem Mittelzahn und 23 zweispitzigen Seiten und Randzähnen; die äußersten Randzähne werden durch das Auftreten von Nebenspitzen dreispitzig.

Sexualorgane: Der schlanke, zylindrische Penis mit einem nur wenig dünneren, gleichlangen Epiphallus und einem sehr langen, peitschenförmigen Flagellum; die kugelige Samenblase mit einem sehr langen Flagellum; die Glandulae mucosae bestehen aus 8 Drüsenschläuchen; die übrigen Verhältnisse sind typisch.

Verbreitungsgebiet: Die Ostalpen bis zur Save im Süden, die Sudeten und Nordkarpathen.

Bemerkenswert ist die große Übereinstimmung der Gehäuse dieser Art mit solchen der Fraticicola erjaveci Brus.

\section{Monacha transsilvanica Westerlund.}

Fruticicola transsilvanica Westerlund, Fauna europaea, p. 55, 1876

Sexualorgane: Nach P. Hesse ist ein spindelförmiger Penis mit einem dünneren und längeren Epiphallus, sowie einem mittellangen Flagellum vorhanden; die länglich ovale Samenblase ist, mittellang gestielt, die Gland. mucos. bestehen aus 6 Drüsenschläuchen; die übrigen Verhältnisse, bescnders der einfache Pfeilsack, sind typisch.

Verbreitungsgebiet: Die Ost- und Südkarpathen.

\section{Monacha kusmici Clessin.}

Helix kuswici Clessin, Malakozoolog. Blätter, N. F., v. 9, p. 52, 1887.

Fruticicola kusmici Kobelt, in Rossm. Icon., II, v. 5, Nr. 723.

Verbreitungsgebiet: Süddalmatien mit den benachbarten Inseln, die Hercegovina, Montenegro und Nordalbanien. 


\section{Monacha rubiginosa A. Schmidt.}

Taf. 23, Fig. 186.

Helix mibiginosa A. Schmidt, Zeitschr. f. Naturw., p. 3, 1853, und Stylom., p. 25, t. 5, f. 27.

Sexualorgane: Der zylindrische Penis mit einem wenig dünneren, gleichlangen Epiphallus und ebensolangem Flagellum; die ovale Samenblase mit sehr langem und schlankem Blasenstiel; die Gland. mucos. bestehen aus 4 Schläuchen; die übrigen Verhältnisse sind typisch.

Verbreitungsgebiet: Anscheinend die ganze zentraleuropäische Region.

Genus Hygromia Risso 1826.

\section{Hygromia cinctella Draparnaud.}

Taf. 24, Fig. $188 a$ bis $c$.

HeTix cinctella D raparn au d, Tabl. moll., 1801 u. Hist. moll. 1805.

Der Kiefer gürtelförmig mit zahlreichen, feinen Querleistchen, welchen an den Rändern feine Einkerbungen entsprechen.

Die Radula mit einem dreispitzigen, symmetrischen Mittelzahn und 25 Seiten- und Randzähnen in einer Halbreihe; am Mittelzahn und den benachbarten Seitenzähnen sind die Nebenspitzen schwach entwickelt; vom 15. Seitenzahne an findet eine Spaltung der Hauptspitze statt, so daß die äußeren Randzähne dreispitzig werden.

Sexualorgane. Der zylindrische Penis mit einem gleichlangen, wenig dünneren Epiphallus und einem sehr kurzen, nahezu rudimentären Flagellum; die ovale Samenblase ist von dem langen, verhältnismäßig dicken Blasenstiel undeutlich abgesetzt; die Gland. mucos. bestehen aus 8 Schläuchen; zwei Pfeilsäcke sind asymmetrisch auf einer Seite der Vagina angeordnet; die zwei kurzen Pfeile sind spiral gebogen.

Verbreitungsgebiet: Das Küstenland, Kroatien, Dalmatien, Italien und Südfrankreich.

\section{Genus Euomphalia Westerlund 1889.}

\section{Euomphalia strigella Draparnaud.}

Taf. 24, Fig. $a$ bis $d$.

Helix strigclla Draparnaud, Tab. moll., 1801 u. Hist. moll., 1805.

Der gürtelförmige Kiefer mit über 20 feinen Querleistchen, welchen an den Rändern deutliche Einkerbungen entsprechen.

Die Radula mit dreispitzigem, symmetrischem Mittelzahn und 40 zweispitzigen Seiten- und Randzähnen in einer Halbreihe.

Sexualorgane: Der zylindrische Penis mit einem wenig dünneren, gleichlangen Epiphallus und einem mittellangen Flagellum; ein Musc. retractor fehlt häufig. Die kugelige Samenblase mit langem, schlanken Blasenstiel; die Gland. mucos, bestehen aus vier Büscheln, von welchen jedes tief dreispaltig ist; Pfeilsäcke fehlen; dafür münden in den vorderen Teil der Vagina zwei schlauchförmige Anhangsorgane (Appendiculae), welche im vorderen Drittel spindelförmig angeschwollen, im mittleren verjüngt, am hinteren Ende wieder keulenförmig verdickt erscheinen.

Das Verbreitungsgebiet erstreckt sich über den größten Teil von Europa.

Die von Westerlund und Kobelt noch bei dieser Gruppe eingeteilten Arten aus Italien gehören mit Rücksicht auf die Verhältnisse der Sexualorgane zur Gruppe Theba Risso der Subfam. Xerophilinae (Theba orsinii Villa, Th. parreyssi Pfr., Th. martensiana Tib., Th. apenina Kob.). Formenreich tritt das Genus Enomplialia dagegen im Kaukasus auf, wo dasselbe durch E. gagriensis Rosen, E. globula Kryn., E. enages Bttg., E. ravergieri Bttg., vertreten wird. Diese Arten wurden zum Teile bei der Gruppe Fruticocampylaea Kob, zum Teile bei Eutota Hartmann eingeteilt, die anatomische Untersuchung ergab jedoch eine vollkommene Übereinstimmung mit den Verhältnissen bei Euomphalia Westerlund. 


\section{INHALTSVERZEICHNIS.}

Beziehungen der Raublungenschnecken zu pflanzenfressenden Stylomatophoren . . . . . 3 [431]

Merkmale der Raublungenschnecken . . . . . 3 [431]

Kiefer und Radula der Raublungenschnecken . . . . 4 [432]

Kiefer und Radula der pflanzenfressenden Stylomatophoren . . . . . . . . . . 4 [432]

Gegenseitige Beziehungen der Gruppen Testacella

Cuv, und Daudebardia Hartm. . . . . . . 5 [433]

Beziehungen der Gruppe Daudebardia zu den Zonitiden 6 [434]

Beziehungen der Oleaciniden zu den Cochlicopiden . 7 [435]

Beziehungen der Gruppen Entea Ad., Gibbulina Beck, Streptaxis Gray zu den Stenogyriden und Pupiden

Familia Testacellidae . . . . . . . . . 8 [436]

Gen. Testacella Cuv. . . . . . . . . . . 8 [436]

Testacella hungarica Soos . . . . . . . . 8 [436]

- gestroilssel . . . . . . . . $10[438$

- haliotidea Drap. . . . . . . . . . 10 [438]

- mangei Fér. . . . . . . . . . . . 10 [438]

- catalonica Poll. . . . . . . . . . 10 [438]

Subgenus Testacella s. str. und Subgen. Testacelloides n. . . . . . . . . . 10 [438]

Familia Zonitidae . . . . . . . . . . . 10 [438]

Subfamilia Daudebardinate . . . . . . . . . . 11 [439] Gen. Daudebardia Hartm. . . . . . . . . 11 [439]

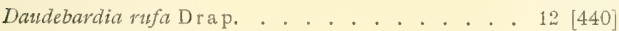

- brevipes Drap. . . . . . . . . . 13 [441]

- brevipes heydeni Bttg. . . . . . . . . . 13 [441]

- wagneri Rosen . . . . . . . . . 13 [441]

- boettgeri Cless. . . . . . . . . 1. 14442

Genus Libania Bgt. . . . . . . . . . . . . . . 14 [442]

Libania saulcyi B g t. . . . . . . . . . . $15[443$

- jetschini A. J. Wagner. . . . . . . . 15 [443]

- praccursor Andrae . . . . . . . . 15 [443]

Genus Carpathica Wagner . . . . . . . 15 [443]
Carpathica calophana Wst1d. . . . . . . . . . $15[443$

- kimakoniczi Wagner . . . . . . . . . . 16 [444]

- langi Pfr. . . . . . . . . . . 16 [444]

- stussineri Wagner . . . . . . . . 16 [444]

Genus Cibinia n. . . . . . . . . . . . . . . $16[444]$

Cibinia transsilvanica Bielz. . . . . . . . . $16[444]$

Subfamilia Zonitinae . . . . . . . . . . . . . . 16 [4t4]

Genus Aegopina Ko b. . . . . . . . . . . . . . 17 [445]

Aegopina nitens Mich. . . . . . . . . . . . . . 17 [445]

- nitens inermis Wagner . . . . . . . 18 [446]

- hiulca Albers ........... . 18 [4ti]

-- hiulca ressmanni Wstld. . . . . . . . 18 [4t(i]

- lenticularis Held . . . . . . . . 19 [447]

Genus Zonites autor. . . . . . . . . . . 19 [4+7]

Genus Aegopis Fitz. . . . . . . . . . . . . . . $20[448$

Aegopis verticillus $\mathrm{F}$ ér. . . . . . . . . . . . . . 21 449]

- croaticus Rssm. . . . . . . . . . . 21 [449]

- croaticus langhofferi n. . . . . . . . . . 21 [449]

- croaticus compressus Rssm. . . . . . . . . 22 [450]

- camiolicus Pfr. . . . . . . . . . . . $22[450]$

- carniolicus cassis Wstld. . . . . . . . . $23[451]$

- carniolicus splendidulus Kob. . . . . . . . 23 [451]

- acies Fér. . . . . . . . . . $23[451]$

- acies Kleciachi Kob. . . . . . . . . . . . 24 [452]

- gemonensis Fér. . . . . . . . . . 24 [452]

- genonensis Kusceri Wagner . . . . . . . 24 [452]

- tenerrimus Brancs. . . . . . . . . 24 [452]

- spelaetrs Wagner . . . . . . . . . $25\lfloor 453\rfloor$

Genus Paraegopis P. Hesse . . . . . . . 25 [453]

Paraegopis albanicus Rssm. . . . . . . . . . 26 [454]

- manritii Wstld. . . . . . . . . . . 26 [454]

- mauritii montenegrinus Bttg. . . . . . . . 27 [455]

Genus Meledella Sturany . . . . . . . . $27[455]$

Meledella werneri Stur. . . . . . . . . . . . . $27 \mid 455$

Genus Hyalinia Ag. . . . . . . . . . . . . $28[456$ 
Subgenus Hyalinia s. str. . . . . . . . . . 28 [456]

Hyalinia cellaria Milllex. . . . . . . . 28 [456]

- cellaria drapamaldi Beck. . . . . . . 29 [457]

- cellaria austriaca Wagner . . . . . . . 29 [457]

- cellaria dalmatina Wagner . . . . . . . 30 [458]

- villae Strobel . . . . . . . . . 30 [458]

— rmelica P. Hesse.......... . 31 [459]

- camelina thracica P. Hesse . . . . . . . 31 [459]

- absotoni Wagner . . . . . . . . . 32 [460]

- nantiliformis Wagner . . . . . . . 32 [460]

- planospira Wagner . . . . . . . . . 32 [460]

- wagneri Köller. . . . . . . . . 33 [461]

- wagneri sinjana Wagner. . . . . . . . 33 [461]

- diaphanella Kryn. . . . . . . . . . . 33 [461]

Subgenus Morlina n. . . . . . . . . . . . 33 [461]

Hyalinia glabra Fér. .

- glabra hungarica Wstld.

$33[461]$

- glabra striaria WstId.

$34[462]$

- glabra bojanae Wagner

34 [462]

- glabra riloensis Wagner

Hyalinia montivaga Kimak.

- depressa Sterki.

- dautzenbergi Wagner.

$3 \pm[462]$ $34[462]$

34 [462]

$34[462]$

Subgenus Retinella Shuttleworth . . . . . . . 35 [463]

Hyalinia mingrelica Mousson . . . . . . . . 35 463]

Genus Schistophallus n. . . . . . . . . . 35 [463]

Subgenus Schistophallus s. str. . . . . . . . . 36 [464]

Schistophallus oskari Kimak . . . . . . . . $36[464]$

- oskaritumidus Kimak . . . . . . . . . $36[464]$

Subgenus Cellariopsis n.

$37[465]$

Schistophallus deubeli $\mathrm{n}$.

37 [465]

Genus Crystallus Love,

$37[465]$

Crystallus spelaeus W a gner

$38[466]$

- crystallinus Müller

$38[466]$

- jetschini Kimak.

$38[466]$

- illyricus Wagner

38 [466]

- contractus subcontractus Wagner

$38[466]$

- contractus botterii Pfr.

- Kutschigi Walderdorff

- Kutschigi zavalae Wagner

$38[466]$

$38[466]$

$39[467]$

- sturamyi Wagner.

$39[467]$

- subrimatus Rhdt.

$39[467]$

- subrimatus litoralis C1ess.

$39[467]$

- subrinatus inflatus Wagner
Crystallus diaphanus Stud.

Seite

- transsilvanicus Cless.

39 [467]

- erjaveci Brus.

39 [467]

- subcarinatus Cless.

39 [467]

Subgenus Hydatimus Westerlund . . . . . . . . 40 [468]

Crystallus liydatinus Rssm. . . . . . . . . 40 [468]

- sphaeroconus Wagnex.

$40[468]$

- endaedalens Bgt.

$40[468]$

- opinatus Cless.

$40[468]$

- maritae Kimak

$40[468]$

- maritae clathratus $\mathrm{Kimak}$

$40[468]$

Familia Vitrinidae $40[468]$

Subfamilia Vitrininae. . . . . . . . . . . 40 [468]

Genus Vitrina Drap. . . . . . . . . . . . . 41 [469]

Vitrina diapltana Drap. . . . . . . . . . . 42 [470]

- glacialis Forbes. .......... . " 42 [470]

- charpentieri Stab. . . . . . . . . . 42 [470]

- kochi Andrae . . . . . . . . . . 42 [470]

Genus Phenacolinax Stab. . . . . . . . 43 [471]

Phenacolimax pellucidus Müller . . . . . . . 43 [471]

- reitteri Bttg. . . . . . . . . . . 44 [472]

- carniolicus Bttg. ........... 44 [472]

- retyezati n............... 44 [472]

- bielzi Kimak . . . . . . . . . . . 44 [472]

— nivalis Dum. et Mort. . . . . . . . . 45 [473]

- austrasiae n. . . . . . . . . . . $45[473]$

- major Fér. ............ . $45[473]$

- anmlaris Stud. . . . . . . . . . $46[474]$

Genus Semilinax Stab. . . . . . . . . . . . $46[474]$

Semilimax elongatus Drap. . . . . . . . . . 46 [474]

Kotulae Wst1. . . . . . . . . . 47 [475]

- truncatus Bttg. . . . . . . . . . . . 47 [475]

- brevis Fér. . . . . . . . . . 47 [475]

Familia Helicidae . . . . . . . . . . . . 48 [476]

Subfamilia Fruticicolinae . . . . . . . . . 48 [476]

Genus Frtiticicola Held . . . . . . . . . . . . . 49 [477]

Subgenus Fruticicola s. str. . . . . . . . . . 51 [479]

Fruticicola erjaveci Brus. . . . . . . . . . 51 [479]

- blani Kob............... . 51 [479]

- erjaveci hirci Cless. . . . . . . . . 52 [480]

- erjaveci osoria Brancs . . . . . . . 52 [480]

- erjaveci.osoria oreinos n. . . . . . . . . 53 [481]

- erjaveci costulala Wohlb. . . . . . . 53 [481]

- erjaveci leptolasia Wagner . . . . . . 53 [481] 


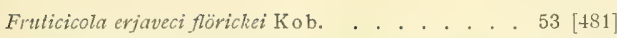

- rufescens montana C. Pfr. . . . . . . . 54 [482]

- villosa Drap. . . . . . . . . . . 55 [483]

- villosula Rssm. . . . . . . . . . 55 [483]

- hiispida L. . . . . . . . . . 55 [483]

- hispida oreinos n. . . . . . . . 56 [484]

- coelata Stud. . . . . . . . . . $56[484]$

- sericea Drap. . . . . . . . . . 56 [484]

- lubomirskii Slosarski........ 56 [484]

- clessini Ulicny . . . . . . . . 56 [484]

- valdemari Wagner ....... . 56 [484]

- zelebori Pfr. . . . . . . . . . . 57 [485]

Subgenus Perforatella Schlüter . . . . . . 58 [486]

Fruticicola unidentata Drap. . . . . . . 58 [486]

Fruticicola unidentata alpestris C1ess. . . . . . 58 [486]

- edentula Drap. . . . . . . . . 59 [487]

- subleucozona Wstld. . . . . . . . . . 59 [487]

- lencozona C. Pfr. . . . . . . . 604488

- lencozona ovirensis Rssm. . . . . . . . . 60 [488]

- lencozona lurida C. Pfr. . . . . . . . . . . 61 [489]

- leucozona filicina Pfr. . . . . . . . . 61 [489]

- leucozona separanda Rssm. . . . . . . 61 [489]
Seite Fruticicola leucozona bosnensis M11dff. . . . . . . 62 [490]

- lencozona bielzi Bielz . . . . . . . . . 62 [490]

- leucozona anodonta Tschapek ..... . 62 [490]

Genus Semifruticicola n. . . . . . . . . 62 [490]

Senifruticicola serbica n. . . . . . . . . 63 [491]

- serbica costulata Brancs . . . . . . . 63 [491]

Genus Monacha Hartmann . . . . . . . . . 64 [492]

Monacha fallax n. . . . . . . . . . . . 64 [492]

- incarnata Müller . . . . . . . . . 64 [492]

- vicina $\mathrm{Rssm}$. . . . . . . . . . 65 [493]

- umbrosa C. Pfr. . . . . . . . . 65 [493]

- transsilvanica Wstld. . . . . . . . . . 65 [493]

- Kustnici Cless. . . . . . . . . . . 65 [493]

- mbiginosa A. Schm. . . . . . . . . . . 66 [494]

Genus Hygromia Risso . . . . . . . . . . . . 66 [494]

Hygromia cinctella Drap. . . . . . . . . . $66[49+]$

Genus Enomphalia WV esterlund . . . . . . . 66 [49.]

Etomphatia strigella Drap. . . . . . . . . . . . 66, 494]

- gagriensis Rosen . . . . . . . . 66 [494]

- globula Kryn............. . . 66 [494]

- ettages Bttg. . . . . . . . . . . . 66 [494]

- ravergieri Bttg. . . . . . . . . . . 66 [494] 


\section{Erklärung der bei den Abbildungen angewendeten Bezeichnungen.}

Die auf der rechten Seite der Figuren stehende Bruchzahl bedeutet die Vergrößerung.
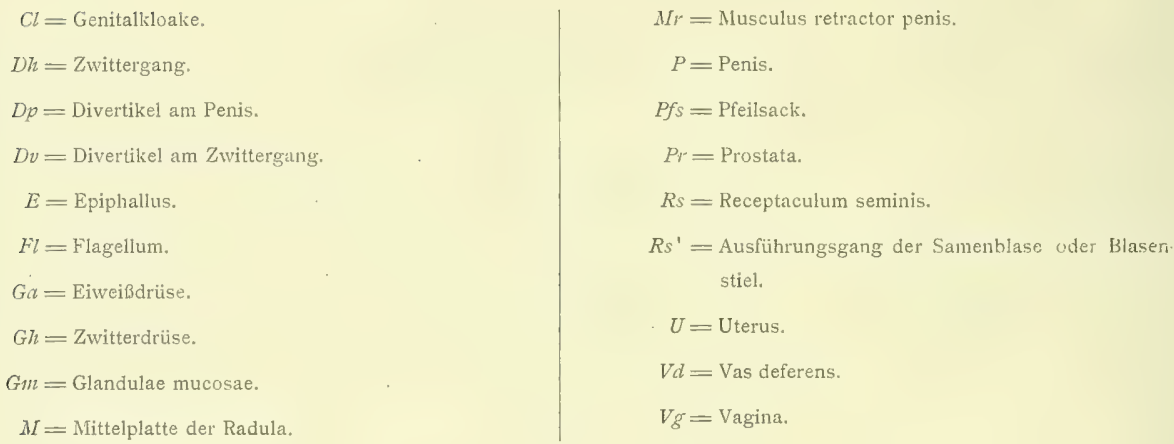
Tafel I.

$\longrightarrow$ 


\section{Tafel I.}

Fig. 1-4. Testacella hungarica Soos $(1=$ Sexualorgane, $2=$ Zahnplatte, $3-4=$ Gebäuse $)$, von Triest.

- 5-7. Testacella gestroi Issel $(5-6=$ Sexualorgane, $7=$ Radula), von Sorgno bei Cagliari.

* 8. Daudebardia boettgeri Cless., von Jalta (Sexualorgane). 
Wagner, A. J.: Anatomie und Systematik der Stylommatophoren.

Taf. I.

1

(1)

Ga

Dh

Gh

2

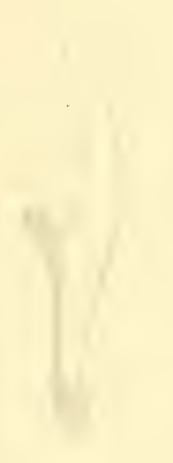

7

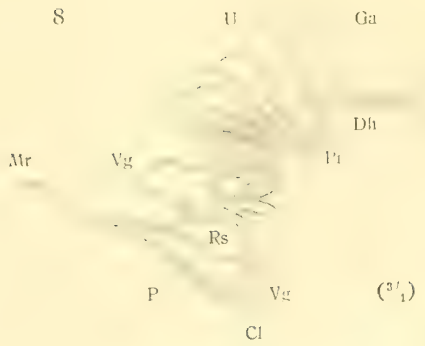

4

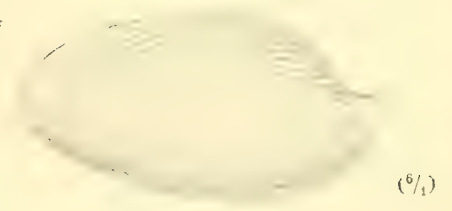

6

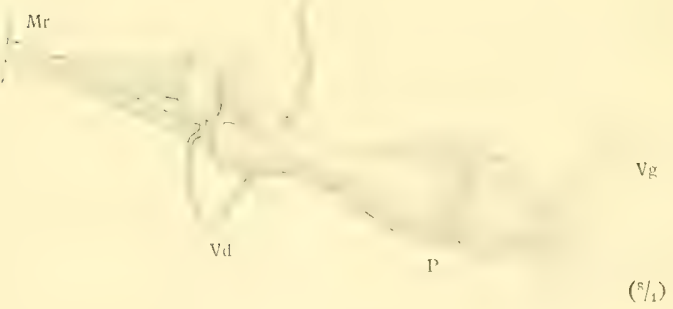

$(6 / 1)$

$(6 / 1)$ k:

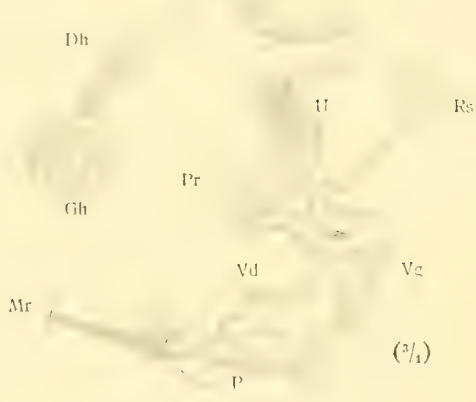

$\mathrm{Cl}$

$(8 / 1)$

(i)

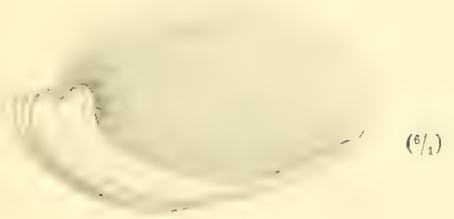

Denkschriften der kaiserl. Akademic der Wiss, matlı. naturw. Kl, $\mathrm{Bd}$. XCl. 

Tafel 2. 


\section{Tafel 2.}

Fig. 9. Daudebardia heydeni Bttg., von Maikop im Kubangebiet (Sexualorgane).

- 10-12. Glandina algyra L., von Nevesinje, Hercegovina $(10=$ Gehäuse, $11=$ Sexualorgane, $12=$ Radula).

- 13-17. Daudebardia (Cibinia) transsilvanica Bielz, vom Götzenberg bei Hermannstadt $(13=$ Sexualorgane, $14-15=$ Gehäuse, $16-17=$ Radula).

- 18. Daudebardia (Carpalhica) calophana Wstld., von Borszek (Radula). 
Wagner, A. J.: Anatomie und Systematik der Stylommatophoren.

Taf. II.

9

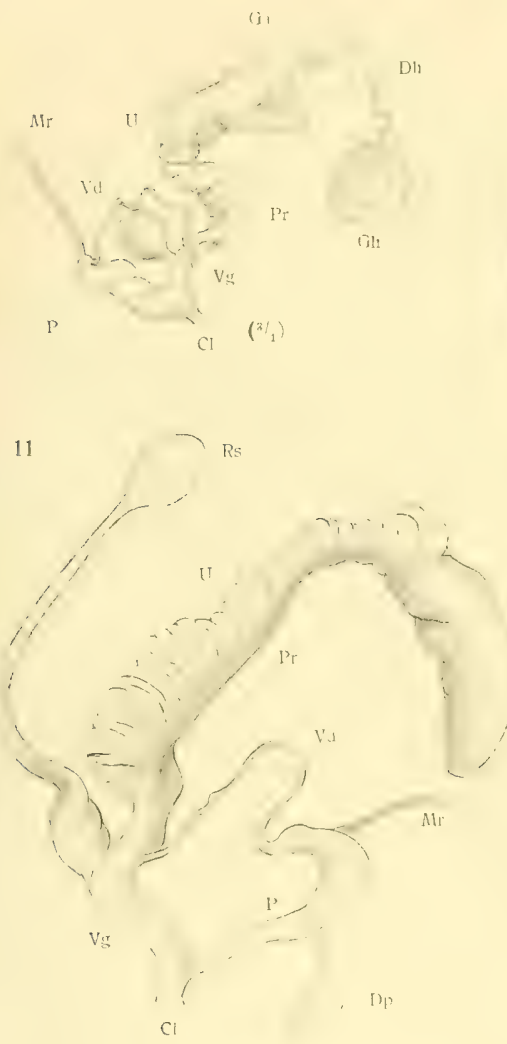

12

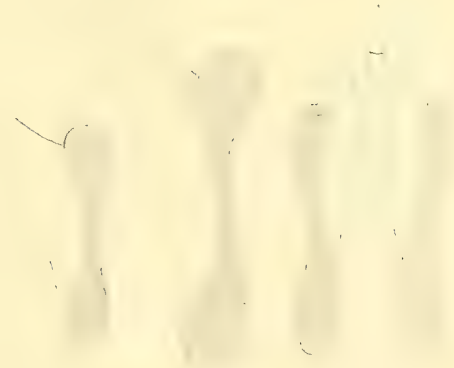

10

13 Ga
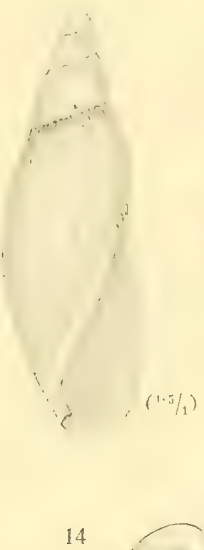

14

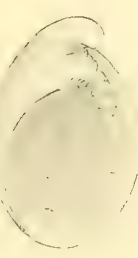

$\mathrm{Vs}$

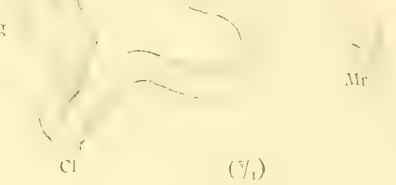

$(12 / 1)$

17

18

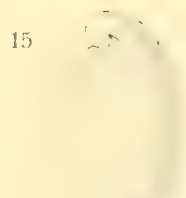

$(10 / 1)$
Dh

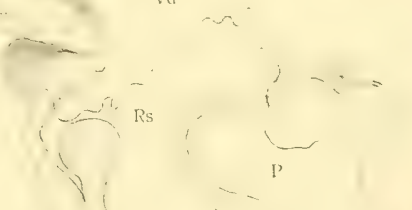

16

Denkschriften der kaiserl. Akademie der Wiss, math. naturw. Kl., Bd. XCI. 
Tafel 3 .

$-\ldots$ 


\section{Tafel 3 .}

Fig. 19-20. Dandebardia (Libania) saulcyi $\mathrm{Bgt}$, von Kreta $(19=$ Sexualorgane, $20=$ Radula).

- 21. Daudebardia (Carparthica) stussineri Wagner, von Sarajevo (Sexualorgane).

* 22-23. Gibbulina newtoni Ad., von Mauritius ( $22=$ Sexualorgane, $23=$ Radula).

" 24-25. Gibbulina mantritiana Morl., von Mauritius ( $24=$ Sexualorgane, $25=$ Radula). 


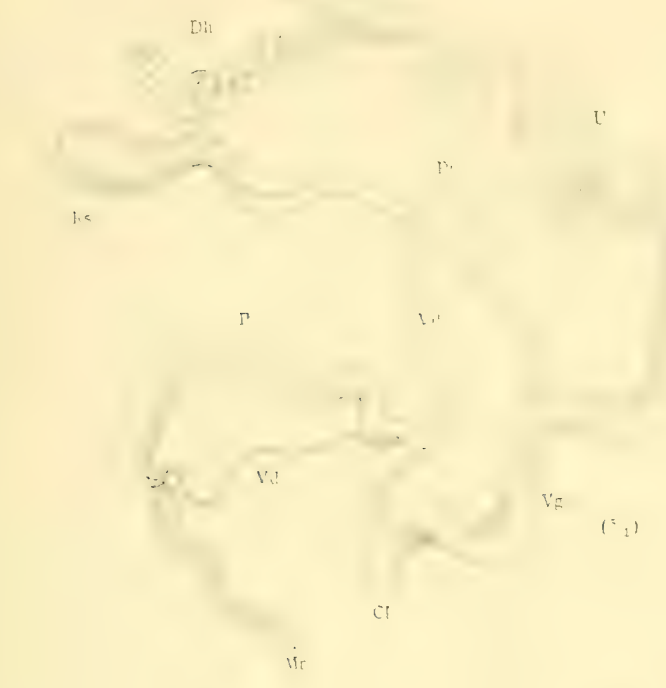

21

24

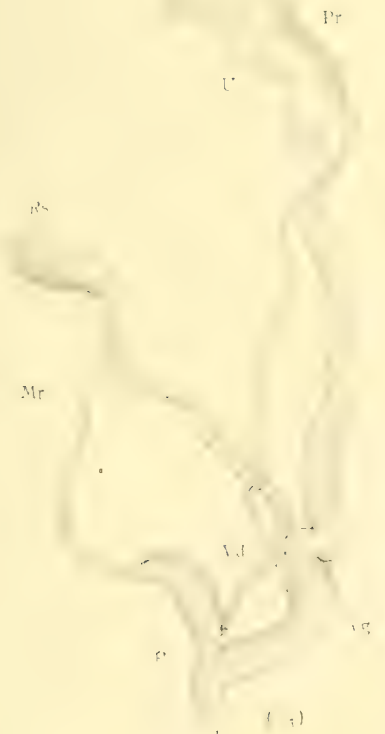

[)

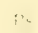

.)

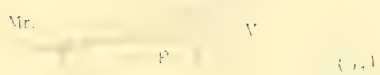

1 it!

25

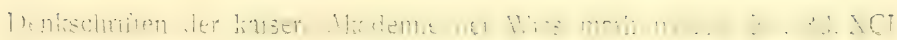



Tafel 4 


\section{Tafel 4 .}

Fig, 26-28. Zonites (Aegopis) verticillus Fér., von Rann in Steiermark ( $26=$ Sexualorgane, $27=$ Kiefer, $28=$ Radula).

> 29-30. Zonites (Aegopis) croaticus Rssm., von Priboj in Kroatien ( $29=$ Kiefer, $30=$ Radula).

31. Zonites (Aegopis) croaticus langhofferi Wagner, von Paklenica in Norddalmatien (Sexulorgane).

\$32. Zonites (Aegopis) acies Fér., von Nevesinje. Hercegovina (Radula).

- 33. Zonites (Aegopis) spelaens Wagner, aus der Höhle Mrcine, Hercegovina (Sexualorgane).

" 34-36. Zoniles (Paraegopis) albanicus Rssm., von Nevesinje, Hercegovina ( $34=$ Sexualorgane, $35=$ Radula, $36=$ Kiefer).

" 37-38. Zonites (Paraggopis) mauritii Wstld., von Celebič bei Sarajevo ( $37=$ Radula, $38=$ Kiefer).

"39. Hyalinia cellaria austriaca Wagner, von Triest (Radula).

* 40. Phenacolimax pellucidus Müller (Kiefer).

s4. Aegopina hiulca Jan., von Kapfenberg (Radula).

* 42. Schistophallus oskari tumidus Kimak, vom Zeidner Berg bei Kronstadt (Radula). 
Wagner, A. J.: Anatomie und Systematik der Stylommatophoren.

Taf. IV.

26

27

(i.t

Ih $\quad$ U $\quad 29$

Vd It

K's

r

$\begin{array}{llllll}11 & 12 & 13 & 14 & 15 & 16\end{array}$

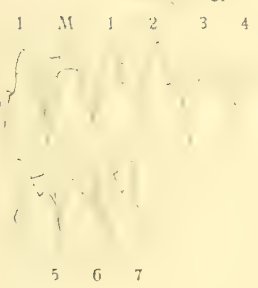

36

34

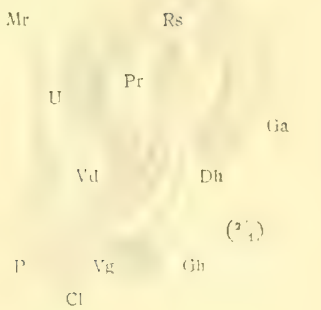

35

28
$31 \quad .11 \mathrm{r}$

G.

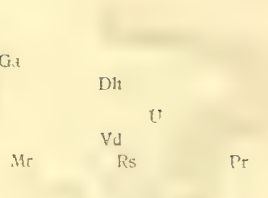

T.1

p Rs

I) $V$ $(5,1)$

$\left({ }^{\prime} i_{1}\right)$

$\mathrm{Cl}$

32

30

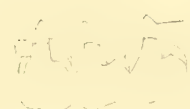

$\begin{array}{lll}\text { MI } & 1 & 2\end{array}$

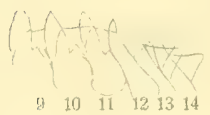

$\mathrm{Cl}$
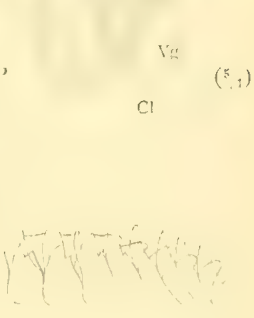

$\begin{array}{llllllll}9 & 10 & 11 & 12 & 13 & 14 & 15 & 16\end{array}$

37

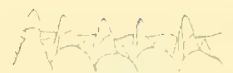

$\begin{array}{lllll}M & 1 & 2 & 3 & 4\end{array}$

$\begin{array}{lllllll}6 & 7 & 8 & 9 & 10 & 11 & 12\end{array}$

39

38
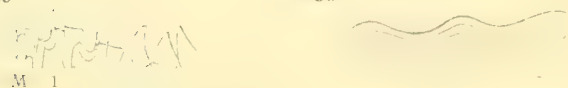

40 

Tafel 5 . 


\section{Tafel 5.}

Fig. 43. Zonites (Aegopis) gemonensis, kusceri Wagner, aus der Dante-Grotte im Isonzotale (Sexualorgane).

> 44-45. Rumina decollata L., von Triest ( $44=$ Sexualorgane, $45=$ Radula).

> 46. Zonites (Aegopis) spelaeus Wagner, Höhle Mrcine, Hercegovina (Radula).

"47. Zonites (Aegopis) carniolicus Pf r., von Adelsberg (Sexualorgane).

- 48. Zonites (Paraegopis) mauritii montenegrinus Bttg., vom Skrečko jezero am Durmitor (Sexualorgane). 
Wagner, A. J.: Anatomie und Systematik der Stylommatophoren.

Tat. $r$.

43

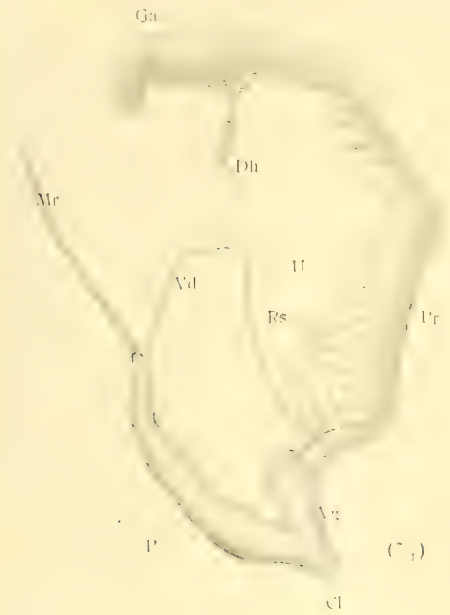

43
44

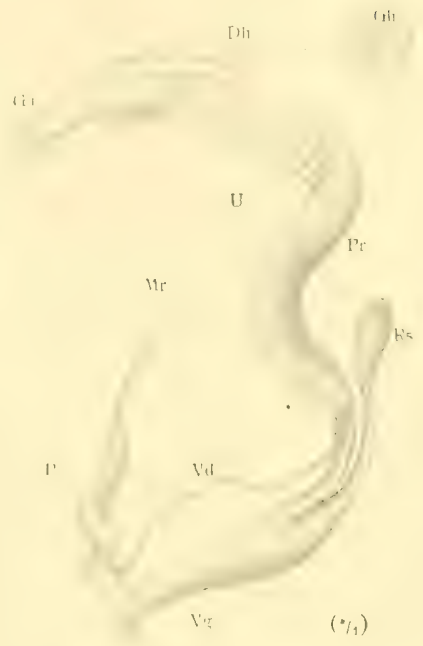

(4)

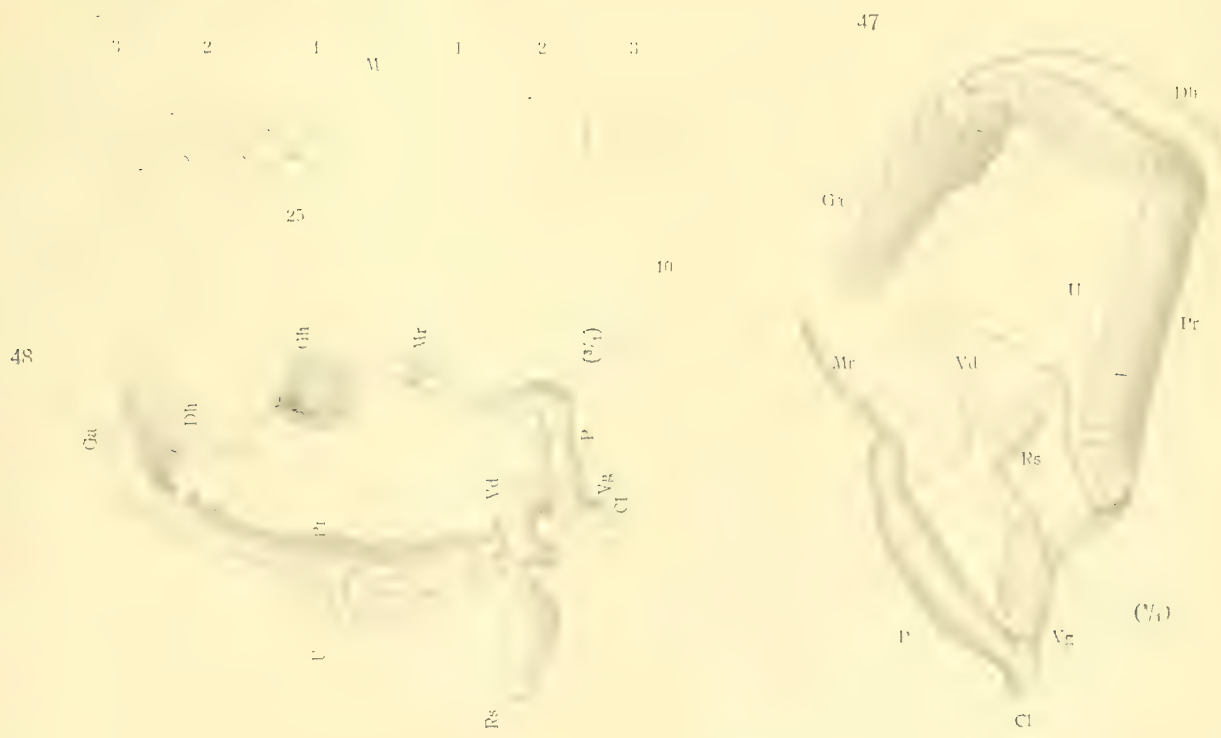

Denkschriften der kaiserl. Akademie der Wiss, math. naturw. Kl., Bd. XCl. 
. 
Tafel 6.

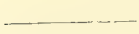




\section{Tafel 6.}

Fig. 49-50. Schistophallus oshari tumidus Kimak., vom Zeidner Berg bei Kronstadt $(49=$ Sexualorgane, $50=$ Penis).

- 51. Schistophallus (Cellariopsis) deubeli Wagner, vom Kapellenberg bei Kronstadt (Sexualorgane).

" 52-53. Hyalinia mingrelica Mss., von Maikop im Kubangebiet ( $52=$ Sexualorgane, $53=$ Radula).

54. Zonites (Aegopis) tencrrimus Brancsik, vom Berge Stolac dei Višegrad in Bosnien (Sexualorgane).

-55. Zonites (Alegopis) acies Fér., von Trebinje (Sexualorgane). 
Wagner, A. I. Anatrmic und Systematik der Stylommanophoren.

49

M. $\mathrm{r}$

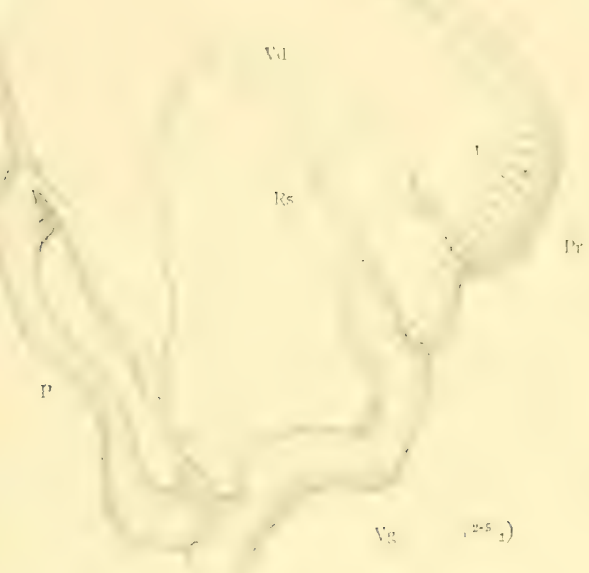

CI
Ijis 'r

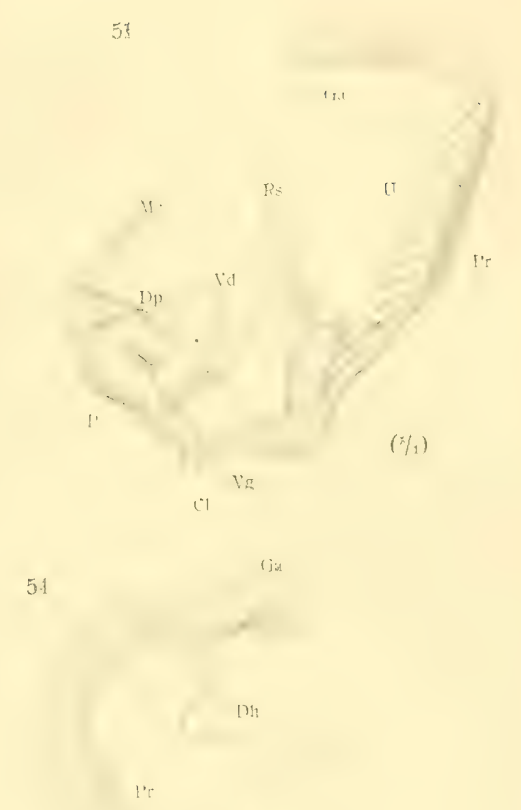

52

50)

M

[1

Fis

Mr

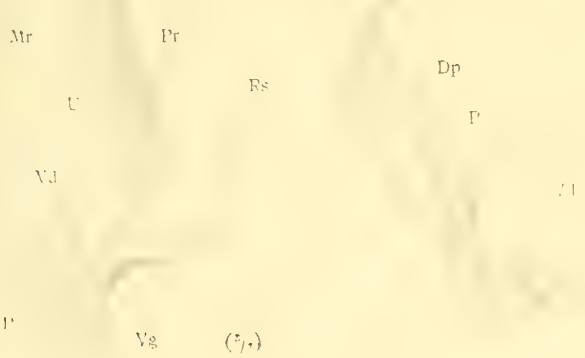

53

53

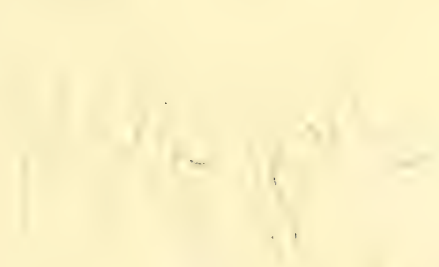

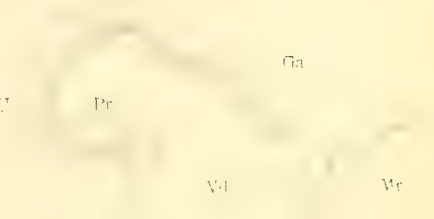

Denkschriften der kaiserl. Akaclemie der Wiss. nath. naturw. K1. Bd. XCl. 

Tafel 7 . 


\section{Tafel 7.}

Fig. 56. Hyalinia cellaria austriaca Wagner, von Triest (Sexualorgane).

, $57 a-b$. Hyalinia glabra Fér., von Niš in Serbien ( $a=$ Sexualorgane, $b=$ Radula).

"58. Aegopina hiulca Albers, von Kapfenberg (Sexualorgane).

" $59 a-$ c. Aegopina nitens Mi ch., von Kronstadt ( $a=$ Sexualorgane, $b=$ Radula, $c=$ Kiefer).

. 60. Schistophallus (Cellariopsis) derbeli Wagner, von Kronstadt (Radula).

» 61. Crystallis diaphanus Stud., von Mur in Württemberg (Sexualorgane). 
Wagner, 1. Jo: Anatomic und Systematik der Stylommatophoren?

56

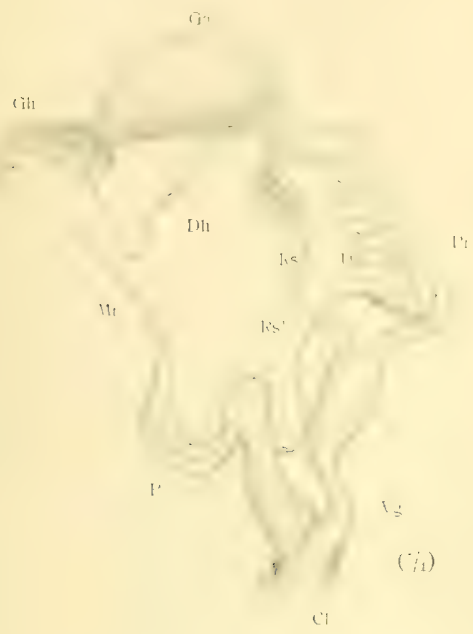

1)!

58

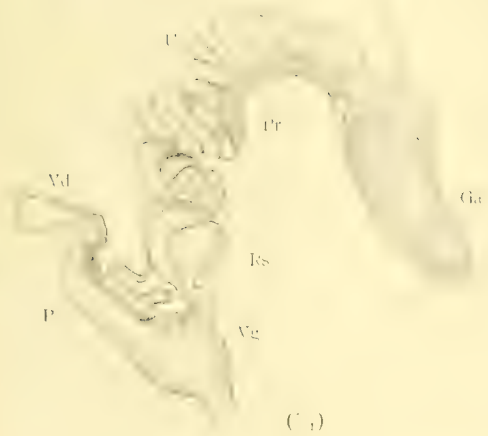

(i)

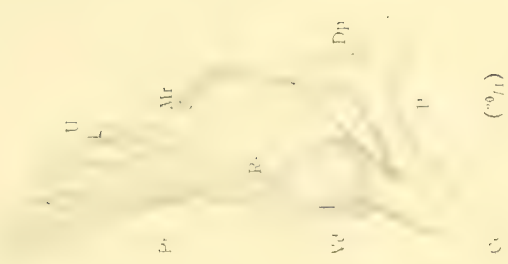

U..

$5 i a$

III

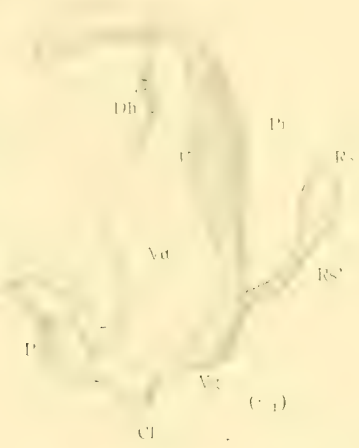

$5 ! c$

59 it

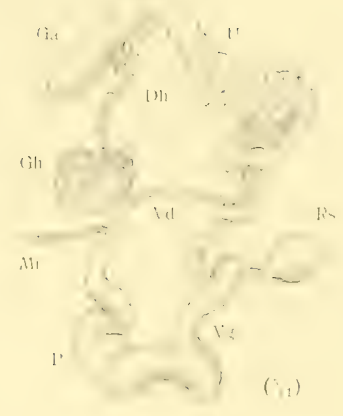

i7 $\mathrm{h}$

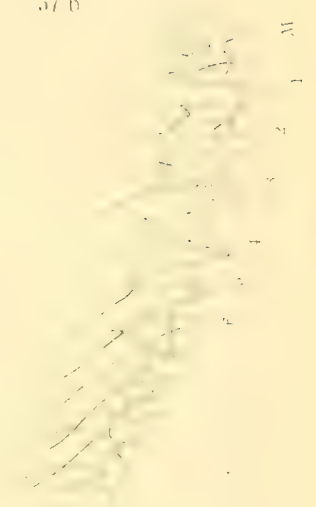

$53 \mathrm{~b}$

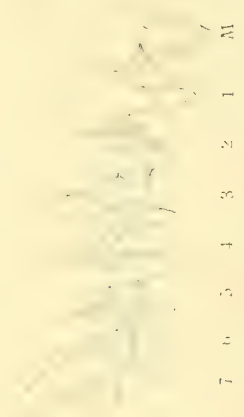

60

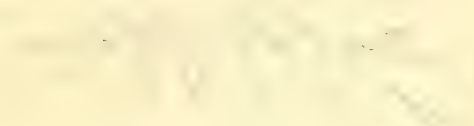

Denkschriften der kaiserl. Akademie der Wiss, math. naturw. KI., Bd. XCI. 

Tafel 8. 


\section{Tafel 8.}

Fig. $62 a-c$. Hyalinia nautilifornis W agner, Höhle Ǩlina Pečina bei Trebinje.

" $63 a-c$. Zonites (Aegopis) spelaews Wagner, Höhle Mrcine, Hercegovina.

- $64 a-c$. Meledella werneri Stur., Höhle Ostaševica auf Meleda. 
Wagnor, A. 1. : Anatomit und Systumatik der Stylummatophomen.

Taiel Vill,

$62 a$

$62 \mathrm{~b}$

(i) 1 .

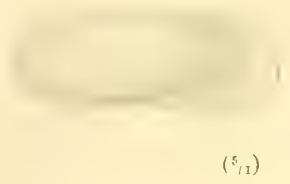

$(\because, 1)$

$(\vdots ! 1)$

$\therefore a$

$63 \mathrm{~h}$

$(3)$

$(3 /, j$

13.

ii4a

$(3)$

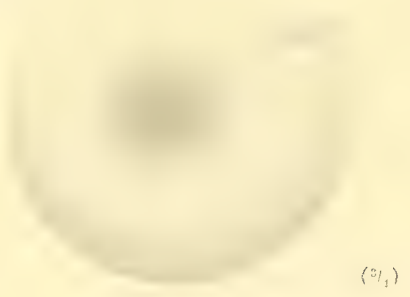

(5) b

64.

$\left(3 /{ }_{1}\right)$

$(3 / 1)$

Denkschriften der kaiserl. Akademie der Wiss, math. naturw. Kl, Bd. XCl. 

Tafel 9. 


\section{Tafel 9.}

Fig. $65 a-c$. Hyalinia cellaria Mülle r, von Dargun in Mecklenburg.

66 a-c. Hyalinia cellaria draparnaldi $\mathrm{Beck}$, von Avignon.

$67 a-b$. Hyalinia cellaria austriaca Wagner, von Laibach.

68. Aegopina lenticularis Held, von Jena (Sexualorgane).

69 a-c. Hyalinia vagneri sinjana Wagner, aus einer Höhle bei Sinj in Dalmatien. 
Wagner A. H- Wmmi un: Systematik der Stylommatophoren. i.

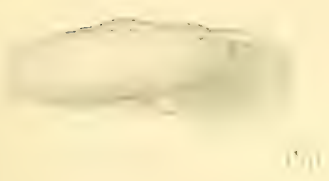
195 13. (. , : $\left({ }^{2}{ }_{1}\right)$ 6): 3

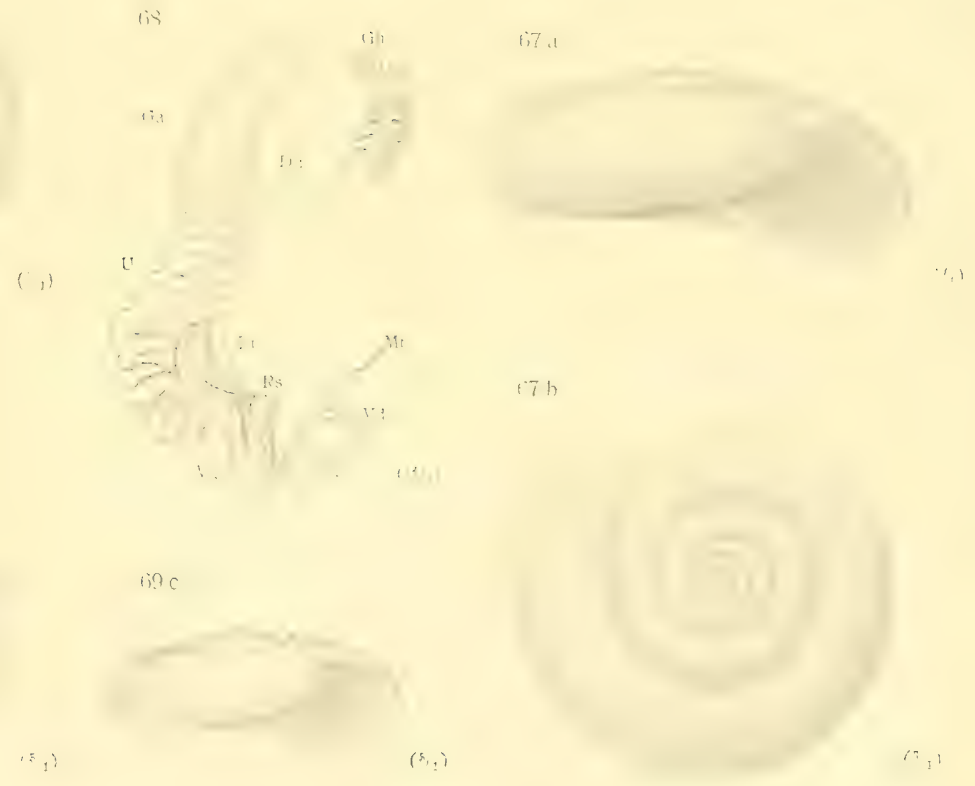

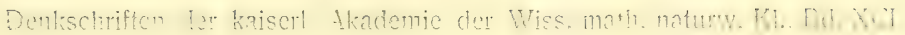



Tafel ı. 


\section{Tafel io.}

Fig. $70 a-c$. Hyalinia cantelina thracica P. Hesse, von Philippopel.

- 71 a-c. Hyalinia runelica P. Hesse, von Philippopel,

* $72 a-c$. Hyalinia wagneri Köhler, von Lesina.

* $73 a-c$. Hyalinia absoloni Wagner, aus der Eliashöhle bei Trebinje. 


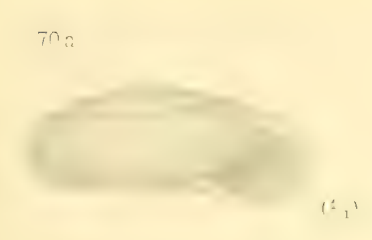

$$
\therefore 1 \text {, }
$$

$7: 1$.

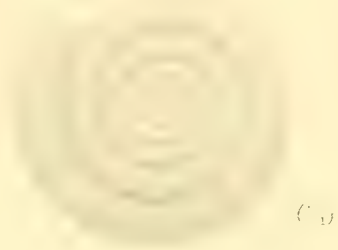

$\left(i_{1}\right)$

71.2

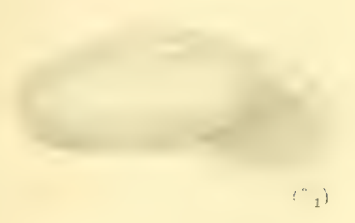

.112

$\because 6$

$\left({ }_{1}\right)$

$! 2_{1} !$

iิ 2

7.:

iz

is:

$(5)$

$73 a$

731,

Denkschriften der kaiserl. Akademie der Wiss, math. natum. KI., Bd. XCI. 

Tafel II. 


\section{Tafel il.}

Fig. $74 a-c$. Crystallus spelaeus W agner, aus der Höhle Crnulja ponor im Popovo polje, Hercegovina.

" 75. Hyalinia dautzenbergi Wagner, von Ragusa (Radula).

- 76. Schistophallus oskari Kimak, aus der Bogater Schlucht bei Kronstadt.

77 a-c. Schistophallus oskari tumidus Kimak, vom Zeidnerberg bei Kronstadt.

: $78 a-b$. Zonites (Aegopis) croaticus langhofferi Wagner, von Paklenica in Norddalmatien.

79. Zonites (Aegopis) croaticus compressus Rs m., von Carlopago.

5. $80 a-c$. Hyalinia dalmatina Wagner, von Ragusa.

" 81 a-c. Hyalinia glabra riloensis Wagner, vom Rilogebirge.

- $82 a-b$. Aegopina lenticularis Held, von Jena ( $a=$ Radula, $b=$ Kiefer).

" $83 a-b$. Senilimax elongatts D rap. ( $a=$ Radula, $b=$ Kiefer).

- S4. Semilimax brevis Fér. (Radula). 
Wagner, A. J.: Anatonie und Systematik der Stylommatophoren.

Taf. XI.

$74 a$

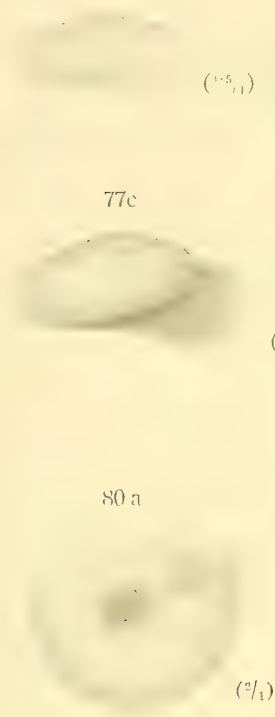

$(1 / 1)$
$74 \mathrm{~b}$

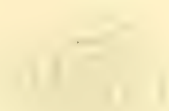

$(1 \cdot / 1)$
$74 \mathrm{c}$

$77:$

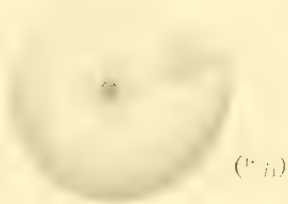

$(\% /)$

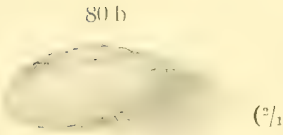

7.5

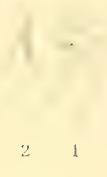

713
$78 \mathrm{~b}$

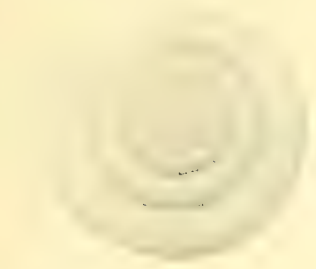

(1ii)
․․

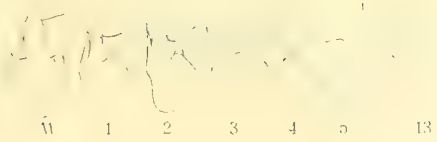

$83 a$

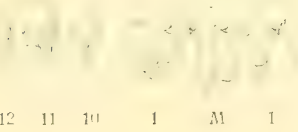

78

\section{(1/1)}

$+21$

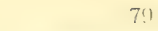

$7 !$

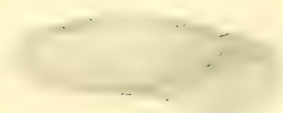

$(2 / 4)$

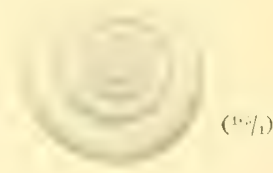

$81 \mathrm{~b}$

i)

$(1.5 / 1)$

4.1

S311

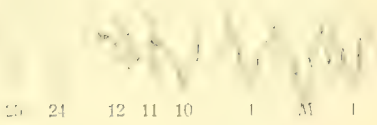

Denkschriften der kaiserl. Akademie der Wiss, math. naturw. KI., Bd. XCI. 

Tafel I2. 


\section{Tafel i2.}

Fig. 85 a-c. Schistophallus (Cellariopsis) detibeli Wagner, von Kronstadt.

, 86-88. Hyalinia villae Mort., vom Mönchsberg bei Salzburg.

\$ 89-91. Hyalinia montivaga Kimak., von Lirasuva im Banat.

> 92-93. Hyalinia villae Stro bel, von Salo am Gardasee ( $92=$ Sexualurgane, $93=$ Radula).

94. Covslallus crytallime .I üller, von Kapfenberg (Sexualorgane). 
Wagner, A. J.: Anatomie und Systematik der Stylommatophoren.

Taf. XII.

$85 a$

$85 b$

$85 c$

$(4,1)$

$(1 / 1)$

$(\%)$

80

$(1 / 1)$

90

89)

91
85

(1)?

$(1 / 1)$

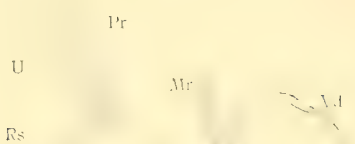

$\left({ }^{3}, 1\right)$

$\left({ }^{\prime \prime}\right)$

$\left({ }^{\prime \prime},\right)$

Denkschriften der kaiserl. Akademie der Wiss, math. naturw. Kl., Bd. XCI, 
Tafel I3. 


\section{Tafel I3.}

Fig. 95-99. Phenacolinax pellucidus Müller, von Kapfenberg ( $95=$ Radula, $96=$ Sexualorgane).

* 100-102. Phenacolimax ammularis Stud., von Torda, Siebenbürgen.

- 103-105. Phenacolimax bielzi Kimak., von Hermannstadt.

" 106-110. Vitrina diaphana Drap., von Kapfenberg (106 = Sexualorgane, $107=$ Radula $)$. 


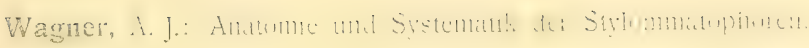

(15)

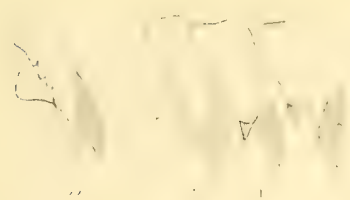

$! 1 i^{2}$

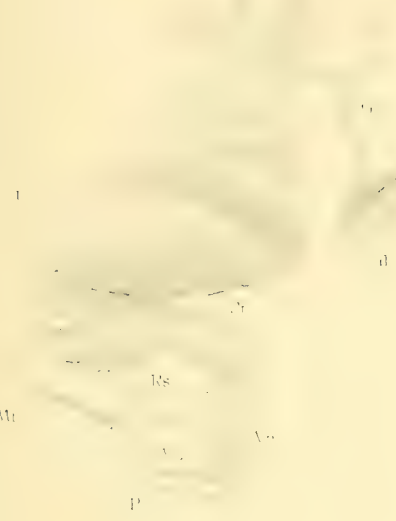

1111

119,

1111
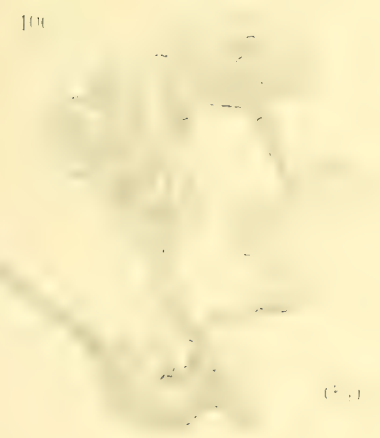

117

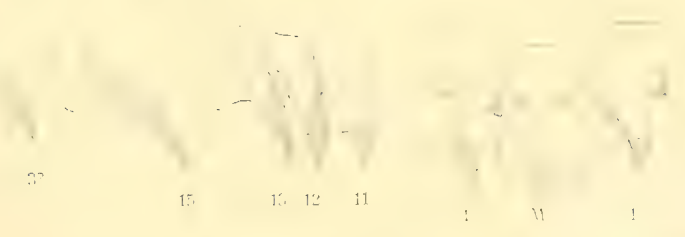

111, !lix

$$
\text { 111: }
$$

(i)

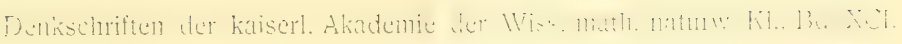



Tafel i4. 


\section{Tafel I4.}

Fig. 111-113. Phenacolimax retyezati n., vom Retyezat in Siebenbürgen.

- $114 a-c$. Phenacolinax nivalis D um. et. Mort., von. Piemont.

" 115-117. Vitrina glacialis Forbes, von Schwarzenbach in Tirol.

. 118-123. Phenacolinax reitteri B ttg. (118-120 vom Mosor in Bosnien, 121-122 vom Klek bei Ogulin, 123= Sexualorgane von Veldes).

- 124. Vitrina charpentieri Stab., vom Schneeberg in Niederösterreich (Sexualorgane).

125-127. Vitrina charpentieri Stab., von Bex, Schweiz. 
Wagner, A. J.: Anatomie und Systematik der Stylommatophoren.

$114 \mathrm{a}$

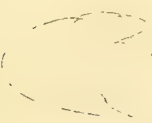

$114 \mathrm{~b}$
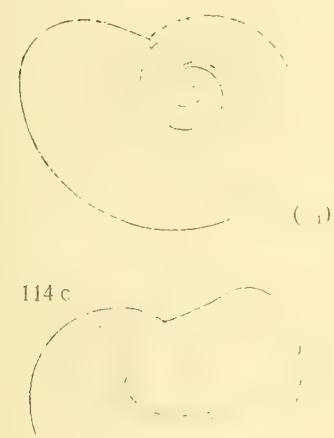

118

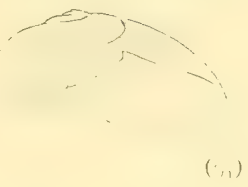

19?

124

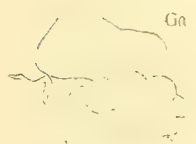

Mi

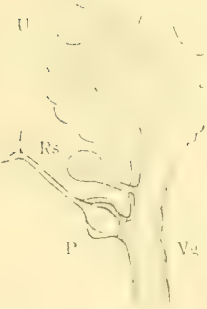

125

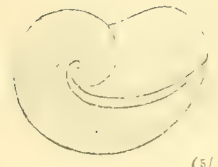

11

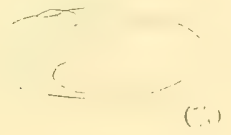

$12+i$

127
112

$(6: 1)$

116

117

$\left(\begin{array}{c}1 \\ 1\end{array}\right)$

$(4)$

119

120
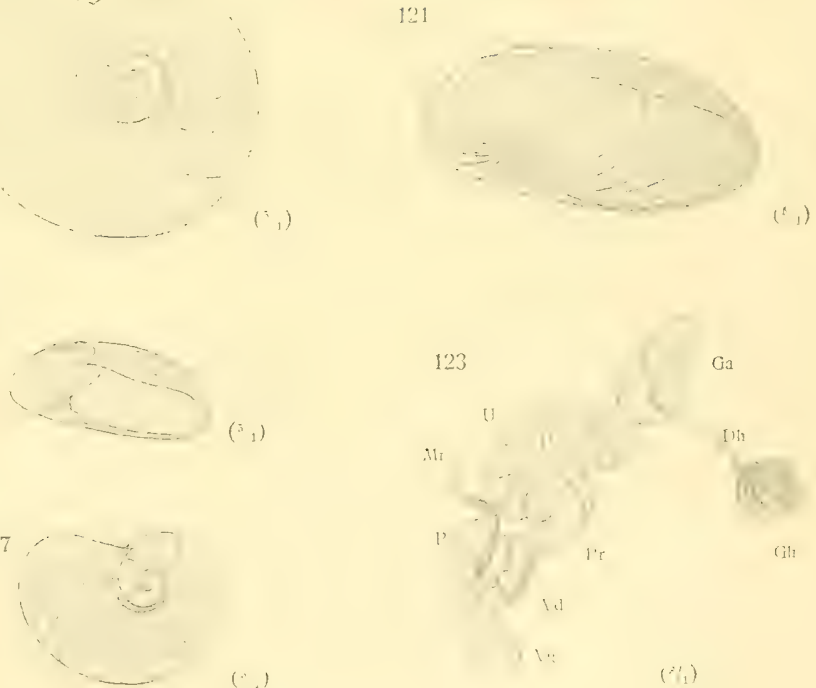

113

$(3,1)$

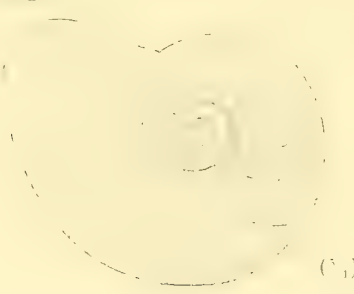

$(*, 1)$

$\left({ }^{3},\right)^{2}$
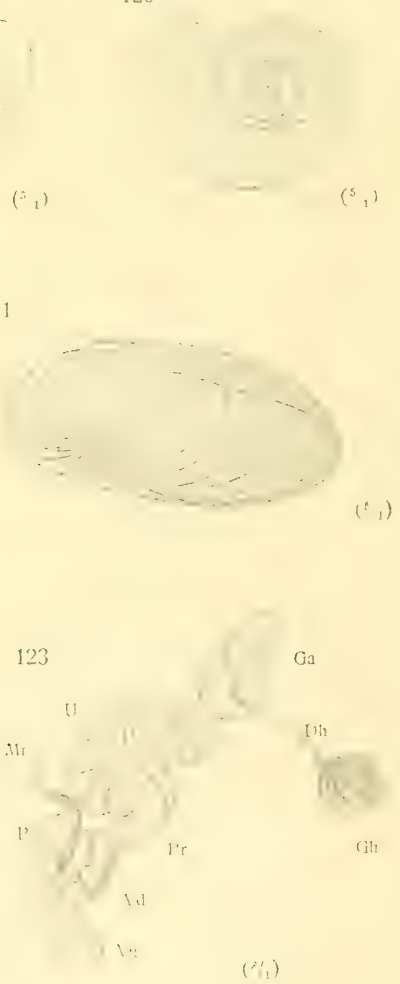

Denkschriften der kaiserl, Akademie der Wiss, math, naturw. Kl., Bd. XCI. 

Tafel 15. 


\section{Tafel I5.}

Fig. 128-129. Vitrina charpentieri Stab, von Patschkau in Schlesien $(128=$ Kiefer, $129=$ Kiefer $)$.

130-133. Semilimax elongatus Drap., von Wien (Sexualorgane).

134-135. Semilimax Kolulae Wst1d., vom Kotlinatal in der Tatra.

136-141. Senitimax trincatus Bttg., von der Teichalpe in Steiermark (136 = Sexualorgane).

142-145. Semilinax brevis Fér., von Triest (145 = Sexualorgane, $140-141=$ Pfeilsack und Pfeil. 
Wagner, A. J.: Anatomie und Systematik der Stylommatophoren.

12.4

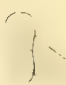

130

(ia<smiles>BrC1CCCCCC1</smiles>

$+$,

$(137$

i $\quad(\vdots)$

i.

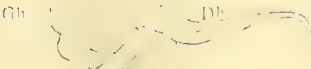

*)

$\therefore \quad 1$

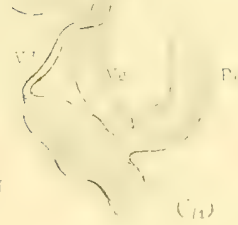

$\mathrm{Cl}$

140

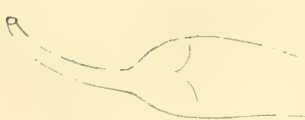

131

$(5 / 1)$

135

132

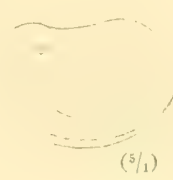

( 1$)$

142

$(5 / 1)$

$(5 / 1)$

$(5 / 1)$
133

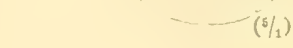

129

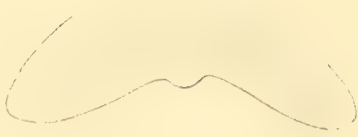

134

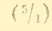

Ga

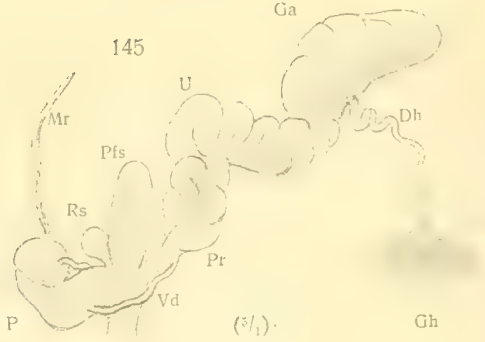

Denks,chriften der kaiserl, Akademie der Wiss. math. naturw. Kl., Bd. XCI. 

Tafel I6. 


\section{Tafel i6.}

Fig. $146 a-g$. Frulicicola erjaveci Brus, von Agram ( $a=$ Sexualorgane, $b=$ Pfeile, $c=$ Kiefer, $g=$ Radula $)$. 147 a-c. Fruticicola erjaveci hirci Cless, von der Kapela bei Jezerane.

148. Fruticicola erjaveci hirci Cless., vom Berge Risnjak in Kroatien. 
Wagner, A. 1.: A.nthmic und Systematik the Stylommatophoren.

1.1

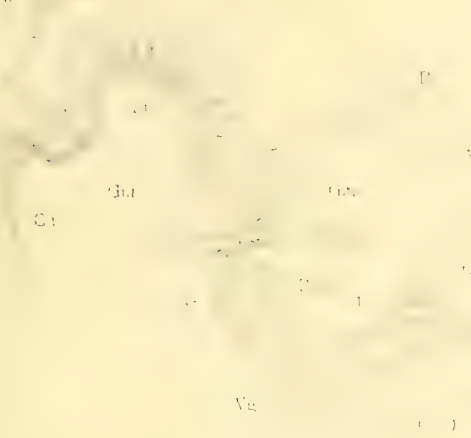

$14 n+$

$1+\mathrm{Ci}_{\mathrm{i}}$

$+1 ; i+1$

-

$1-1+1+2$

1":

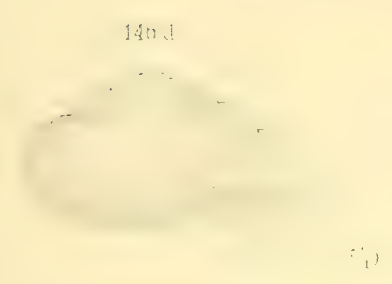

$1+7 i$

1472

$1.17 \mathrm{~h}$

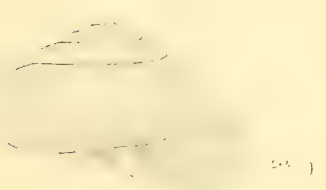

$140 \ddot{3}$ 

Tafel I 7 . 


\section{Tafel i 7 .}

Fig. $149 a-c$. Frnticicola erjaveci hirci Cless., von der Visoěica m Velebit.

" 150 a-c. Fruticicola erjaveci leptolasia Wagner, vom Lavšabach bei Travnik ( $c=$ Sexualorgane).

. $151 a-d$. Fruticicola rufescens montana C. Pfr., von Stockerau bei Wien ( $d=$ Sexualorgane).

" 152 a-c. Fruticicola erjaveci osoria Brancs., von Sarajevo.

$153 a-c$. Fruticicola erjaveci osoria Brancs, von der Treskavica bei Sarajevo. 
Wagner, A. J.: Anatomie und Systematik der Stylommatophoren.

Taf. XVII.

$149 \mathrm{~b}$

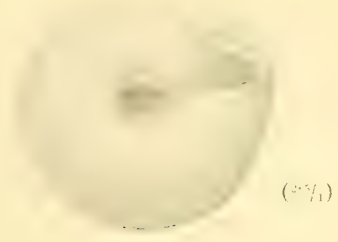

$149 \mathrm{c}$

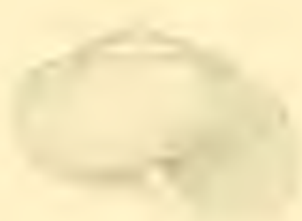

$\left({ }_{1}\right)$

150 a

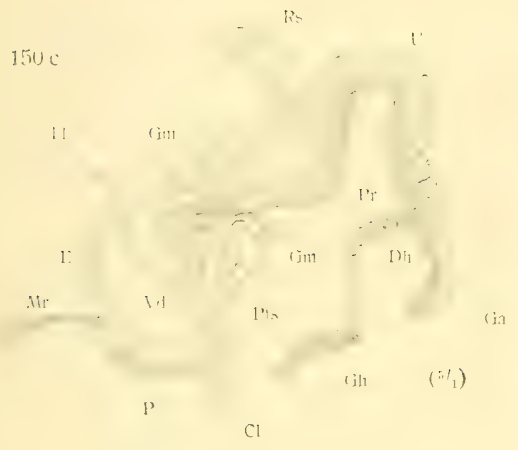

$152 c^{\circ}$

152 a
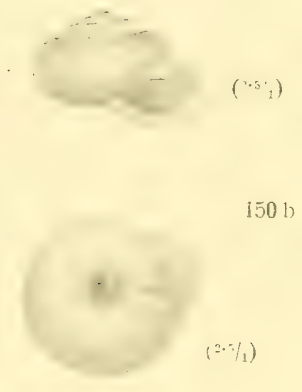

152 h
149 a

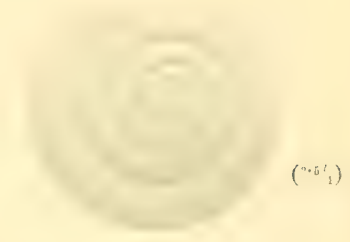

$153 c$

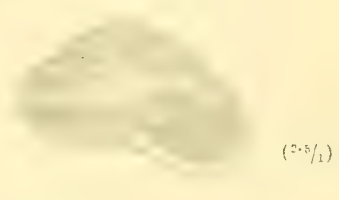

153 a

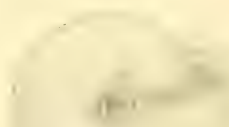

$153 \mathrm{~h}$

151 i

$(\cdots, ;$

$(\cdot \cdot 3)$

$151 c$

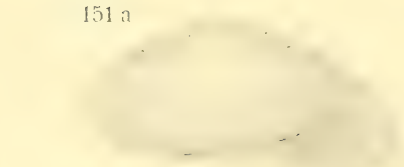

$151 \mathrm{~b}$

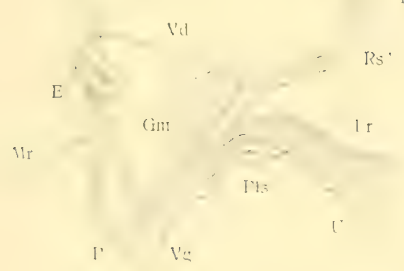

Cl

$(4 / 1)$
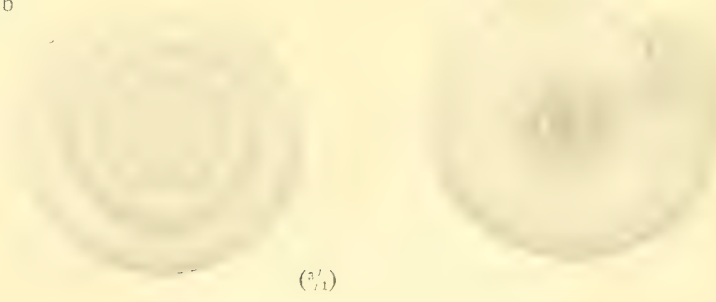

Denkschriften der kaiserl. Akademie der Wiss, math. naturw. Kl., Bd. XCI. 

Tafel I8. 


\section{Tafel i8.}

Fig. $154 a-d$. Fruticicola erjaveci osoria Brancs., forma oreinos, von der Ljubična in Bosnien (d= Sexualorgane).

\$ 155 a-c. Fruticicola erjaveci leptolasia Wagn er, von Jablanica.

- $156 a-c$. Fruticicola erjaveci costulata Wohlb., vom Bubatov Kuk am Durmitor.

» $157 a-f$. Fralicicola erjaveci flörickei Kob., vom Skrečko jezero am Durmitor ( $a=$ Kiefer, $b=$ Pfeil, $f=$ Sexualorgane).

* 158 a-b. Fruticicola erjaveci flörickei Kob., vom Bušat im Komgebiet.

* $159 a-b$. Fruticicola erjaveci flörickei Kob., von Kolašin in Montenegro. 
Wagner, A. J.: Anatomie und Systematik der Stylommatophoren.

Taf XVIII.

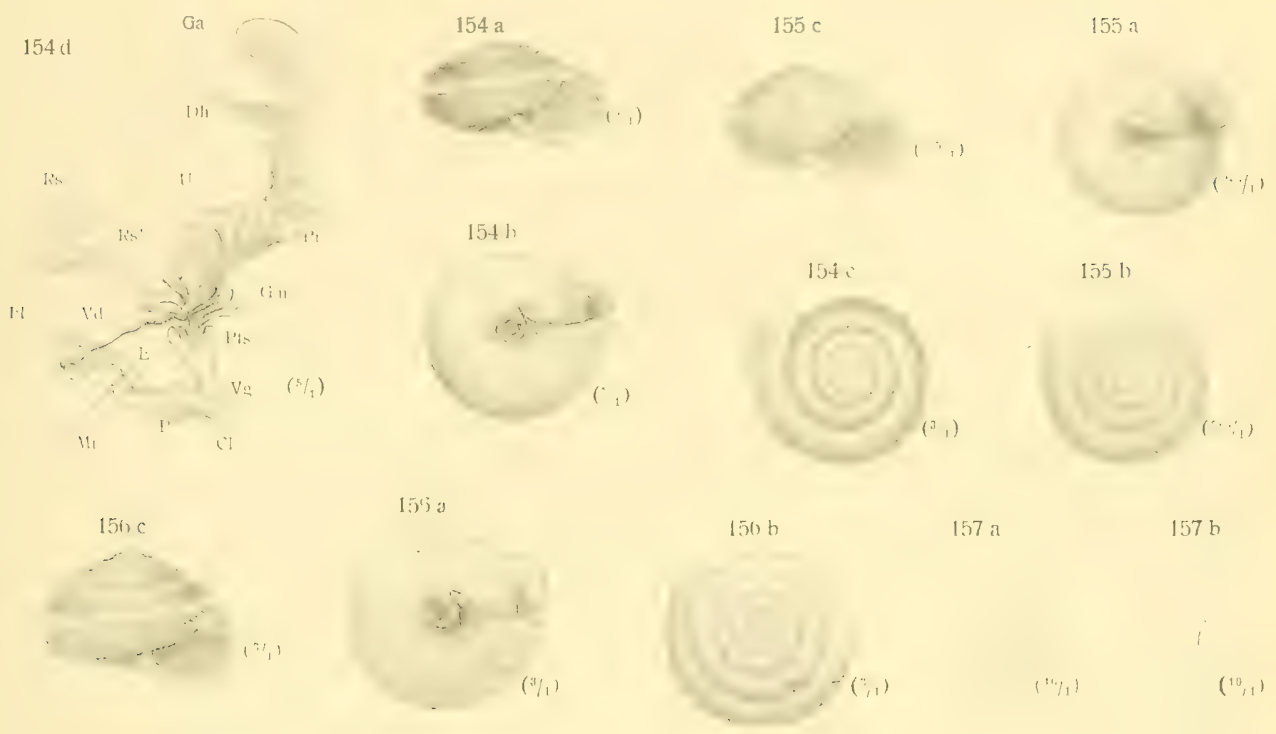

$157 \mathrm{C}$

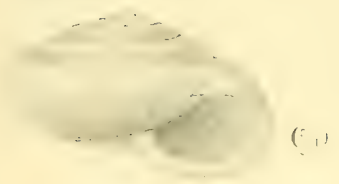

159!

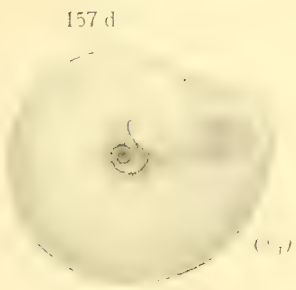

$15 ! 3 \mathrm{a}$

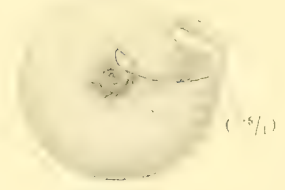

$158 \mathrm{~b}$

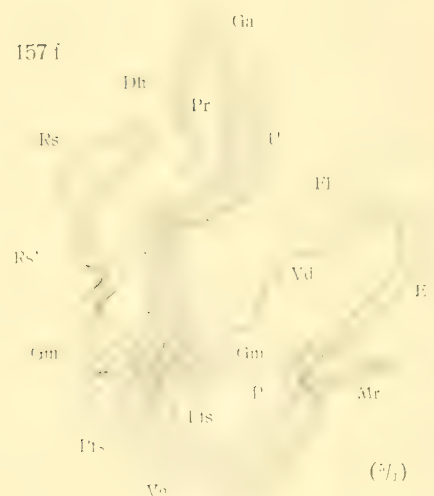

$157 \mathrm{e}$
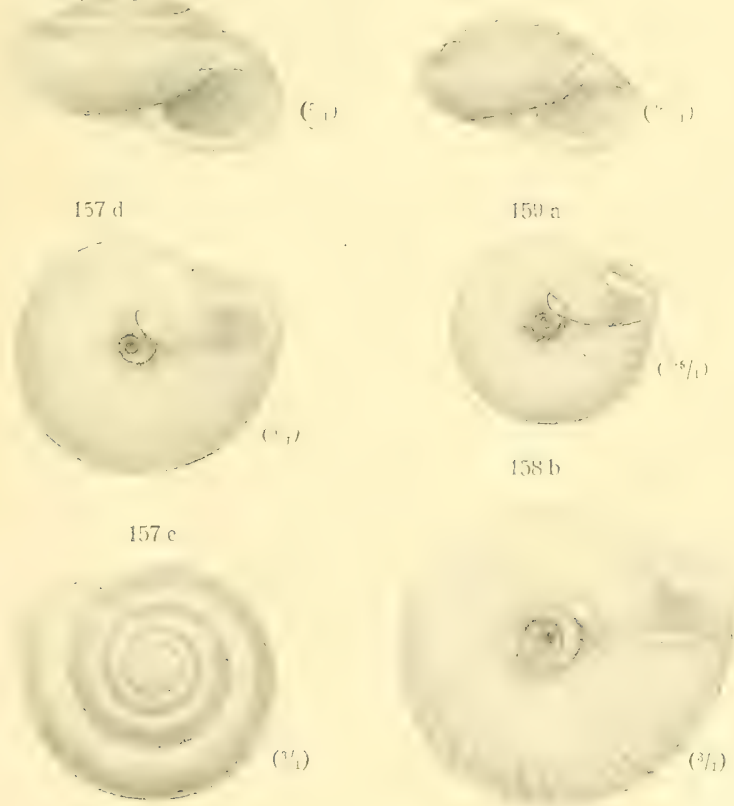

(c)

158 a

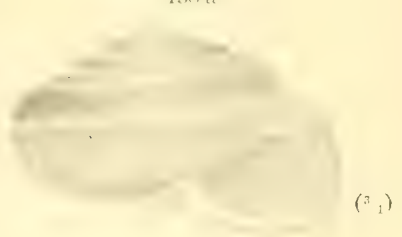

Denkschriften der kaiserl. Akadenic der Wiss. math. naturw. KI., Bd. XCI. 

Tafel Iو. 


\section{Tafel Ig.}

Fig. 160 a-c. Fruficicola erjaveci flörickei Kob., von der Skakala in Montenegro.

" $161 a-f$. Fruticicola zelebori Pfr., von Zljep bei Višegrad ( $a=$ Pfeil, $b=$ Kiefer, $f=$ Sexualorgune).

\$ 162 a-c. Firuticicola zelebori Pfr., von Višegrad in Bosnien.

" $163 a-c$. Fruticicola waldemari Wagner, von Jajce in Bosnien.

" 164. Fruticicola hispida L., vom Floninggraben bei Kapfenberg (Sexualorgane).

* 165. Fruticicola sericea Drap., von Trins im Gschnitztal in Tirol. 
Wagner, A. J. : Anatomie und Systematik der Stylommatophoren.

$160 \mathrm{c}$

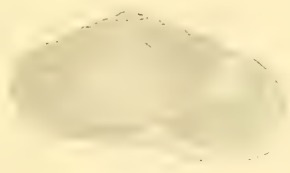

160 a

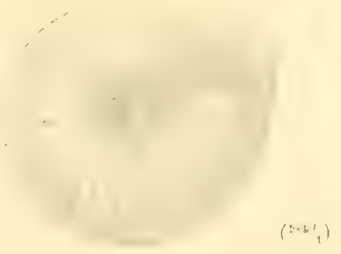

$1160 \mathrm{a}$
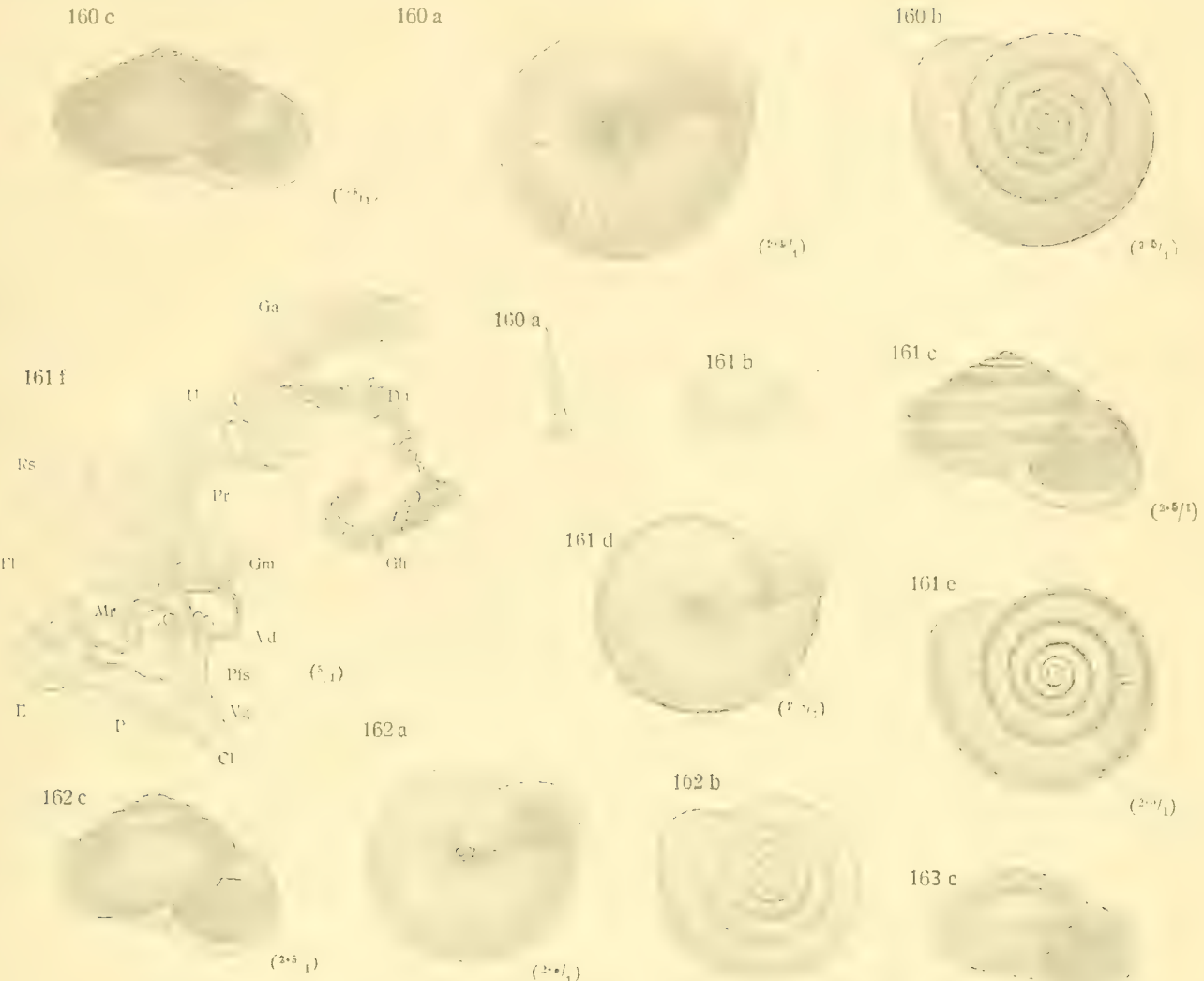

164

165
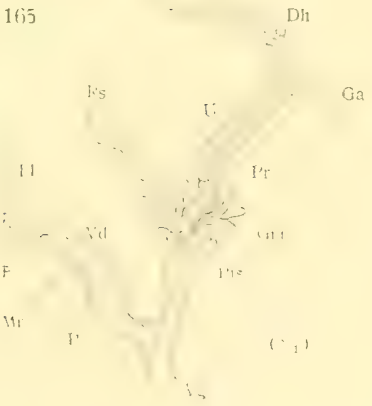

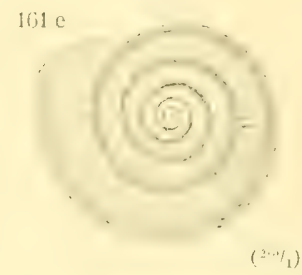

$163 c$

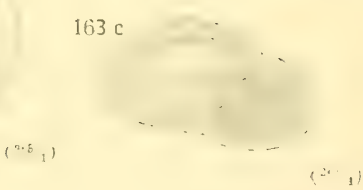

$1633 \mathrm{a}$

$(3.5 / 1)$

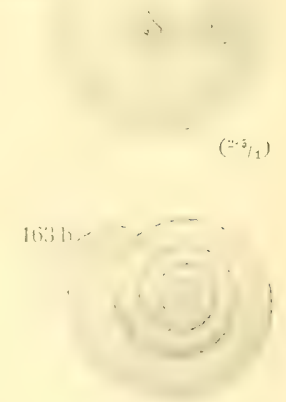

$(2 \cdot 5 / 1)$

Denkschriften der kaiserl. Akademie der Wiss, nath. naturw, Kl, Bd. XCI. 

Tafel 20. 


\section{Tafel 20.}

Fig. $166 a-c$. Fruticicola sublencozona WV stld, vom Thörlgraben bei Kapfenberg ( $c=$ Sexualorgane).

- $167 a-b$. Fruticicola edentula D ra p., nach dem Originalexemplar des Autors.

$168 a-c$. Fruticicola midentata Drap., nach dem Originalexemplar des Autors.

$169 a-b$. Fruticicola unidentata alpestris Cless., von der Spitze des Schneeberges in Niederösterreich.

. 170. Fruticicola leucozona C. Pfr., von Wolts chach im Isonzotal (Sexualorgane).

v $171 a-b$. Fruticicola leucozona C. Pfr., von Villach. 
$166 c$

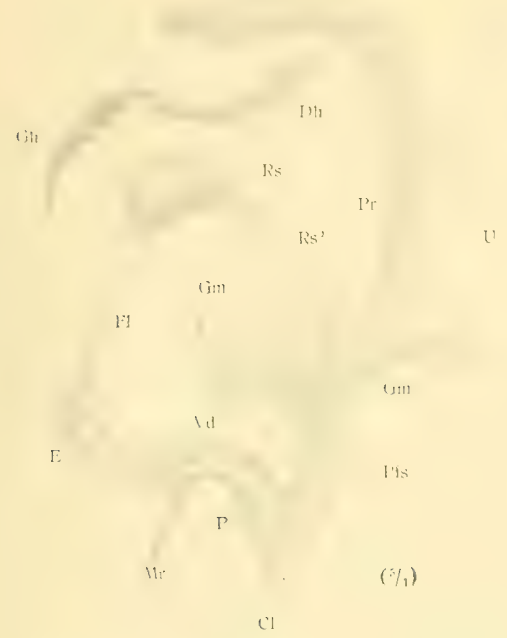

Iutia

$168 \mathrm{C}$

$169 \mathrm{~h}$

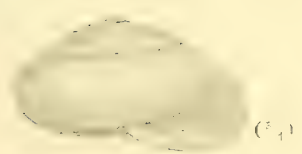

169 a

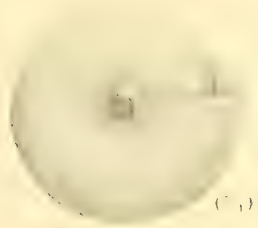

170
$161 ;$ i

$1671:$

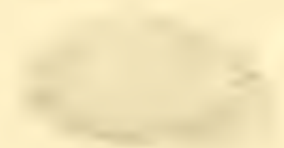

$\left(\begin{array}{l}3,1 \\ , 1\end{array}\right)$

$(5 / 1)$

$166 \mathrm{~b}$

16ĩ a

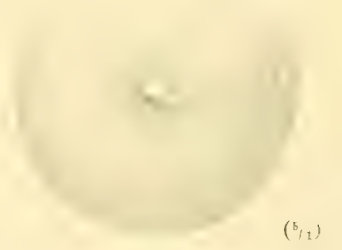

$168 \mathrm{~h}$

Rs

\section{(1)}

U

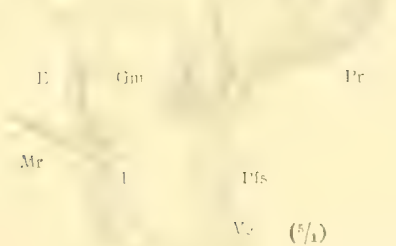

1710

$\left({ }^{\prime}+1\right)$

171 a

Denkschriften der kaiserl. Akademie der Wiss. math. naturw. Kl., Bd. XCI. 
Tafel 2r. 


\section{Tafel 2I.}

Fig. $172 a-f$. Fruticicola lencozona C. Pfr, von Idria.

$173 a-b$. Fruticicola leucozona ovirensis Rssm., vom Hoch Obir.

. 174. Fruticicola lencozona ovirensis Rssm., vom Matajur.

$175 a-c$. Fruticicola leucozona lurida C. Pfr.. von Lokve in Kroatien.

176. Fruticicola leucozona separanda Rssm., Saveauen bei Agram.

" 177 a-c. Fruticicola leucozona filicina C. Pfr., Saveauen bei Agram.

" $178 a-b$. Fruticicola Teucozona bosnensis M11dff., vom Berge Stolac in Bosnien.

$179 a-b$. Fruticicola leticozona bielzi Bielz, von Schäßburg in Siebenbürgen. 
Wagner, A. J.: Anatomie und Systematik der Stylommatophoren.

Taf. XXI.

$172 d$

172 a

$172 \mathrm{~b}$

$172 \mathrm{C}$
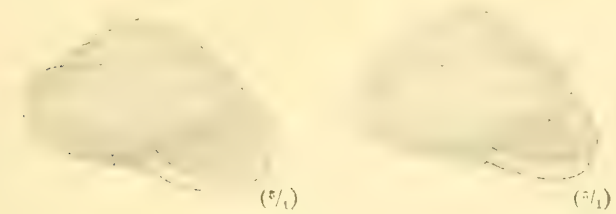

173 a

$173 \mathrm{~b}$

$178 b$

$\left({ }^{\prime}{ }_{1}\right)$

176

$175 \mathrm{~b}$

178 a

$\left({ }_{1}\right)$ $(1 / 1)$ (a)

$175 a$

$177 \mathrm{~b}$

$(1 / 1)$

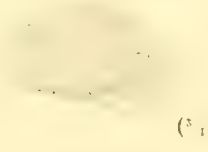

$\left(5 \cdot{ }_{1}\right)$

$(\because i)$ $\left(i_{i 2}\right)$

177 a

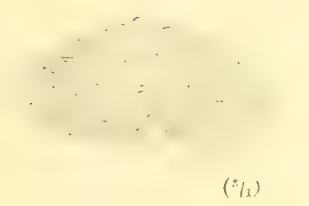

. $179 \mathrm{~h}$

$\left({ }^{3}\right)$

$172 \mathrm{f}$

172 e

$179 a$

11

$(\pi / 1)$

Denkschriften der kaiserl. Akademie der Wiss, math. naturw. KI., Bd. XCI. 

Tafel 22 


\section{Tafel 22.}

Fig. 180. Semifruticicola serbica Wagner, von Prosječenica vrata in Bosnien ( $d=$ Kiefer, $e=$ Pfeil, $f=$ Radula, $e=$ Sexualorgane).

181 a-c. Semifruticicola serbica costutata Brancs, am Bubatov Kuk in Montenegro.

* $182 a-d$. Monacha incarnata Müller, von Agram ( $a=$ Pfeil, $b=$ Kiefer, $c=$ Radula, $d=$ Sexualorgane). 
Wagner, A. J.: Anatomic und Systematik der Stylommatophoren.

Taf. XXit.

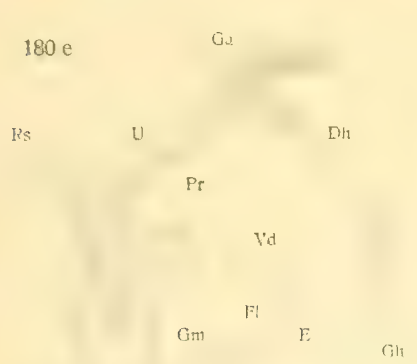

$180 a$

$180 \mathrm{~h}$
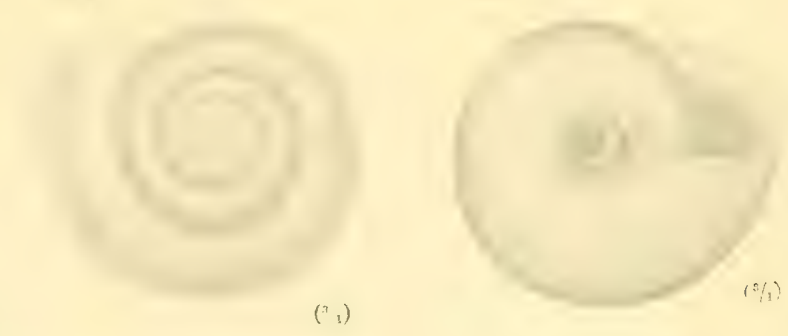

Pfs

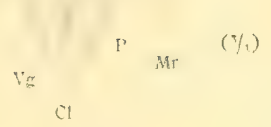

1804
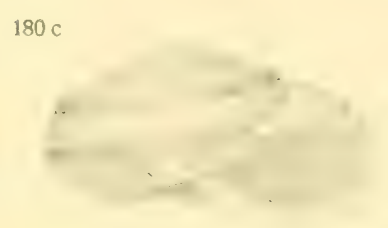

1801

$(2 / 9)$

1810

$182 \mathrm{~d} \quad(\mathrm{ia}$

$(3,1)$

181 a

$181 b$

$(3 ; 3)$

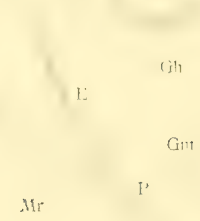

$180 \mathrm{~g}$

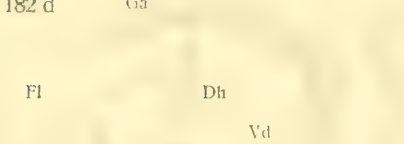

$\mathrm{Rs}$

$182 a$

$182 \mathrm{~b}$

$182 \mathrm{C}$

$\left(i_{i}\right)$

$M$

Denikschriften der kaiserl. Akademie der Wiss, math. naturw, KL, Bd, XCI. 

Tafel 23. 


\section{Tafel 23.}

Fig, 183. Monacha vicina Rssm., von Kronstadt (Sexualorgane).

184. Munacha umbrosa C. Pfr., Stockerau bei Wien (Sexualorgane).

- $185 a \cdot d$. Mmacha fallax Wagner, vom Trebovič bei Sarajevo ( $d=$ Sexualorgane). 186. Monacha rubiginosa A. Schm., von Mödling bei Wien. 
Wagner, A. J.: Anatomie und Systematik der Stylommatophoren
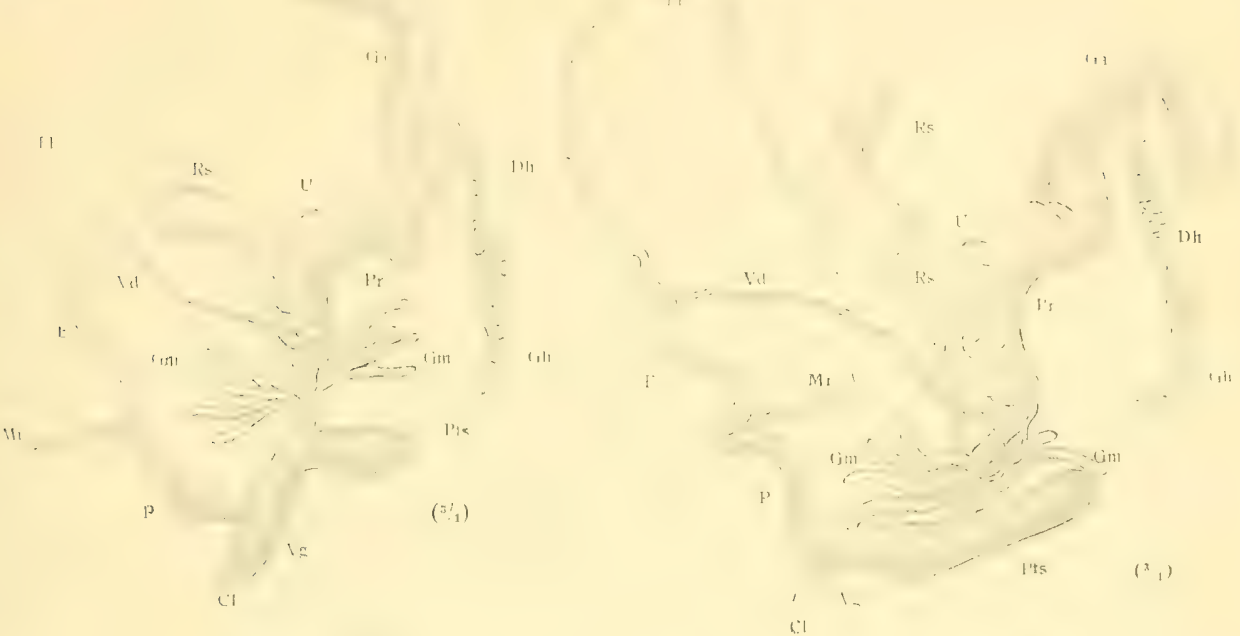

$1 \times 5 \mathrm{~d}$

186

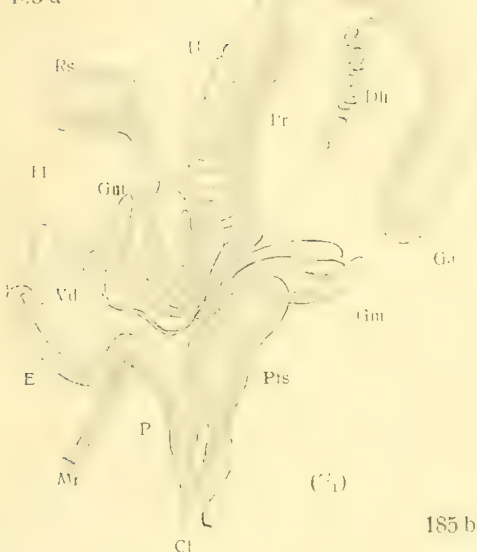

$185 \mathrm{c}$

$\mathrm{Cl}$

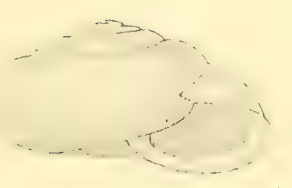

$(3 / 1)$
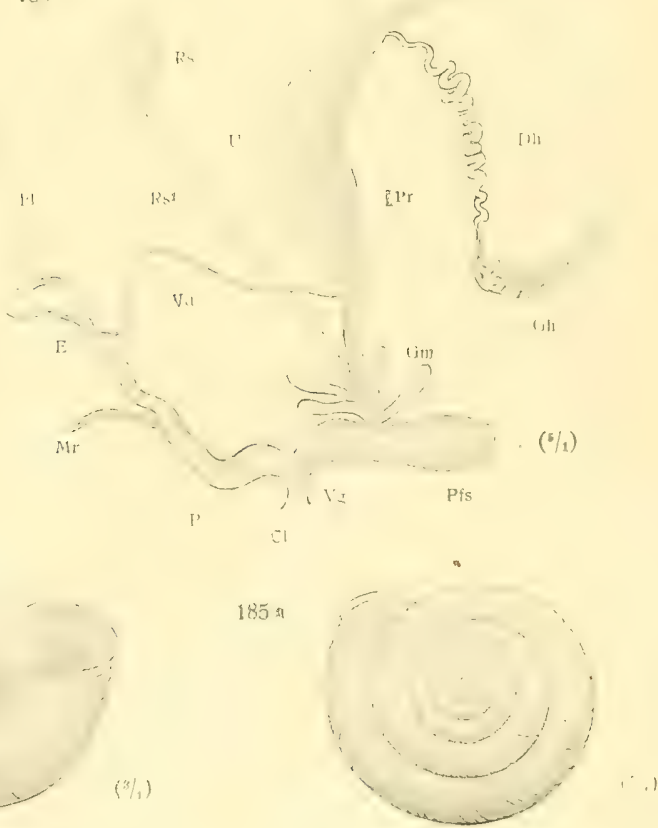

Denkschriften der kaiserl. Akademie der Wiss, matı. naturw K1., Bd. XCI. 

Tafel 24 


\section{Tafel 24.}

Fig. 187. Monacha fallax Wagner, vom Trebovič (Kiefer).

* $188 a-c$. Hygromia cinctella Drap., von Triest ( $a=$ Pfeile, $b=$ Kiefer, $c=$ Sexualorgane).

- $189 a-$ d. Euompluatia strigella D rap., von Kronstadt $(a=$ Kiefer, $b=$ Zwitterdrïse, $c=$ Glandulae mucosae, $d=$ Sexualorgane). 
$188 \mathrm{c}$

jis

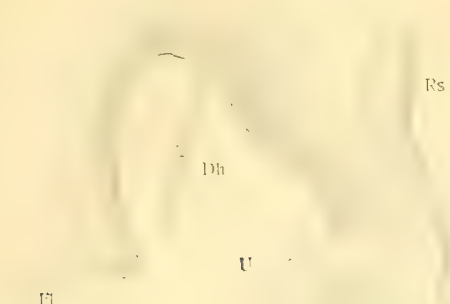

I7

Nit

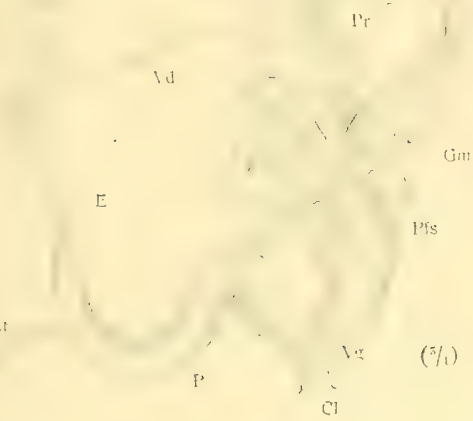

188 a

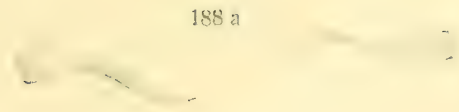

$189 \mathrm{~d}$

U

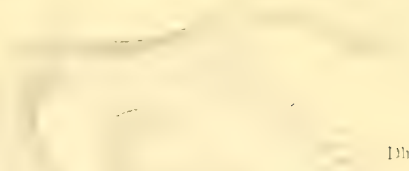

Fi

r':

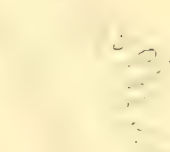

E

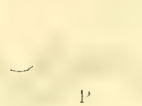

lis

. 1

(jou:

in:

$183 \mathrm{~b}$

$189 ?$

187

18116

$189 \mathrm{C}$

Denkschiriften der kaiserl. Akademie dẹ Wiss, math. naturw, KI., Bd. XCI. 
80,80 




